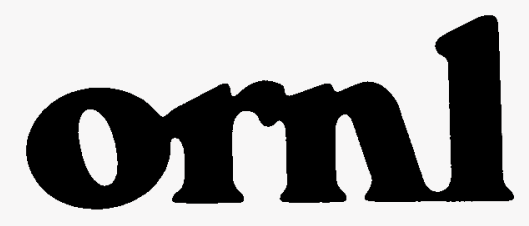

OAK RIDGE NATIONAL LABORATORY

MARTIN MARUETRA

\section{Advanced Neutron Source Radiological Design Criteria}

PEO 271300

OSTI 
This report has been reproduced directly from the best available copy.

Available to DOE and DOE contractors from the Office of Scientific and Technical Information, P.O. Box 62, Oak Ridge, TN 37831; prices available from (615) 576-8401, FTS 626-8401.

Available to the public from the National Technical Information Service, U.S. Department of Commerce, 5285 Port Royal Rd., Springfield, VA 22161.

This report was prepared as an account of work sponsored by an agency of the United States Government. Neither the United States Government nor any agency thereof, nor any of their employees, makes any warranty, express or implied, or assumes any legal liability or responsibility for the accuracy. completeness, or usefulness of any information, apparatus, product, or process disclosed, or represents that its use would not infringe privately owned rights. Reference herein to any specific commercial product, process, or service by trade name, trademark, manufacturer, or otherwise, does not necesserily constitute or imply its endorsement, recommendation, or favoring by the United States Government or any agency thereof. The views and opinions of authors expressed herein do not necessarily state or reflect those of the United States Government or any agency thereof. 


\title{
ADVANCED NEUTRON SOURCE
}

\section{RADIOLOGICAL DESIGN CRITERIA}

\section{J. L. Westbrook}

August 1995

\author{
Prepared by \\ OAK RIDGE NATIONAL LABORATORY \\ Oak Ridge, Tennessee 37831 \\ managed by \\ LOCKHEED MARTIN ENERGY SYSTEMS, INC. \\ for the \\ U.S. DEPARTMENT OF ENERGY \\ under contract DE-AC05-840R21400
}

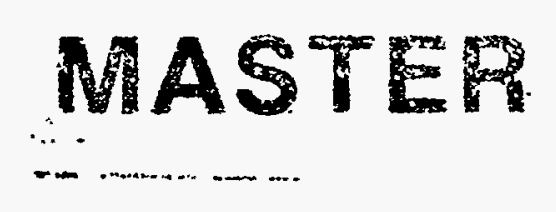

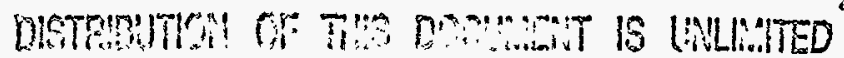





\section{CONTENTS}

LIST OF TABLES $\ldots \ldots \ldots \ldots \ldots \ldots \ldots \ldots \ldots \ldots \ldots \ldots \ldots \ldots \ldots \ldots$

ACRONYMS, INITIALISMS, AND ABBREVIATIONS $\ldots \ldots \ldots \ldots \ldots \ldots \ldots \ldots \ldots$ vii

1. INTRODUCTION $\ldots \ldots \ldots \ldots \ldots \ldots \ldots \ldots \ldots \ldots \ldots \ldots \ldots \ldots \ldots \ldots \ldots \ldots \ldots . . \ldots 1$

1.1 RADIATION PROTECTION DESIGN OBJECTIVES $\ldots \ldots \ldots \ldots \ldots \ldots \ldots \ldots \ldots$ 1-1

1.2 SCOPE AND ORGANIZATION OF THIS DOCUMENT $\ldots \ldots \ldots \ldots \ldots \ldots \ldots \ldots$

1.3 CONVENTIONS USED IN THIS DOCUMENT $\ldots \ldots \ldots \ldots \ldots \ldots \ldots \ldots \ldots . . \ldots$

2. RESTRICTIONS ON DOSES, EXPOSURE LEVELS, AND RELEASES $\ldots \ldots \ldots \ldots \ldots$ 2-1

2.1 RESTRICTIONS ON DOSES TO AND EXPOSURE

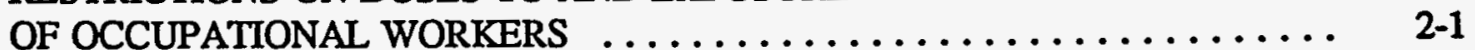

2.2 RESTRICTIONS ON DOSES TO AND EXPOSURE OF MEMBERS

OF THE PUBLIC ............................. $2-2$

2.3 RESTRICTIONS ON RELEASES TO THE ENVIRONMENT ............ 2 .5

2.4 RESTRICTIONS ON DOSES TO EQUIPMENT $\ldots \ldots \ldots \ldots \ldots \ldots \ldots \ldots \ldots \ldots$

3. SAFETY AND ACCIDENT MITIGATION $\ldots \ldots \ldots \ldots \ldots \ldots \ldots \ldots \ldots \ldots \ldots$

4. RADIOLOGICAL AREA AND ZONE CLASSIFICATION AND ACCESS CONTROL . . 4-1

4.1 RADIOLOGICAL AREA CLASSIFICATIONS AND POSTING

REQUIREMENTS ........................... 4-1

4.2 RADIOLOGICAL ZONE CLASSIFICATIONS AND RELATED

REQUIREMENTS ............................ 44

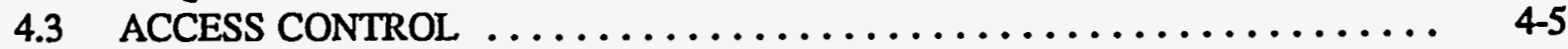

5. CONTAINMENT, CONFINEMENT, AND VENTILATION $\ldots \ldots \ldots \ldots \ldots \ldots \ldots \ldots$

5.1 DEFINITIONS AND BASIC REQUIREMENTS $\ldots \ldots \ldots \ldots \ldots \ldots \ldots \ldots \ldots . \ldots$

5.2 SPECIFICATION OF CONFINEMENTS AND CONTAINMENTS $\ldots \ldots \ldots \ldots .5-3$

5.3 VENTILATION AND PURGING . . . . . . . . . . . . . . . . $5-6$

6. DOSE MONITORING, PERSONAL PROTECTION, AND HUMAN FACTORS

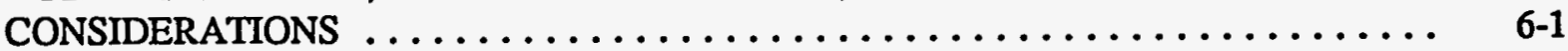

6.1 PERSONAL DOSE MONITORING DEVICES $\ldots \ldots \ldots \ldots \ldots \ldots \ldots \ldots \ldots \ldots . \ldots$

6.2 BREATHING AIR AND RESPIRATORY PROTECTION $\ldots \ldots \ldots \ldots \ldots \ldots \ldots .6 . \ldots$

6.3 OTHER PROTECTIVE CLOTHING AND EQUIPMENT ............. $6-3$

6.4 HUMAN FACTORS $\ldots \ldots \ldots \ldots \ldots \ldots \ldots \ldots \ldots \ldots \ldots \ldots \ldots \ldots \ldots \ldots \ldots$

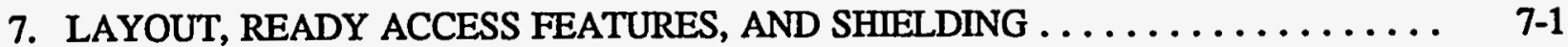

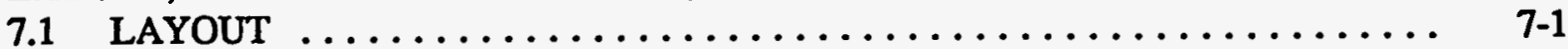

7.2 READY ACCESS FEATURES $\ldots \ldots \ldots \ldots \ldots \ldots \ldots \ldots \ldots \ldots \ldots \ldots \ldots$

7.3 SHIELDING $\ldots \ldots \ldots \ldots \ldots \ldots \ldots \ldots \ldots \ldots \ldots \ldots \ldots \ldots \ldots \ldots$ 
8. REQUIREMENTS FOR MATERIALS AND COMPOSITIOIN SELECTION $\ldots \ldots \ldots$. $8-1$

8.1 GENERAL REQUIREMENTS . . . . . . . . . . . . . . . . . . . . 8-1

8.2 MATERIALS REQUIREMENTS WHEN TRITIUM MAY BE PRESENT . . . . . 8-2

9. GENERAL EQUIPMENT DESIGN AND SELECTION . . . . . . . . . . . . $9-1$

9.1 GENERAL REQUIREMENTS . . . . . . . . . . . . . . . . . . $9-1$

9.2 TANKS, VESSELS, AND HEAT EXCHANGERS . . . . . . . . . . . . 9-1

9.3 PUMPS, THEIR ASSOCIATED SEALS, AND FANS AND BLOWERS $\ldots \ldots \ldots .99$

9.4 VALVES AND THEIR ASSOCIATED PARTS ... . . . . . . . . . . 9-3

9.5 PIPING AND TUBING ......................... 94

9.6 CONNECTIONS AND WELDS $\ldots \ldots \ldots \ldots \ldots \ldots \ldots \ldots \ldots \ldots \ldots \ldots \ldots \ldots$

9.7 INSTRUMENTS $\ldots \ldots \ldots \ldots \ldots \ldots \ldots \ldots \ldots \ldots \ldots \ldots \ldots \ldots \ldots \ldots \ldots$

9.8 TOOLS ................................... 9-6

9.9 MISCELLANEOUS . . . . . . . . . . . . . . . . . . . . 9.7

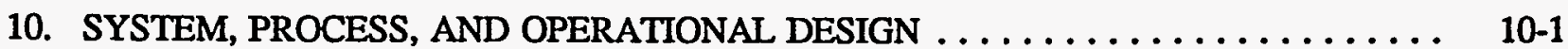

10.1 GENERAL REQUIREMENTS $\ldots \ldots \ldots \ldots \ldots \ldots \ldots \ldots \ldots \ldots \ldots \ldots \ldots \ldots \ldots \ldots \ldots$ 10-1

10.2 FLUSHING, PURGING, AND CLEANING $\ldots \ldots \ldots \ldots \ldots \ldots \ldots \ldots \ldots \ldots \ldots$

10.3 UNPLUGGING, SPARGING, AND MIXING $\ldots \ldots \ldots \ldots \ldots \ldots \ldots \ldots \ldots \ldots \ldots \ldots$

10.4 HEAT TRACING AND MISCELLANEOUS MEASUREMENTS $\ldots \ldots \ldots \ldots \ldots \ldots$

10.5 PIPING SYSTEMS . . . . . . . . . . . . . . . . . . . . . 10-6



10.7 VENTS, DRAINS, AND PRESSURE RELIEF $\ldots \ldots \ldots \ldots \ldots \ldots \ldots \ldots \ldots \ldots \ldots . . \ldots \ldots$

10.8 MISCELLANEOUS PROCESS REQUIREMENTS $\ldots \ldots \ldots \ldots \ldots \ldots \ldots \ldots \ldots \ldots . . \ldots 10.7$

10.9 OPERATIONAL AND RELIABILITY REQUIREMENTS $\ldots \ldots \ldots \ldots \ldots \ldots \ldots \ldots$. . . .

11. FUEL AND FUEL POOLS . . . . . . . . . . . . . . . . . . . . . 11-1

11.1 POOL AND RELATED SYSTEM DESIGN REQUIREMENTS . . . . . . . . . . 11-1

11.2 FUEL-HANDLING EQUIPMENT, CONTROLS, RACKS, AND CASKS . . . . . 11-2

11.3 LOOSE PARTS CONTROL $\ldots \ldots \ldots \ldots \ldots \ldots \ldots \ldots \ldots \ldots \ldots \ldots \ldots \ldots$

11.4 MISCELLANEOUS ........................... 11-4

12. RADWASTE HANDLING AND STORAGE $\ldots \ldots \ldots \ldots \ldots \ldots \ldots \ldots \ldots \ldots \ldots \ldots \ldots$

12.1 GENERAL REQUIREMENTS . . . . . . . . . . . . . . . . . . . . . $12-1$

12.2 GASEOUS AND LIQUID RADWASTE, SLURRY, AND SOLIDIFICATION ... 12-2

12.3 SOLID RADWASTE HANDLING AND STORAGE REQUIREMENTS $\ldots \ldots \ldots$. 124

12.4 RADWASTE CONTAINER STORAGE AND HANDLING $\ldots \ldots \ldots \ldots \ldots \ldots$

13. CONTAMINATION CONTROL, DECONTAMINATION, AND DECOMMISSIONING . 13-1

13.1 CONTAMINATION CONTROL $\ldots \ldots \ldots \ldots \ldots \ldots \ldots \ldots \ldots \ldots \ldots \ldots \ldots \ldots$



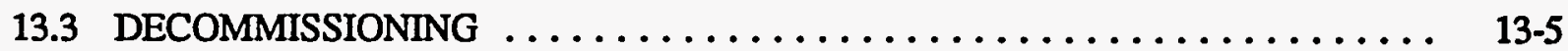

14. MONITORING AND SAMPLING $\ldots \ldots \ldots \ldots \ldots \ldots \ldots \ldots \ldots \ldots \ldots \ldots \ldots$ 14-1

14.1 GENERAL REQUIREMENTS FOR MONITORING $\ldots \ldots \ldots \ldots \ldots \ldots \ldots \ldots \ldots$. . . .

14.2 GENERAL REQUIREMENTS FOR DETECTORS, READOUTS,

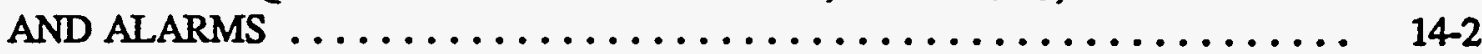


14.3 REQUIREMENTS FOR OCCUPATIONAL AIR MONITORING

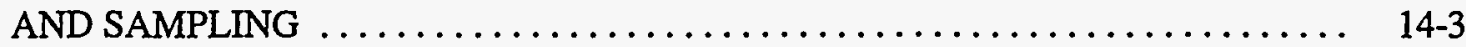

14.4 REQUIREMENTS FOR AREA MONITORING AND "AREA

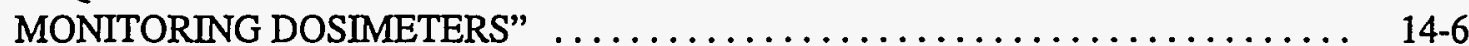

14.5 REQUIREMENTS FOR PROCESS AND EFFLUENT MONITORING

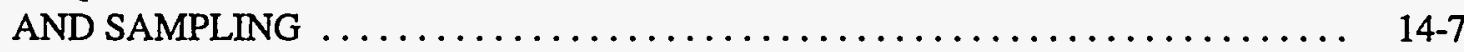

14.6 ACCIDENT MONITORING AND SAMPLING AND NUCLEAR ACCIDENT DOSIMETRY ................................. 14-9

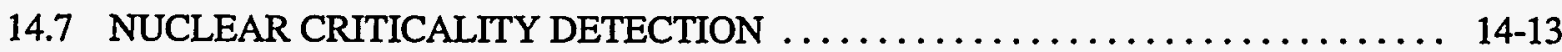

14.8 REQUIREMENTS FOR SAMPLING LINES AND COMPONENTS AND FOR SAMPLE HANDLING $\ldots \ldots \ldots \ldots \ldots \ldots \ldots \ldots \ldots \ldots \ldots .14-14$

15. RADIATION PROTECTION FACILITIES AND OPERATIONS $\ldots \ldots \ldots \ldots \ldots \ldots \ldots, 15-1$

15.1 RADIATION PROTECTION AND RELATED FACILITIES . . . . . . . . . . . . . 15-1

15.2 PORTABLE AND PERSONNEL MONITORING INSTRUMENTATION $\ldots \ldots \ldots \ldots 15$ -

15.3 PERSONNEL AND EQUIPMENT ACCESS CONTROL POINTS $\ldots \ldots \ldots \ldots \ldots \ldots 15-2$

15.4 RADIATION PROTECTION PERSONNEL ACCESS $\ldots \ldots \ldots \ldots \ldots \ldots \ldots \ldots \ldots \ldots \ldots, 15-2$

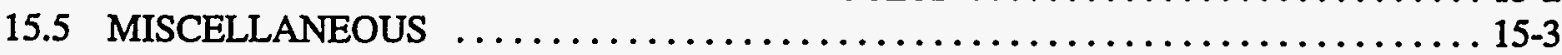

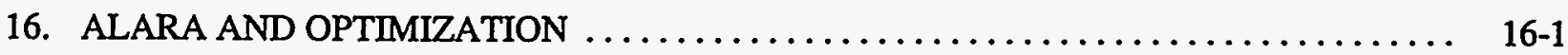

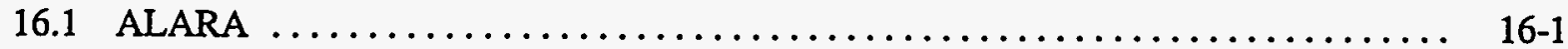

16.2 OPTIMIZATION $\ldots \ldots \ldots \ldots \ldots \ldots \ldots \ldots \ldots \ldots \ldots \ldots \ldots \ldots \ldots \ldots \ldots \ldots \ldots \ldots \ldots \ldots, 16-2$

17. HUMAN FACTORS AND INDUSTRIAL HYGIENE AND SAFETY $\ldots \ldots \ldots \ldots \ldots \ldots$ 17-1

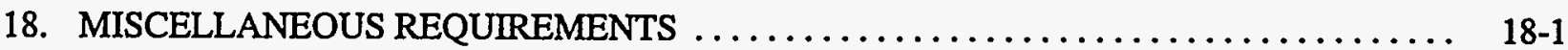

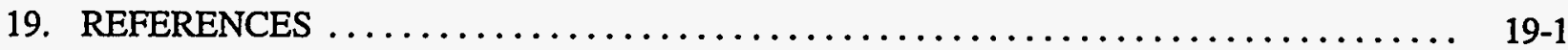

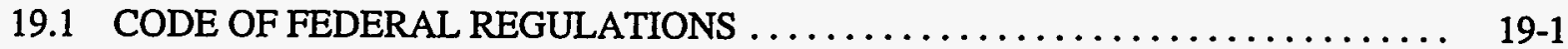

19.2 U.S. DEPARTMENT OF ENERGY ORDERS, POLICY STATEMENTS, AND GUIDANCE $\ldots \ldots \ldots \ldots \ldots \ldots \ldots \ldots \ldots \ldots \ldots \ldots \ldots \ldots \ldots \ldots \ldots \ldots \ldots \ldots, 19-1$

19.3 NUCLEAR REGULATORY COMMISSION (NRC) GUIDANCE . . . . . . . . . 19-3

19.4 FEDERAL POLICY STATEMENT $\ldots \ldots \ldots \ldots \ldots \ldots \ldots \ldots \ldots \ldots \ldots \ldots, 19-4$

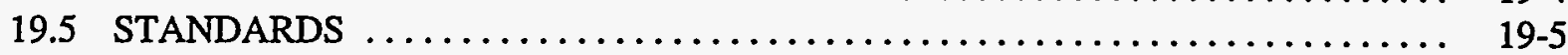

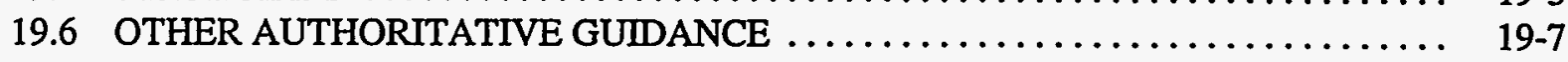

19.7 MARTIN MARIETTA ENERGY SYSTEMS (MMES) AND OAK RIDGE NATIONAL LABORATORY (ORNL) REQUIREMENTS AND PROCEDURES






\section{LIST OF TABLES}

$4.1 \quad$ Surface contamination limits $\ldots \ldots \ldots \ldots \ldots \ldots \ldots \ldots \ldots \ldots \ldots$

$4.2 \quad$ ANS radiological zones $\ldots \ldots \ldots \ldots \ldots \ldots \ldots \ldots \ldots \ldots \ldots \ldots \ldots$

6.1 Activity levels or concentrations above which tritium bioassay programs should be provided $\ldots \ldots \ldots \ldots \ldots \ldots \ldots \ldots \ldots \ldots \ldots \ldots \ldots \ldots$

14.1 Accident-related requirements for monitoring and sampling: Type C variables $\ldots \ldots$ 14-16

14.2 Accident-related requirements for monitoring and sampling: Type E variables . . . . . 14-17 
ACGIH

ADE

ALARA

ALI

ANS

ANSI

ANSI/ANS

AOO

ASME

BAT

CEDE

CFR

Ci

CH TRU

DAC

DBA

DCG

DOE

DOE-ORO CCP

DOP

dpm

EPA

EPRI

EQ

G-M

HEPA

HP

HPM

HTO

IAEA

ICRP

ID

IEEE

IG

INPO

LOCA

MMES

MMES RCM

MOP
American Conference of Governmental Industrial Hygienists

annual dose equivalent

as low as (is) reasonably achievable

annual limit of (or on) intake

Advanced Neutron Source

American National Standards Institute

American National Standards Institute/American Nuclear Society

anticipated operational occurrence

American Society of Mechanical Engineers

best available technology

committed effective dose equivalent

Code of Federal Regulations

curie

contact-handled transuranic (waste)

derived air concentration

design-basis accident

derived concentration guide

Department of Energy

DOE-Oak Ridge Reservation Contamination Control Policy

dioctyl phthalate

disintegrations per minute

Environmental Protection Agency

Electric Power Research Institute

equipment qualification

Geiger-Muller

high-efficiency particulate air (filter)

health physics or health physics technician

Health Physics Procedures Manual

tritiated water

International Atomic Energy Agency

International Commission on Radiation Protection

inner diameter

Institute of Electrical and Electronic Engineers

Implementation Guide (for 10 CFR 835)

Institute of Nuclear Power Operations

loss-of-coolant accident

Martin Marietta Energy Systems

Martin Marietta Energy Systems Radiological Control Manual

member of the public 
NCRP

NIOSH/MSA

NRC

ORNL

PCs

R

RBA

RCM

RCRA

RG

RH TRU

RP

RW

RWP

SCBA

T

TEDE

TRU

TSHC
National Council on Radiation Protection and Measurements

National Institute for Occupational Safety and Health/Mine Safety

Adminstration

Nuclear Regulatory Commission

Oak Ridge National Laboratory

protective clothing

roentgen

radiological buffer area

Radiological Control Manual

Resource Conservation and Recovery Act

Regulatory Guide

remote-handled transuranic (waste)

radiation protection

radwaste

Radiation Work Permit

self-contained breathing apparatus

tritium (chemical symbol)

total effective dose equivalent

transuranic

Tritium Safe Handling Course 


\section{INTRODUCTION}

\subsection{RADIATION PROTECTION DESIGN OBJECTIVES}

The operation of the proposed Advanced Neutron Source (ANS) facility will present a variety of radiological protection problems. Because it is desired to design and operate the ANS according to the applicable licensing standards of the Nuclear Regulatory Commission (NRC), it must be demonstrated that the ANS radiological design basis is consistent not only with state and Department of Energy (DOE) and other usual federal regulations, but also, so far as is practicable, with NRC regulations and with recommendations of such organizations as the Institute of Nuclear Power Operations (INPO) and the Electric Power Research Institute (EPRI). Also, the ANS radiological design basis is in general to be consistent with the recommendations of authoritative professional and scientific organizations, specifically the National Council on Radiation Protection and Measurements (NCRP) and the International Commission on Radiological Protection (ICRP).

As regards radiological protection, the principal goals of DOE regulations and guidance are to keep occupational doses ALARA [as low as (is) reasonably achievable], given the current state of technology, costs, and operational requirements; to control and monitor contained and released radioactivity during normal operation to keep public doses and releases to the environment ALARA; and to limit doses to workers and the public during accident conditions. These goals are rephrased below as general objectives to be met in the design of the ANS.

1. Individual radiation doses (as the sum of external and internal doses) to workers or the public should not only be kept below regulatory and operational limits, but should also be minimized.

2. Collective radiation dose (as the sum of external and internal doses) to a work group or population should be minimized.

3. Action taken to reduce radiation risks to workers or the public should not result in a significantly higher risk from other, nonradioactive hazards.

4. Action taken to reduce occupational doses should generally not result in significantly higher doses or risk to the public, and vice versa.

5. Contamination of personnel, areas, equipment, and the environment should be minimized.

6. The generation of radioactive waste, both during operation and at the end of facility life, should be minimized.

Meeting these general design objectives requires that principles of dose reduction and of radioactivity control be employed in the design, operation, modification, and decommissioning of the ANS. The purpose of this document is to provide basic radiological criteria for incorporating these principles into the design of the ANS. Operations, modification, and decommissioning will be covered only as they are affected by design.

The manner in which these objectives are achieved may be affected by regulatory uncertainties. The current regulations may not be applicable when the ANS begins operation or may be superseded by agreements between the parties involved, e.g., the State of Tennessee and Oak Ridge National Laboratory (ORNL). In this document it is assumed that current regulations will apply, but consideration must be given to any pending or proposed changes. The exception is that certain NRC regulations are included here principally for information purposes, with applicability to be determined later. This is because for the ANS to be designed as an NRC-licensable facility, it would have to be demonstrated that the ANS met the NRC requirements outright or met equivalent (or more stringent) but alternatively phrased DOE requirements. It will often be more advisable to demonstrate this by 
translating the NRC requirements into DOE terms and limits, so that a uniform set of terms and limits can be used. Also, some NRC guidance is out of date when viewed from the perspective of current radiation protection thinking, and some of it is not generally applicable (e.g., it would be difficult to apply it to anything but a power reactor) or is unduly restrictive or: lenient. The principal example is 10 CFR 50, Appendix I's "ipso facto" numerical ALARA limits. Thus in general, where for a given type of limit or requirement a DOE version and an NRC version rnay be applicable and are apparently in conflict, the DOE one is to be assumed to apply preferentially and the applicability of the NRC one is to be determined.

The various ORNL procedures and facilities on which the ANS may depend may also change (e.g., environmental monitoring practices and waste disposal sites). Again, it is assumed that the procedures and facilities that are operative now or are planned to be operative by the time of ANS startup will not have changed significantly by then. In this document it is assumed that the ANS will be built at ORNL.

\subsection{SCOPE AND ORGANIZATION OF THIS DOCUMENT}

Requirements and recommendations were chosen for inclusion in this document first on the basis that they were given in one or more DOE documents; second, that they were given in a document issued or promulgated by another governmental agency; third, that they were given in a document issued by an authoritative radiation protection authority; and fourth, that they were given in a good practices document issued by other entities or were generally regarded as good practices by knowledgeable radiation protection specialists.

All of the requirements and recommendations relate in some way to radiation protection and to design and operational planning of the ANS, although this may not appear to be the case on a first reading. For example, some training requirements are given, which some might think would not need to be considered until the ANS is about to go into operation. However, these requirements are provided to show what training might be required for access to a given areas and thus to show what limitations there might be on access for those who do not have this training. This is relevant, for example, to the case of what areas should be accessible to researchers who are working at the ANS on a short-term basis and who therefore may not have the need or time for a complete radiation worker course but must to be able to work without a constant escort.

In organizing a document such as this, it is difficult to decide where to put some statements, since they apply to several subjects that may be covered in different sections. So while an effort was made to minimize repetition, in some sections a statement that was made in another section will be repeated.

\subsection{CONVENTIONS USED IN THIS DOCUMENT}

In this document, individual specifications-requirements, recommendations, and statements of good practice-are so numerous and varied that it would be difficult to trace each one back to a particular reference in the list of references unless the reference is given with the specification, so that has been done here. However, in order to make it easier to determine what the reference is and to shorten the statement of what the reference is in the text, the following convention has been adopted. Note that acronyms and initialisms are also listed near the front of this document. 
1. In the text proper, including parenthetical explanatory remarks:

- Spaces are used in citations of the Code of Federal Regulations, e.g., "10 CFR 835"

- Implementation Guides for 10 CFR 835 are given in the form "IG G-10CFR835/XY," e.g., "IG G-10CFR835/G1"

- "Regulatory Guide" is spelled out, e.g., "Regulatory Guide 8.25"

- The form "DOE XXX.XX" is used for DOE Orders, e.g., "DOE 5480.11"

- Radiological Control Manual and Health Physics Manual, after their first use, are abbreviated "RCM" and "HPM" respectively; "the RCM" means the DOE RCM

- ANSI or ANSI/ANS standards numbers are given in full except for the date, e.g., "ANSI/ANS-55.1"

- Report numbers are given in full, e.g., "MLM-3719"

- Books are referenced by the author's last name

- The Tritium Safe Handling Course given by the Canadian Fusion Fuels Technology Project is referred to, after its first use, as "THSC"

2. As references, appearing in parentheses at the end of a phrase, sentence, or paragraph in the text:

- Spaces are not used in citations of the Code of Federal Regulations, e.g., "(10CFR835)"

- Implementation Guides for 10 CFR 835 are given in the form "(IGXY)," e.g., "(IGGI)" for "(IG G-10CFR835/G1)"

- "Regulatory Guide 8.25" appears as "(RG8.25)"

- The form "XXXX.XX" is used for DOE Orders, e.g., "(5480.11)"

- Radiological Control Manual and Health Physics Manual are given as "(RCM)" and "(HPM)"; "(RCM)" means the DOE RCM

- For ANSI or ANSI/ANS standards, only principal numerals are given, e.g., "(55.1)"

- Report numbers are given in full, e.g., "(MLM-3719)"

- Books are referenced by the author's last name

- The Tritium Safe Handling Course is referred to as "(THSC)"

Additionally, in order to make clear what part of a statement the reference applies to, the following convention has been adopted: the reference appears in parentheses directly at the end of what it applies to. Thus in the sentence "Means of decontamination shall be provided for tools (55.6), areas $(55.4,55.6)$, and personnel $(5480.11,55.4)$," it is to be understood that ANSI/ANS-55.6 applies to tools and areas, ANSI/ANS-55.4 applies to areas and personnel, and DOE 5480.11 applies to personnel only. If the sentence reads "Means of decontamination shall be provided for tools, areas, and personnel $(5480.11,55.6)$," then it is to be understood that both references apply to decontamination of all three items, i.e., that both references make the same statement regarding all three items. If there is a paragraph ending in "Means of decontamination shall be provided for tools, areas, and personnel. (55.4)," then it is to be understood that ANSI/ANS 55.4 applies to the entire paragraph rather than just to the last sentence in the paragraph. A sentence without a textual reference (e.g., "MLM-3719 states that...."), a reference in parentheses at the end of it inside its period, or a "floating" reference at the end of its paragraph is simply a statement of good practice, with no particular reference for it. 


\section{RESTRICTIONS ON DOSES, EXPOSURE LEVELS, AND RELEASES}

\subsection{RESTRICTIONS ON DOSES TO AND EXPOSURE OF OCCUPATIONAL WORKERS}

Important points for ANS design and planned operation are summarized below. References are as noted. The Martin Marietta Energy Systems Radiological Control Manual (MMES RCM) is not cited unless it states something that is not in the DOE RCM (i.e., ORNL site-specific information). Where a dose is given, it is assumed to be the annual total effective dose equivalent ("annual dose" or "annual limit") unless stated otherwise; see Item 1a below and the definitions.

1. Dose limits for occupational workers are as follows.

a. The annual total effective dose equivalent (TEDE) limit for an occupational worker is 5 rem (10CFR20, 10CFR835, RCM, 5480.11). This is equal to the sum of the annual external dose equivalent and the internal committed effective dose equivalent incurred in the corresponding year and can be exceeded only with extraordinary approval (e.g., during an emergency).

b. The Administrative Control Level for the DOE complex, an annual limit that can be exceeded only with DOE-Washington approval, is 2 rem (RCM).

c. The Administrative Control Level (annual limit) for MMES, set as per the RCM, is 1500 mrem (MMES RCM).

d. The dose equivalent limit for individual organs and tissues is $\mathbf{1 5}$ rem to the lens of the eye and 50 rem to any other organ, tissue (including skin of the whole body), or extremity (10CFR20, 10CFR835, RCM, 5480.11). This includes both the external and internal doses to the organ or tissue.

e. Regardless of the limits above, which apply to already-operating facilities, designs for new facilities should use an individual annual limit of 500 mrem (RCM). However, 10CFR835 and 5480.11 give " $20 \%$ of the applicable dose limits," or the equivalent of $1 \mathrm{rem} / \mathrm{year}$, for annual doses in areas not continuously occupied. The design objective for areas of continuous exposure shall be $0.5 \mathrm{mrem} / \mathrm{h}$ (10CFR835, 5480.11), assuming an occupancy of $2000 \mathrm{~h} /$ year (10CFR835).

2. To ensure that radiation exposures are kept at a small fraction of regulatory limits, ORNL administrative exposure guidelines have been established as follows (HPM). These may be exceeded with appropriate approvals.

a. The 1995 annual limit for an occupational worker is $650 \mathrm{mrem}$, as approved by the ORNL ALARA Steering Committee.

b. The annual dose equivalent (ADE) limit for individual organs and tissues is $\mathbf{5}$ rem to the lens of the eye and 15 rem to any other organ.

c. The weekly limit for an occupational worker is $100 \mathrm{mrem}$.

d. The weekly dose equivalent limit for individual organs and tissues is $300 \mathrm{mrem}$ to the lens of the eye and 1 rem to any other organ.

e. The daily limit for an occupational worker is $20 \mathrm{mrem}$; this is the limit above which a Radiation Work Permit (RWP) must be written.

f. The daily dose equivalent limit for individual organs and tissues is $60 \mathrm{mrem}$ to the lens of the eye and 200 mrem to any other organ. 
3. Exposure of personnel to inhalation of airborne radioactive materials is to be avoided under normal operating conditions (10CFR20, 10CFR835, RCM, 5480.11, and HPM). As a guide for control of internal exposure, the following guidelines have been established (HPM).

a The (individual) total annual limit on exposure to airborne radioactivity is 200 derived air concentration (DAC) hours.

b. The total weekly limit on exposure to airborne radioactivity is 4 DAC-hrs.

4. For the unborn child of a declared pregnant worker, the dose limit is 0.5 rem over the entire gestation period, i.e., nine months (10CFR20, 10CFR835, RCM, 5480.11, HPM). Substantial variation above a uniform monthly exposure rate (i.e., about 50 mrem per month) shall be avoided (10CFR20, 10CFR835, RCM, 5480.11).

5. Outside Radiological Areas, the concentration of airborne radioactive materials shall be kept to well below $10 \%$ of a DAC (HPM). If the isotope(s) in a vork area is unidentified, the DAC for the most limiting isotope commonly existing at that facility shall be used (10CFR20, 10CFR835, HPM).

6. Any drinking water system operating by the DOE (or contractor) must have no more than $4 \%$ of the derived concentration guide (DCG) for the mix of radionuclides it may contain, as a monthly average; site workers are assumed to be exposed to $4 \%$ of DCG values or to the radium and gross alpha limits (from DOE 5400.5; see Sect. 2.2, item 4, below) in their drinking water away from the site. (These are taken to be the same as the standards given in 40 CFR 141, to which drinking water levels in controlled areas are limited according to DOE 5480.11).

7. Notwithstanding the dose limits given above, doses to occupational workers shall be kept ALARA (RCM, 10CFR20, 10CFR835, 5480.11, 5480.30, 6430.1A, HPM), including annual, committed, and cumulative dose equivalents (5480.11).

8. Doses to on-site personnel shall be evaluated for postulated accident situations (specifically or by inference: $5480.5,5480.6,5480.30,5500.3,6430.1 A, 10 C F R 50)$. For siting purposes, 10 CFR 50 (Criterion 19) states that for the control room, provisions shall be made to permit access and occupancy of the control room under accident conditions without any person's receiving radiation exposures in excess of 5 rem whole body or its equivalent to any part of the body, over the duration of the accident. [Note: the duration is commonly taken to be 30 days for a loss-of-coolant accident (LOCA), but this may vary according to the type of accident.]

\subsection{RESTRICTIONS ON DOSES TO AND EXPOSURE OF MEMBERS OF THE PUBLIC}

The controlling document for radiation protection of members of the public is 5400.5 . Some information is also given in DOE 5480.11, DOE 5500.3, and DOE 6430.1A. Important points for ANS design and planned operation are summarized below; these are from DOE 5400.5 unless otherwise noted. Where a dose is given, it is assumed to be the annual total effective dose equivalent ("annual dose" or "annual limit") unless stated otherwise. 
1. For a member of the public, student, or minor entering a controlled area, the annual limit is 0.1 rem per year (10CFR835, 10CFR20, RCM, 5400.5, 5480.11); the annual dose equivalent (ADE) limit to any tissue (including the lens of the eye and the skin) is 5 rem (5400.5, 5480.11). (At ORNL, members of the public and minors under age 18 are not permitted to work in controlled areas where an annual dose of 100 mrem could be received or in any area where there is a potential for intake of radioactive materials, according to the HPM.)

2. The exposure of members of the public to radiation sources as a consequence of all routine DOE activities shall not result in an annual dose greater than 100 mrem. (10 CFR 20 phrases this as "from the licensed operations,...excluding the dose contribution from disposal of radioactivity into sanitary sewerage"; it appears that 5400.5 does include this contribution, but it is not clear.) 10 CFR 20 states that the dose in any "unrestricted area" (as defined by the NRC) from external sources shall not exceed 0.002 rem in any one hour (this would be an average of $2 \mathrm{mrem} / \mathrm{h}$ in the DOE's "uncontrolled area"). "Reasonable efforts" should be made to include an allowance for non-DOE manmade or enhanced sources of radiation in the 100 mrem. Medical sources, consumer products, residual fallout from past nuclear accidents and weapons tests, and naturally occurring radiation sources are specifically excepted from the allowance, but "planned sampling or reentry" from underground nuclear weapons tests must be included.

3. The annual dose resulting from postulated or expected releases from a facility shall be considered in combination with the annual doses resulting from the planned or expected releases from other facilities at the same site; the sum shall be limited as given in DOE 5400.5 $(5400.5,6430.1 \mathrm{~A})$.

4. As required by the Clean Air Act (40 CFR 61), the exposure to members of the public to radioactive materials released to the atmosphere as a consequence of routine DOE activities shall not cause members of the public to receive an annual dose greater than 10 mrem. Releases of radon, however, are subject to the limits given in DOE 5400.5, Fig. III-3.

5. Doses to members of the public in the vicinity of DOE activities and to the population within $80 \mathrm{~km}$ of the site shall be evaluated for normal operations and anticipated operational occurrences (AOOs). Doses to (public) individuals from normal operation are to be evaluated using approved data and methods. Multiple emission points at a site may be combined into one centrally located point for the purpose of calculating collective public dose; this may also be done for calculating the doses to maximally exposed individuals if the distances between release points are small with respect to their distances to the site boundary. All pathways must be included in any calculation of dose to the public.

6. Notwithstanding the dose and release limits given above, doses to members of the public and students and releases to the environment shall be kept ALARA (10CFR20, 5400.5, 5480.30). These are to include the maximum dose to a member of the public and the collective dose to the population. Qualitative judgments are permitted under some circumstances, especially where potential doses are well below the dose limit, except for meeting requirements of the National Environmental Policy Act. Alternative processes and methods shall be considered.

7. Doses to members of the public in the vicinity of DOE activities and to the population within $80 \mathrm{~km}$ of the site shall be evaluated for accident situations. For siting of nonreactor nuclear 
facilities, the maximum dose to an off-site individual from a design basis accident (DBA) or other limiting accident is to be calculated assuming that the individual is at the point of highest concentration or exposure rate, as applicable, outside the boundary controlled by the site management. In this calculation it is also to be assumed that meteorological conditions are representative of unfavorable dispersion and that the duration of exposure is $2 \mathrm{~h}$. The dose limits for siting purposes are a 50-year committed effective total dose equivalent of 25 rem to the whole body and a 50-year committed dose equivalent of 300 rem to the thyroid, 300 rem to the bone surface, 75 rem to the lung, or 150 rem to any other organ (6430.1A).

8. "Numerical guides for design objectives and limiting conditions for operation" to meet the ALARA criterion for effluents are given in 10 CFR 50, Appendix I, as paraphrased below. These are for reference only; as flat umbrella numbers, despite the assertion of 10 CFR 50 that "conforming to (these guidelines) shall be deemed a conclusive showing of compliance with" the ALARA requirements of 10 CFR 50, they may be un-ALARA in the case of a particular facility. Also, they exceed the limits in DOE 5400.5 in some cases (noted below), and the different treatment of gamma and beta radiation is not in accordance with modern thinking. Note that DOE 5480.30, in Attachment 3, states that "for reactors with a containment system, as with the confinement systems,...10 CFR 50, Appendix I presents specific methods and evaluation criteria that are acceptable to DOE in implementing ALARA with respect to exhaust systems from a containment system." However, DOE has apparently not attempted any reconciliation of this statement with DOE 5400.5, nor is it clear whether they included anticipated operational occurrences in their determination of acceptability. Thus the statements of 10 CFR 50, Appendix I, though noted here for completeness, should not be taken seriously.

Similar caution must be exercised in determining the applicability of the 10 CFR 20 regulation mentioned below. Finally, the NRC dollar per man-rem value given below is quite outdated, is not in agreement with ORNL-approved values, and was intended to apply only to prospective radwaste processing determinations. $10 \mathrm{CFR} 50$ notes that its numerical guidelines are appropriate only for nuclear power reactors and not for other types of facilities. It also states that the aim is to "assure that the average population exposure is equivalent to small fractions of doses from natural background radiation," but it is not clear that DOE has made any similar statement of intent in citing 10 CFR 50.

a. For liquid effluents and from all pathways of exposure, the annual release of radioactivity to uncontrolled areas should not result in an annual dose to any individual in an uncontrolled area greater than 3 mrem to the whole body or 10 mrem to any organ. However, in the NRC statement of position at the end of Appendix I, the number is 5 mrem (it is unclear whether this is the TEDE) to the total body or to any organ, and the annual quantity of radioactive material released, except for tritium and dissolved gases, is not to exceed 5 curies.

b. For airborne effluents and for any location near ground level, the annual release of radioactivity to uncontrolled areas should not result in an annual external dose to any individual in an uncontrolled area greater than $10 \mathrm{mrad}$ for gamma radiation or $20 \mathrm{mrad}$ for beta radiation.

c. Notwithstanding (a) and (b) above, the NRC may specify for design (1) a lower quantity of radioactive material to be released to the atmosphere if it appears that (a) and (b) are likely to result in an annual external dose from gaseous effluents to an individual in an uncontrolled area greater than 5 mrem whole body or (2) a higher quantity of radioactive 
material to be released to the atmosphere if it appears that (a) and (b) are not likely to result in an annual external dose from gaseous effluents to an individual in an uncontrolled area greater than $5 \mathrm{mrem}$ to the whole body or $15 \mathrm{mrem}$ to the skin.

d. For radioactive iodine and radioactive materials in particulate form released to the atmosphere, the annual release to uncontrolled areas should not result in an annual dose to any individual in an uncontrolled area greater than $15 \mathrm{mrem}$ to any organ. The same number appears in the NRC statement of position at the end of Appendix I, with the addition of the restriction that the annual quantity of radioactive iodine in gaseous effluents should not exceed 1 curie.

f. Account may be taken of any real phenomenon or factors affecting the estimate of radiation exposure, including the characteristics of the facility, modes of discharge of radioactive materials, physical processes tending to attenuate the quantity of radioactive material to which an individual would be exposed, and the effects of averaging exposures over times during which determining factors may fluctuate.

MLM-3719 notes that the current version of $10 \mathrm{CFR} 20$ gives $1 \times 10^{-3} \mathrm{Ci} / \mathrm{m}^{3}$ for tritium in effluent liquids, not the $2 \times 10^{-3} \mathrm{Ci} / \mathrm{m}^{3}$ given by DOE 5400.5 and the old $10 \mathrm{CFR} 20$. $10 \mathrm{CFR} 20$ states that from sanitary sewage systems, (1) not more than $10 \mathrm{mCi} / \mathrm{d}$ and $5 \mathrm{Ci} /$ year and (2) not more than $0.1 \mathrm{Ci} / \mathrm{m}^{3}$ averaged over a day and averaged over a month may be discharged. MLM-3719 also states that in "other NRC regulations," liquid scintillation cocktails are exempt from NRC regulation and can be treated as nonradioactive waste (this is usually taken to be less than $0.05 \mu \mathrm{Ci} / \mathrm{g}$ ). However, MLM-3719 continues, it is considered hazardous waste if it is material covered in the Resource Conservation and Recovery Act (RCRA) or if it exhibits flammability as per RCRA; in that case, it must be treated as mixed waste if the radioactive content is greater than $0.05 \mu \mathrm{Ci} / \mathrm{g}$.

g. 10 CFR 20 states that a licensee shall comply with the provisions of the Environmental Protection Agency (EPA) radiation standard in 40 CFR 190 where applicable. It also states that a licensee shall show compliance with the annual dose limit to the public either by demonstrating by measurement or calculation that the highest individual dose does not exceed the dose limit, or by demonstrating that the annual average concentrations in Table 2 of Appendix B of 10 CFR 20 are not exceeded in releases at the "unrestricted area" boundary and that, if an individual were continually present in an "unrestricted area," the dose from external sources would not exceed $0.002 \mathrm{rem} / \mathrm{h}$ and $0.050 \mathrm{rem} / \mathrm{year}$. (The last part would imply an average of $2 \mathrm{mrem} / \mathrm{h}$ and $50 \mathrm{mrem} / \mathrm{year}$ in DOE's "uncontrolled area.")

\subsection{RESTRICTIONS ON RELEASES TO THE ENVIRONMENT}

The controlling document for releases to the environment is DOE 5400.5. Some information is also given in DOE 5480.11, DOE 5500.3, and DOE 6430.1A. Important points for ANS design and planned operation are summarized below; these are from DOE 5400.5 unless otherwise noted. See also Sect. 2.2 for some release limits expressed as dose limits.

1. The radioactive liquid discharge requirements of DOE 5400.5 shall apply. Liquid discharges shall be controlled on a batch basis, analyzed prior to release, and monitored during release. Capability provided to terminate the release before completion to avoid exceeding any preset limits. (RCM) 
2. Liquid discharge limits and requirements are as follows. [Note that DOE 5400.5 states that derived concentration guides (DCGs) are not release limits, but are "screening values" for considering "best available technology" (BAT) for liquid discharges and for making dose estimates.]

a. The liquid effluents from DOE activities shall not cause private or public drinking water systems downstream of the facility discharge to exceed the drinking water radiological limits in 40 CFR 141; these are an effective dose equivalent of $4 \mathrm{mrem} / \mathrm{year}$ for all radionuclides, less than $5 \times 10^{-9} \mu \mathrm{Ci} / \mathrm{ml}$ of combined $\mathrm{Ra}-226$ and $\mathrm{Ra}-228$, and less than 1.5 $\times 10^{-8} \mu \mathrm{Ci} / \mathrm{ml}$ of gross alpha activity (including Ra-226 but not radon and uranium) (5400.5, HPM). [Thus the contribution of the ANS liquid effluent to Oak Ridge Reservation liquid discharge(s) must be such as not to exceed these limits.]

b. For discharges to surface waters, BAT is the level of treatment sufficient to bring the surface waters, prior to dilution, down to the DCG level or below for the mix of radionuclides in the discharge. iNo treatment is required for discharges below the DCG levels, but such treatment may be justified on an ALARA basis. MLM-3719 interprets DOE 5400.5 as stating that the limits apply at the boundary of the restricted area [sic], so appropriate factors for dilution or dispersion between the point of discharge (e.g., the stack) and the boundary may be applied.

c. Liquid process waste streams containing radioactive material in the form of settleable solids may be released to natural waterways if the concentration of radioactive material in the solids (above background level) does not exceed $5 \mathrm{pCi} / \mathrm{g}$ of alpha-emitting radionuclides or $50 \mathrm{pCi} / \mathrm{g}$ of beta-gamma-emitting radionuclides.

d. The absorbed dose to native aquatic animal organisms from exposure to the radioactive material in liquid discharges to natural waterways shall not exceed $1 \mathrm{rad} / \mathrm{d}$.

e. For discharges from DOE activities to sanitary sewerage, monthly concentrations may average 5 times the DCG for the mix, provided that a long-term buildup of activity at the sewage disposal plant will not result and provided that it will not result in doses exceeding a small fraction of the basic annual dose limit $(100 \mathrm{mrem})$. Higher concentrations may be discharged if the system is owned by the federal government and has no drain fields, but ALARA considerations must apply; the discharge from the sewerage system must be treated as in Item $\mathrm{b}$ above if necessary to get down to IDCG levels before release to surface waters. The preceding sentence also applies to liquid wastes discharged to chemical ("sewerage") systems.

f. Tritium decay in transit in confined ground water may be an acceptable alternative to direct release to the atmosphere or to surface waters.

3. Notwithstanding the release limits given above, releases to the environment shall be kept ALARA (10CFR20, 5400.5, 5480.30), except where the BAT concept is applied rather than the ALARA concept (5400.5; MLM-3719 appears to misinterpret this point). Qualitative judgments are permitted under some circumstances, especially where potential doses are well below the dose limit, except for meeting requirements of the National Environmental Policy Act. Alternative processes and methods shall be considered. DOE 5480.30 states that design shall limit the release of radioactive materials in effluents and emissions to ALARA levels during normal operation and shall "control" the release of radioactive materials under accident conditions "so that Rad Con Manual limits are not exceeded"; radioactive effluents released to the environment should not exceed the limits given in DOE 5400.1 and DOE 5400.5. Note, however, that no such limits are given in the RCM-DOE 5400.5 must be meant, but DOE 5400.5 does not cover accident doses. 
4. Sufficient holdup capacity shall be provided for retention of gaseous and liquid effluents containing radioactive materials, particularly where unfavorable site environmental conditions can be expected to impose unusual operational limitations upon the release of such effluents to the environment (5480.30; 10CFR50, Appendix A, Criterion 60). In addition, radioactive effluents shall meet the provisions of the National Environmental Policy Act as required by 5400.1 (5480.30).

\subsection{RESTRICTIONS ON DOSES TO EQUIPMENT}

Unattributed statements below are "good practice" and have no specific reference.

1. Nonsafety-related equipment and materials (including lubricants, coatings, and insulation) shall be radiation-qualified for an appropriate design life, consisting of a normal operating design life and the period after an anticipated operational occurrence, where appropriate. The radiation qualification shall be in conjunction with qualification for other parameters affecting performance life, such as temperature, pressure, and humidity. Dose from radioactivity deposited on or in the equipment or material shall be considered in addition to external dose from areas or sources outside the equipment or material, including airborne sources.

2. Safety-related equipment and materials (including lubricants, coatings, and insulation) shall be radiation-qualified for an appropriate design life (5480.30, 56.6), consisting of a normal operating design life and the period postaccident or after an anticipated operational occurrence during which it is expected to have to function, as appropriate, plus a small margin; it should therefore be able to function even after receiving an absorbed dose corresponding to the total design life (10CFR50). The radiation qualification shall be in conjunction with qualification for other parameters affecting performance life, such as temperature, pressure, and humidity (6430.1A, 10CFR50). [ANSI/ANS-57.1 says, "Any components required to function following an accident shall be designed for the accumulated environmental effects (pressure, temperature, humidity, corrosive vapors, spray, and flooding) of the accident."] Dose from radioactivity deposited on or in the equipment or material shall be considered in addition to external dose from areas or sources outside the equipment or material, including airborne sources.

3. Accident analyses should document the derivation of environmental qualification requirements for safety components, including environmental conditions that may develop in the course of credible accidents $(5480.23,10 \mathrm{CFR} 50)$. 



\section{SAFETY AND ACCIDENT MITIGATION}

See Sect. 14 below for postaccident monitoring requirements. See Sect. 5 for the definitions of "confinement" and "containment" and for several more specific requirements for confinement, containment, and ventilation. Note that Items 16 and 17 below imply that the Exclusion Area and Low Population Zone boundaries are set where the dose limit falls with respect to the design, rather than that the design is made so as to meet these limits at preset boundaries.

1. Primary radiation protection shall be through physical controls, e.g., confinement, containment, ventilation, remote handling, equipment layout, and shielding; secondary radiation protection shall be provided by administrative controls (10CFR835, 10CFR20, RCM, 5480.11).

2. Facility accident analyses should identify and classify the spectrum of accident sequences or scenarios that release radioactive materials, ranging from anticipated operational occurrences ("normal events") through design-basis accidents (those identified as "low probability, high consequences") (5480.23, 10CFR50). (Note that 10 CFR 50, in Section 50.49, defines design-basis events as "conditions of normal operation, including anticipated operational occurrences, design-basis accidents, external events, and natural phenomena"; thus the term "design-basis events" should not be used identically with "design-basis accidents.") Accident analyses should be developed in such a manner as to furnish an objective basis for verifying the adequacy of provisions to prevent or mitigate accidents (5480.23). They should also provide the bases for evaluating alternatives that may reduce facility risks $(5480.23)$.

3. The safety design shall generally follow the principle that occurrences resulting in high radiation doses or releases of radioactivity shall be of low probability and that occurrences of high probability shall result in only small doses or minimal releases of radioactivity (IAEA Safety Series No. 50-C-D).

4. The "defense in depth" concept shall be applied; this includes the use of conservative design margins, the provision of multiple barriers against the release of radioactivity, the provision of multiple means of ensuring that the primary safety functions are performed, and the provision of mitigating measures (5480.30).

5. A reactor containment and associated systems shall be provided to establish a barrier against uncontrolled release of materials to the environment; the design of this containment and associated systems shall meet the requirements of 10 CFR 50, Appendix A, Criteria 38-43 and 50-57 (5480.30) in a graded fashion (5480.30, Attachment 3 ). Reference should also be made to 10 CFR 50, Appendix A, Criteria 16, 20-23, 29, and 60-64.

6. The "confinement system" concept, as used in DOE 6430.1A, shall be applied to the design of the ANS, including its detritiation plant. The number and type(s) of confinement systems (including their associated subsystems, such as ventilation systems) for each confinement area of the ANS shall be chosen so as to function to prevent or limit the release of radionuclides during normal operation and during anticipated operational occurrences (AOOs) and postulated accidents (6430.1A). Individual confinement systems shall effectively perform their required functions for normal operations, AOOs, and the design-basis accidents (DBAs) 
they are required to withstand (6430.1A). Sufficient redundancy shall be provided in the unlikely event of a confinement system failure, and at least one of the confinement systems shall be designed to ensure that it can withstand the effects of severe natural phenomena and man-made events (for their postulated DBAs) and remain functional to the extent that release limits are not violated [6430.1A;5480.30 refers to DBA releases likely to exceed (unspecified) "DOE guidelines"] following any credible DBA (5480.30).

7. Safety-class air cleanup and ventilation systems shall be designed to provide the required confinement capability under all AOOs and DBAs with the addition of a single failure to the system, that is, to remain functional throughout the event and to retain collected radioactivity afterward (5480.30). Each such system shall have suitable redundancy in components and features and suitable interconnections, leak detection, isolation, and containment capabilities to ensure that its safety function can be accomplished, assuming a single failure (10CFR50, Criterion 41). For high-level liquid waste systems, the process cell or the secondary storage tank and its associated ventilation system shall be designed to remain functional during normal operations, AOOs, and the DBA(s) they are required to withstand; the same applies to the tertiary system, when present $(6430.1 \mathrm{~A})$. See Sect. 5 for other criteria regarding containment and confinement.

8. For experiments or operations, either facility design shall include (at least) two lines of defense to prevent the escape of radioactive materials to the environment, or analysis shall demonstrate that the worst credible accident is acceptable without either line of defense (HPM).

9. Extraordinary design features are warranted to avoid any potential dose to personnel that is large enough to cause acute biological effects; such features include positive control of ingress, permanent shielding, source removal, or combinations of these (RG8.8). Interlocked airlock doors should be considered in order to ensure that at least one door is closed during reactor operations and accident conditions (IAEA Safety Series 50-C-D).

10. Facility safety analyses should not take credit for the use of respiratory protection for routine work involving potential exposure to airborne radioactive materials (RCM). Half-face respirators shall not be used for emergency evacuation. (10CFR20 states merely that respirators shall be "specially certified or had certification extended for emergency use by NIOSH/MSA." [sic])

11. Criticality in the fuel storage and handling system(s) shall be prevented by physical systems or processes and adequate subcriticality shall be maintained at all times (5480.30). Facility design shall ensure that criticality is prevented in storage and handling of new fuel under normal and accident conditions (57.3) and that storage and handling can be accomplished without damaging a fuel assembly or reducing the required margin to criticality (57.2). The preferred method of maintaining subcriticality is favorable geometry; beyond that, passive, engineered safety features are preferred to active, engineered safety features (5480.30).

12. Structural design of spent fuel pool racks and other fuel-associated equipment shall be such that deformations are limited to preclude criticality for all plant conditions and should limit physical damage so as to permit normal insertion and removal of fuel during handling operations for normal operations and AOO events corresponding to a frequency of greater than $10^{-2} /$ year (57.2). 
13. The facility design basis (for criticality) shall reflect the requirements of DOE 5480.24, "Nuclear Criticality Safety" (5480.30). The requirements of DOE 5480.5 shall be applied as appropriate to fissile material storage and handling facilities and operations within a reactor facility (5480.6). Safety analysis shall consider credible occurrences such as tipping, falling, or dropping of a fuel element; tipping of a storage rack; misplacement or incorrect movement of a fuel element; the dropping of an object or a heavy load onto stored assemblies or the spent fuel pool(s); missiles; and stuck fuel assembly or crane uplifting forces (5480.30, Attachment 3, which uses the term "nuclear criticality AOOs"; 57.2). In the event of loss of control or motive power, a fuel assembly or control component shall remain in a safe condition (57.1). In particular, criticality effects resulting from these events shall be considered.

14. Credit may be taken for the inherent neutron-absorbing effect of materials of construction (57.2). However, nuclear poisons not inherent in structural materials may be taken into account only under the following conditions: design and fabrication of the storage racks is such that poisons are not inadvertently removed by mechanical and chemical action, poisons are compatible with the radiation environment to be encountered, and the quality and effectiveness of the poison is verifiable initially and on a periodic basis (57.2). Credit shall not be taken in the evaluation of $\mathrm{k}_{\mathbf{z}}$ (the evaluated maximum multiplication factor of fuel in the fuel storage racks) for normal conditions or AOO events corresponding to a frequency of greater than $10^{-2} /$ year; credit may taken for events with a frequency of $10^{-2} /$ year or less until the point where poisonless makeup begins (57.2).

15. The design of the facility shall ensure prompt, safe shutdown in emergencies. It shall allow ready access to areas where manual corrective actions are required after an AOO or accident and to areas that contain postaccident radiation monitoring equipment $(6430.1 \mathrm{~A})$.

16. Emergency planning shall be in accordance with DOE 5500.2, DOE 5500.3, and DOE 5500.4 (5480.6, 5480.23). Adequate provisions shall be made and described for emergency facilities and equipment, including equipment at the site for personnel monitoring; for determining the magnitude of and continuousiy assessing the impact of the release of radioactive materials to the environment; and for facilities and supplies at the site for decontamination of onsite individuals (10CFR50, Appendix E). The potential for variations in accident situations or unusual occurrences (e.g., gross leakage of contamination, pressure surges, fires, wounds) shall be considered; contingency planning shall be performed such that the potential for such occurrences is reduced and the capability for coping with the situations expeditiously is enhanced (RG8.8).

17. An Exclusion Area shall be selected such that an individual located at any point on its boundary for the 2 hours immediately following the onset of a DBA would not receive a total radiation dose to the whole body in excess of 25 rem or an iodine dose to the thyroid in excess of 300 rem (10CFR100).

18. A Low Population Zone shall be selected such that an individual located at any point on its boundary for the entire period of passage of the radioactive cloud resulting from the design-basis accident would not receive a total radiation dose to the whole body in excess of 25 rem or an iodine dose to the thyroid in excess of 300 rem (10CFR100). 



\section{RADIOLOGICAL AREA AND ZONE CLASSIFICATION AND ACCESS CONTROL}

"Radiological Areas" are defined in 10 CFR 835, the RCM, and DOE 5480.11 for the purposes of posting and access control. However, for purposes of shielding design, layout, and operational planning, a different classification scheme, that of "Radiological Zones," will also be useful.

In this set of design criteria, a capitalized term, such as "Radiation Area," denotes the formally defined meaning of the term, while an uncapitalized term, such as "radiation area," is a generic reference. Thus the term "Radiation Area" can mean only an area in which the general area dose rate (see definitions below) is between 5 and $100 \mathrm{mrem} / \mathrm{h}$, while the generic term "radiation area" can mean Radiation Area, High Radiation Area, or Very High Radiation Area. Similarly, the generic term "contamination area" includes Contamination Areas and High Contamination Areas. Note that the capitalized terms "Radiological Area" and "Radiological Zones" are already generic as regards the divisions they comprise; thus the meaning is the same whether they are capitalized or not.

\subsection{RADIOLOGICAL AREA CLASSIFICATIONS AND POSTING REQUIREMENTS}

The definitions below are from 10 CFR 835, the highest authority of all the references in this document, except for the definition of the Radiological Buffer Area. The RCM, DOE 5480.11, and IG G-10 CFR 835/G1 generally give the same definitions as these, so only the differences from or additions to 10 CFR 835 will be noted. Some of these are repeated in the Glossary (Sect. 20), for convenience.

1. A Controlled Area is any area to which access is managed to protect individuals from exposure to radiation or radioactive materials (10CFR835) at levels above natural background (IGG1). Individuals who enter only the Controlled Area without entering Radiological Areas are not expected to receive a total effective dose equivalent of more than $100 \mathrm{mrem} / \mathrm{year}$. Controlled Area borders should not be established contiguous with the site boundary, and there may be more than one Controlled Area within a site (IGG1, RCM).

2. A Radiological Area is any area within a Controlled Area that qualifies as a Radiation Area, High Radiation Area, Very High Radiation Area, Contamination Area, High Contamination Area, or Airborne Radioactivity Area, as defined below. Note that the Radiological Buffer Area (see below) is not mentioned or defined in 10 CFR 835; thus the Radiological Buffer Area is not a Radiological Area.

3. A Radiological Buffer Area (RBA) shall be established within a Controlled Area to provided a secondary boundary to control the spread of radioactive material contamination and to provide a mechanism to control the exposure of personnel to external radiation (RCM). The requirement for such an area is based on protecting individuals who do not have radiological worker training from inadvertent exposure to radioactive material or radiation fields at levels at which such training would be required (RCM). RBAs should be established as buffer areas for entrance or exit between Contamination, High Contamination, or Airborne Radioactivity Areas, except that no RBA is needed for the latter areas if they are completely contained within Contamination Areas (IGG1). An RBA should surround radiation areas (IGG1). 
4. A Radiation Area is any area accessible to individuals in which radiation levels could result in an individual's receiving a deep dose equivalent of more than 5 mrem but less than or equal to $100 \mathrm{mrem}$ in $1 \mathrm{~h}$ at $30 \mathrm{~cm}$ from the source or from any surface through which the source radiation penetrates.

5. A High Radiation Area is any area accessible to individuals in which radiation levels could result in an individual's receiving a deep dose equivalent of more than 100 mrem but less than or equal to $500 \mathrm{rad}$ in $1 \mathrm{~h}$ at $30 \mathrm{~cm}$ from the source or from any surface that the source radiation penetrates. The boundaries of permanent High Radiation Areas should be the physical barriers (e.g., walls or fences) that prevent access to the area except at designated access points (IGG1).

6. A Very High Radiation Area is any area accessible to individuals in which radiation levels could result in an individual's receiving a deep dose equivalent of more than $500 \mathrm{rad}$ in $1 \mathrm{~h}$ at $1 \mathrm{~m}$ from the source or from any surface that the source radiation penetrates. A physical barrier(s) should be provided to prevent personnel access to the area while the radiological conditions creating the Very High Radiation Area exist (IGG1).

7. A Contamination Area is any area where contamination levels are greater than the values specified in Appendix D of 10 CFR 835 but less than or equal to 100 times those values. Note that "contamination" is defined similarly (i.e., as cutoff levels) for workplace surfaces in Appendix D of 10 CFR 835, Table 2.2 of the RCM, and Attachment 2 of DOE 5480.11. (The total limit for the transuranics is lower in DOE 5480.11 than it is in the other two documents, but both supersede DOE 5480.11 in areas where there is a conflict.) A level is given for tritium in the RCM, but the tritium level is "reserved" (i.e., to be determined) in $10 \mathrm{CFR} 835$ and is not mentioned at all in DOE 5480.11. The values to be used for design on ANS are those given in Table 4.1 of this set of design criteria, which are the 10 CFR 835 values with the addition of the RCM tritium values.

For the free release of objects from Controlled Areas, DOE 5400.5 (although it does not use the term "free release") gives the same values as the other three documents, except that it does not mention tritium and its transuranic values are "reserved." Note that 10 CFR 20 says virtually nothing about contamination except for that on packages.

8. A High Contamination Area is any area where contamination levels are greater than 100 times the values specified in Appendix D of 10 CFR 835 (refer to Table 4.1 of this set of design criteria and the discussion in Item 7 above). If practical, High Contamination Areas should be located within Contamination Areas and permanent barriers should be used (IGG1).

9. An Airborne Radioactivity Area is any area where the measured concentration of airborne radioactivity above natural background exceeds or is likely to exceed $10 \%$ of the Derived Air Concentration (DAC) values given in Appendix A or C of $10 \mathrm{CFR}$ 835. Permanent barriers should be used whenever practical (IGG1). (Note that Regulatory Guide 8.25 states that an area should not be posted as an Airborne Radioactivity Area on the basis of unlikely accidents that might cause the DAC to be exceeded, but rather on the basis of the radioactivity levels normally encountered or of levels that can reasonably be expected to occur when work is being performed.) 
10. A Hot Spot is formally defined as any localized source of radiation or radioactive material, normally within facility piping or equipment, that produces radiation levels that exceed the general area radiation level by more than a factor of 5 and are greater than $100 \mathrm{mrem} / \mathrm{h}$ on contact (IGG1, RCM). Note that, Hot Spots are not mentioned or defined in 10 CFR 835, but IG G-10CFR835/G1 states that, since the purpose of posting them is to identify to the worker the significant localized sources of radiation in accessible areas frequented by workers, Hot Spots should not be posted in High Radiation Areas with general area dose rates greater than $1 \mathrm{rem} / \mathrm{h}$ or in Very High Radiation Areas. In areas not normally accessible to personnel and not routinely surveyed (e.g., piping in high overhead areas), it is not necessary to post Hot Spots until personnel access is required, and not even then if posting would consume an incommensurate amount of dose (IGG1).

The term "hot spot" (not capitalized) will be used informally to denote any localized area of elevated dose rate, down to about twice the general or typical area dose rate (e.g., see Sect. 7.3).

11. A Hot Particle Area is undefined as such in any of the documents mentioned. However, the RCM and IG G-10CFR835/G1 imply that any area known to have had a hot particle(s) is ipso facto a Radiological Area, and they state that any posting of a Contamination or High Contamination Area with a history of hot particles must include the words "Hot Particles." IG G-10CFR835/G1 defines hot particles as those particies that "can deliver high localized doses and may not be detected during normal personal monitoring at exit areas."

12. A Radioactive Material Area is any area where radioactive material is used, handled, or stored.

13. An Underground Radioactive Material Area is any area having underground items containing radioactive material (IGG1, RCM) and is posted to prevent the inadvertent excavation of buried radioactive material (IGG1).

14. Posting for an open radiography installation shall be as given in ANSI N43.3 (IGG1). The posting of open installations using sealed sources should be according to 10 CFR 34 (IGG1, RCM). However, if the requirements of 10 CFR 835 are more stringent, they should take precedence (IGG1). The physical boundaries for radiography operations should be determined by a qualified radiographer (IGG1).

15. Radiological Buffer Areas and Radiological Areas should have boundary identifiers on each side, appropriately identified (e.g., by yellow and magenta floor tape) (IGG1). However, the boundary of a Radiological Buffer Area that is the same as that of a radiation area is not required to be posted as a Radiological Buffer Area (IGG1, RCM). Existing physical barriers such as fences or walls may be used as boundary identifiers if the posting is adequate to prevent inadvertent access to the Radiological Area (IGG1). High Radiation Areas should be located within Radiation Areas, if practical (IGG1).

16. Appropriate signs should be placed intermittently along the boundary of an area if personnel could be expected to enter, and signs should be visible and unblocked from both sides, from any normal avenue of approach, and during normal operations (IGG1). Physical barriers need not be erected to identify the boundaries of Radiological Areas not accessible to personnel 
(such as Underground Radioactive Material Areas), but appropriate signs should be placed along area boundaries (IGG1). All personnel entrances and exits to Radiological Areas shall be clearly and conspicuously posted with the appropriate signs, including dose rate and contamination levels (IGG1). Permanent signs and postings should be mounted on chains, posts, walls, and doors and should not interfere with the operation of emergency exits (IGG1). Warnings regarding the hazards of a large contamination containment that a person might enter should be posted on the interior, if access is allowed, or on the exterior, if access is not allowed (IGG1).

17. Instructions for removing personal protective clothing should be posted in step-off pad areas (RCM). Instructions for frisking should be posted adjacent to personnel monitoring instruments (RCM).

18. During transportation of radioactive material that is emitting radiation at levels that meet the criteria for a Radiation Area, if it is not possible for a physical barrier to be established at the point where the dose rate drops below $5 \mathrm{mrem} / \mathrm{h}$, then the exterior of the material package or container shall be labeled as a Radiation Area and the individual transporting the material is responsible for communicating the radiation hazard.

\subsection{RADIOLOGICAL ZONE CLASSIFICATIONS AND REIATED REQUIREMENTS}

The radiological zone definitions below are specifically for ANS. They have been chosen considering the Radiological Area classifications of 10 CFR 835, etc., and the "radiation zone" classifications of ANSI/ANS (e.g., as in ANSI/ANS-55.6), as well as the ORNL-specific access controls as given in the ORNL HPM and the various specific dose rate limits recommended by various ANSI/ANS standards. For comparison, note that the ANSI/ANS radiation zones (for external dose rate only) are as follows: I, $\leq 1.0 \mathrm{mrem} / \mathrm{h} ; \mathrm{II}, \leq 2.5 ; \mathrm{III}, \leq 15 ; \mathrm{IV}, \leq 100 ;$ and $\mathrm{V},>100 \mathrm{mrem} / \mathrm{h}$. The recommendations of Item 4 below, when applied, should be "translated" from the ANSI/ANS scheme into that of Table 4.2 .

1. The radiological zones used for design and operational planning purposes at ANS shall be as given in Table 4.2.

2. In the absence of specific information regarding dose rates, contamination levels, or airborne radioactivity levels in an area, the radiological zone designation of that area shall be applied as appropriate for shielding design, personnel dose calculations based on expected occupancy of the area, radioactive materials movement evaluations, equipment qualification, and radiation protection and operational planning.

3. In general, the maximum dose rate and contamination and airborne levels for the range of the zone assigned to an area shall apply for purposes of calculating shielding and personnel and equipment doses (implied by RG8.8 for the case of personnel). However, in cases where this is clearly not warranted (e.g., when the maximum dose rate is applicable to one side of a room while personnel are occupying an area of much lower dose rate on the other side), exceptions such as using the average dose rate may be made if justified. 
4. Recommendations for preliminary zone assignments for design purposes for various systems and pieces of equipment are as given below, from various ANSI standards.

a. The need for personnel to enter zones with dose rates that exceed the upper limit of ANSI/ANS Zone 3, and the time they spend there, should be limited (55.6).

b. Radwaste processing areas required for routine access should be in ANSI/ANS Zones 1, 2, or $3(55.1,55.4,40.35)$. All operation of gaseous radwaste systems (control panels, etc.) should be from ANSI/ANS Zones 1, 2, or 3 (55.4; 55.6 says that dose rates in frequently occupied control areas should be less than $1 \mathrm{mrem} / \mathrm{h}$ and that any remote-control areas should be located in ANSI/ANS Zones 1,2, or 3). Except for control or sensing elements that must be located at the equipment or in equipment cells, instrumentation shall be located in areas of $15 \mathrm{mrem} / \mathrm{h}$ or less $(55.4,55.6)$, in particular instrument transmitters and flow elements in piping systems (55.6). Required lubrication addition, chemical addition, and hydraulic fluid fill points should be in areas less than $2.5 \mathrm{mrem} / \mathrm{h}$ (40.35).

c. Pipe runs containing unprocessed liquid wastes (excluding low-level wastes such as detergent wastes) shall not be routed through ANSI/ANS Zones 1, 2, or 3 unless they can be shielded to below the zone upper limit (55.6).

d. Fuel-handling equipment shall be designed such that the operator will not be exposed to a whole-body radiation dose rate greater than $2.5 \mathrm{mrem} / \mathrm{h}$ from an irradiated fuel assembly, control component, or both, that is elevated to the up-position interlock with the pool at normal operating water level (57.1).

e. Nonradioactive valves and equipment should be located in ANSI/ANS Zones 1,2 , or 3 $(55.4,55.6)$.

\subsection{ACCESS CONTROL}

1. In general, access control should function to keep unauthorized people out of radiological areas and to verify entries by authorized people, to enable the operators and managers of the facility to ascertain the general location of all persons at all times, and to prevent contamination from being carried out of contamination areas. These principles should be applied in cases where two criteria below conflict.

2. An entry control program shall be established for areas of potential or actual airborne or surface contamination, including RBAs where appropriate, and for areas of potential or actual significant external dose rates (10CFR835, RCM). The level of control should correspond to the degree of hazard (RCM, 5480.11, 6430.1A, HPM).

3. In particular, the following should be considered for High Radiation Areas. For High Radiation Areas where dose rates are such that a person could receive a whole-body dose of $1 \mathrm{rem} / \mathrm{h}$ at $30 \mathrm{~cm}$ from the source or from any surface that the radiation penetrates, and for Very High Radiation Areas, at least one of the following shall be provided (10CFR835, RCM, 5480.11; 10 CFR 20 and Regulatory Guide 8.38 state virtually the same, except for requiring all of these for Very High Radiation Areas, except as noted; ANSI/ANS-55.4 and ANSI/ANS-55.6 provide for physically isolating areas of greater than $100 \mathrm{mrem} / \mathrm{h}$ to prevent inadvertent entry by personnel).

a. A control device on each access point that functions automatically to prevent entry, that permits entry only if the dose rate is reduced to $\leq 100 \mathrm{mrem} / \mathrm{h}$, or that prevents use or operation of the radiation source while personnel are present 
b. A control device that energizes conspicuous visible or audible alarm signals so that the individual entering the area through a failed control device is aware of the radiation level and so that radiation protection or operational personnel are aware of his entry

c. Locked entryways, with positive control over the area when access is required

d. Control devices that automatically generate audible and visible alarm signals to alert personnel in the area before use or operation of a radiation source in time for them to evacuate or to activate a secondary control device to prevent use or operation of the source (not given in 10 CFR 20 or Regulatory Guide 8.38 for High Radiation Areas)

e. Continuous direct or electronic surveillance that is capable of preventing unauthorized entry

f. Additional measures to preclude entry into areas while the dose rate exceeds $500 \mathrm{rad} / \mathrm{h}$ there

4. When cocooning is practiced (i.e., when there is a substantial physical barrier such as chain-link fencing or a bolted cover enclosing a Very High Radiation Area or a High Radiation Area above $1 \mathrm{rem} / \mathrm{h}$, and there are no openings in the barrier), the area is considered to be inaccessible, and the requirements of Item 3 above do not apply (10CFR20, RG8.38). However, when the barrier is breached, the requirements are in effect (RG8.38). Openings in physical barriers around a High Radiation Area are not required to be controlled as entrances if exceptional measures are needed to access them, such as a tank or vessel manway whose cover is bolted in place or an opening in a shield wall that is physically difficult to access without a ladder or a mobile platform (RG8.38).

5. Physical barriers should be placed so that they are clearly visible from all directions and so that they are not easily bypassed or walked under except at identified access points (IGG1, RCM). Physical barriers surrounding High Radiation Areas should be sufficient to prevent inadvertent entry (RG8.38); rope barriers should be 24-40 in. in height (IGG1). Physical barriers should, to the extent practicable, completely enclose Very High Radiation Areas sufficiently to thwart undetected circumvention of the banier (RG8.38). If shielding is used as a barrier, it should not be readily removable; if it is at removable, it should be posted with a warning sign and local radiation monitors with audible and visible alarms should be installed to warn personnel of high exposure rates that may be created by removal of the shielding (RG8.38). If the shield is a liquid, means shall be provided to monitor the integrity of the shield and to provide an automatic signal on loss of adequate integrity (e.g., some types of hot cell windows, spent fuel pool water) (10CFR20).

6. Physical controls should not unduly impede passage toward emergency exits or evacuation routes (including the control barriers of Item 3 above) (10CFR835, RCM, RG8.38). They should also not preclude personnel access to the interior of the area when access is required for emergency response (RG8.38).

7. Control points for High Radiation Areas may be established at locations beyond the immediate boundaries of the High Radiation Areas to take advantage of natural or existing barriers (RG8.38). The use of one locked door (or one control point where positive control over personnel entry is exercised) to establish control over multiple High Radiation Areas is acceptable provided that the individual areas are barricaded and posted separately, control points are established sufficiently close to the areas that adequate supervision of access to the 
areas can be ensured, and the required protective measures and other requirements for entering the areas can be enforced at the control point (RG8.38).

Multiple Very High Radiation Areas should be kept locked except during periods when access to the areas is required (RG8.38). Multiple Very High Radiation Areas may be controlled with one locked entrance to take advantage of natural or existing barriers provided that the individual areas are barricaded and posted separately (RG8.38). Entries to such areas may be monitored by continuous direct electronic surveillance (RG8.38).

A key for access to a Very High Radiation Area should unlock only that area (RG8.38). However, master keys may be made for use during emergency situations as long as they are not used for normal personnel access (RG8.38).

8. Access control points (or area portals) shall be established on the boundaries of posted areas as required for the control of personnel and materials entering and leaving the posted areas (HPM). Entrance to and exit from an RBA or contamination area shall be made through a specified control point(s) (HPM). The number of control points should be minimized. A control point may be temporary or permanent depending on the degree of access required (HPM). The main access control point should be located on the (or a) major route into the outer radiological boundary(-ies) (i.e., the entry(-ies) into the containment, the guide hall, etc.). Positive control over each individual entry is required (by 10 CFR 20) when access is required to a High Radiation Area that is normally controlled by being locked (RG8.38).

9. Entry and exit access control points that are used for transporting materials to and from an irradiation or source area and are not intended for personnel traffic must be controlled so as to preclude inadvertent entry by individuals. Exit points for potentially radioactive materials must be equipped to detect and signal the presence of any loose radiation sources being carried out of the area. (These statements are all from 10 CFR 20, which actually says "processed materials" instead of "potentially radioactive" materials, but in the context of irradiation of the materials.)

10. Traffic patterns shall be planned so that people and equipment do not pass through clean areas to get from one potentially contaminated area to another except in limited cases.

11. Pool areas that may contain highly activated or contaminated materials do not have to be controlled as High or Very High Radiation Areas solely because of the materials in them, under the following conditions (RG8.38).

a. Control measures are implemented to ensure that the materials are not inadvertently raised above or brought near the surface of the pool water.

b. All drain line attachments, system interconnections, and valve lineups are such as to prevent accidental drainage of the water.

c. Necessary procedural controls for preventing accidental water loss and drops in water levels that may create High and Very High Radiation Areas are implemented (or anticipated).

12. Continuous observation of diving operations is required (RG8.38). Where practical, physical barriers should be provided to prevent access by divers to highly radioactive underwater items or areas (RG8.38). Markers such as lights and signs that are visible underwater should also be considered. Provisions should be made for each diver to have a safety line and 
continuous voice communication with surface personnel, a calibrated and alarming dosimeter suitable for underwater use, and a remote-readout radiation detector that can be continuously monitored by health physics (HP) personnel (RG8.38).

13. Interlocks shall be provided as necessary to minimize personnel exposure and operator error (55.1). An interlock shall be provided to restrict travel of the fuel transfer carriage (or ANS analogue) unless the transfer tube valve(s) is in a predetermined open position (57.1). Provisions shall be made for placement of barriers to prevent unauthorized access to the truck loading area during the loading of filled radwaste containers (55.1).

14. Weekly inspections of the physical controls for High and Very High Radiation Areas should be made (RCM). If control devices are not functioning properly, the operator shall not conduct operations (with a source or in the source area) except to perform a repair or to put the source in a safe condition (10CFR20).

15. Efforts should be made to identify "special areas" for access, that is, those that do not usually qualify as Very High Radiation Areas but have the potential to qualify as such during certain normal operations. [The examples given in Regulatory Guide 8.38 are a pressurized water reactor cavity sump, as a result of withdrawal of the retracting in-core detector thimble tubes, and systems that can be chemically decontaminated, as a result of (relatively sudden) movement of large quantities of contamination.] Provision should be made for appropriate control measures for these areas, including appropriate provisions for rapid evacuation. (RG8.38)

16. Successful completion of the appropriate level(s) of radiation worker training shall be required for unescorted entrance to RBAs (RCM) or to Contamination Areas (RCM, HPM). Thus access control measures, access control points, and the need for access should be planned with this requirement in mind. 
Table 4.1. Surface contamination limits

\begin{tabular}{lcc}
\hline \multicolumn{1}{c}{ Nuclides } & $\begin{array}{c}\text { Removable } \\
\left(\mathrm{dpm} / 100 \mathrm{~cm}^{2}\right)\end{array}$ & $\begin{array}{c}\text { Total } \\
\left(\mathrm{dpm} / 100 \mathrm{~cm}^{2}\right)\end{array}$ \\
\hline U-nat, U-235, U-238, and associated decay products & 1,000 alpha & 5,000 alpha \\
$\begin{array}{l}\text { Transuranics, Ra-226, Ra-228, Th-228, Th-230, } \\
\text { Pa-231, Ac-227, and I-129 }\end{array}$ & 20 & 500 \\
$\begin{array}{l}\text { Th-nat, Th-232, Sr-90, Ra-223, Ra-224, U-232, } \\
\text { I-125, I-126, I-131, and I-133 }\end{array}$ & 200 & 1,000 \\
$\begin{array}{l}\text { Beta-gamma emitters (decay modes other than alpha } \\
\text { emission or spontaneous fission) except Sr-90 and } \\
\text { others noted above, but including fission products } \\
\text { containing Sr-90 }\end{array}$ & $1,000 \mathrm{~B}-\gamma$ & $5,000 \mathrm{~B}-\gamma$ \\
$\begin{array}{l}\text { Tritium organic compounds, surfaces contaminated } \\
\text { by HT, HTO, and metal tritide aerosols }\end{array}$ & 10,000 & 10,000 \\
\hline
\end{tabular}

Notes:

1. These limits are based on 10 CFR 835, Appendix D, and (for tritium) the DOE RCM, Table 2.2. They are included for the purpose of illustrating how the Contamination and High Contamination Areas are defined. Specifications regarding maxima and averages are given in the 10 CFR 835 and RCM tables but are not repeated here.

2. These values are also given by the DOE (5400.5) to represent the "free release" levels, that is, the levels below which an item or area may be released to an uncontrolled or public area.

3. ANSI/ANS-15.11 gives the same values for "removable" and "average" values as for "removable" and "total" values here, except that it gives 100 for the average (total) value of the transuranic class and that it does not give any values for tritium.

4. MLM-3719 gives 10,000 for removable tritium and 50,000 for total (average) tritium for free release, and 20,000 and 100,000 , respectively, for release to "controlled usage onsite." 
Table 4.2. ANS radiological zones"

\begin{tabular}{|c|c|c|}
\hline $\begin{array}{c}\text { Zone } \\
\text { designation }\end{array}$ & Range & Interpretation \\
\hline \multicolumn{3}{|c|}{ External dose rate ${ }^{b}$} \\
\hline $\begin{array}{l}1 \\
2\end{array}$ & $\begin{array}{l}\leq 0.05 \mathrm{mrem} / \mathrm{h} \\
0.05-0.25 \mathrm{mrem} / \mathrm{h}\end{array}$ & $\begin{array}{l}\text { Free MOP access } \\
\text { Free nonradiological worker access }\end{array}$ \\
\hline $\begin{array}{l}3 \\
4 \\
5 \\
6\end{array}$ & $\begin{array}{l}0.25-2.5 \mathrm{mrem} / \mathrm{h} \\
2.5-5.0 \mathrm{mrem} / \mathrm{h} \\
5.0-20 \mathrm{mrem} / \mathrm{h} \\
20-100 \mathrm{mrem} / \mathrm{h}\end{array}$ & $\begin{array}{l}\text { Areas of greatest } \\
\text { radiation protection interest }\end{array}$ \\
\hline $\begin{array}{r}7 \\
8 \\
9 \\
10\end{array}$ & $\begin{array}{l}100-1000 \mathrm{mrem} / \mathrm{h} \\
1-10 \mathrm{rad} / \mathrm{h} \\
10-100 \mathrm{rad} / \mathrm{h} \\
100-500 \mathrm{rad} / \mathrm{h}\end{array}$ & $\begin{array}{l}\text { Very limited access, EQ, } \\
\text { accident use }\end{array}$ \\
\hline 11 & $\geq 500 \mathrm{rad} / \mathrm{h}$ & Very high radiation area \\
\hline \multicolumn{3}{|c|}{ Contamination potential } \\
\hline None & & \multirow{2}{*}{$\begin{array}{l}\text { No potential } \\
\text { Buffer area-low potential (low concentrations if } \\
\text { contamination occurs) }\end{array}$} \\
\hline a & & \\
\hline b & & $\begin{array}{l}\text { 1-100 } \times 10 \text { CFR } 835 \text {, Appendix D limits, potential or } \\
\text { actual (Contamination Area) }\end{array}$ \\
\hline c & & $\begin{array}{l}\geq 100 \times 10 \text { CFR } 835, \text { Appendix D limits, potential or } \\
\text { actual (High Contannination Area) }\end{array}$ \\
\hline \multicolumn{3}{|c|}{ Airborne concentration } \\
\hline None & $\leq 0.01 \mathrm{DAC}$ & \multirow{2}{*}{$\begin{array}{l}\text { Virtually no potential. } \\
\text { Low potential, low level (respirator or air suit use not } \\
\text { likely) }\end{array}$} \\
\hline A & $0.01-0.10 \mathrm{DAC}$ & \\
\hline B & $0.1-1.0 \mathrm{DAC}$ & $\begin{array}{l}\text { Light-control range (respirator or air suit use likely, air } \\
\text { sampling or monitoring) }\end{array}$ \\
\hline C & 1-10 DAC & $\begin{array}{l}\text { Medium-control range (respirator or air suit use } \\
\text { required, other strict clothing requirements, air } \\
\text { monitoring) }\end{array}$ \\
\hline D & $\geq 10 \mathrm{DAC}$ & $\begin{array}{l}\text { Strict-control range (the most stringent personnel } \\
\text { protection measures) }\end{array}$ \\
\hline
\end{tabular}

"Every radiological zone defined has an external dose rate number and may have a contamination potential letter or airborne radioactivity concentration letter or both, depending on potential. The meaning of the abbreviations can be found in the acronyms and initialisms list.

${ }^{b}$ Small areas of elevated dose rate do not affect the zoning. Dose rates given are those above background. 


\section{CONTAINMENT, CONFINEMENT, AND VENTILATION}

See also Sect. 3.0 for some other containment and confinement requirements based on general principles of designing for accident mitigation.

\subsection{DEFINITIONS AND BASIC REQUIREMENTS}

1. DOE 6430.1A, which is applicable to nonreactor nuclear facilities, defines the terms "confinement area" and confinement system" but not "confinement" alone; in DOE 5480.30, which is applicable to reactors, "confinement system" and "containment system" are defined, but it is not clear that these definitions agree with all uses of the terms in DOE 6430.1A. Both characterize confinement ventilation systems, but DOE 5480.30 refers to DOE 6430.1A for specifics. DOE 6430.1A sometimes uses the word "enclosure" also. In view of the fact that there may still be confusion regarding this, the definitions of "containment," "confinement," and "enclosure" and their associated systems that are used for ANS shall be as given below.

a. Containment: a radioactivity-containing area that is enclosed by or associated with one or more passive or active barriers whose purpose is to control radioactivity (i.e., to confine it to the area or to direct it to another desired control location) by ensuring that all openings to the area are closed (except for those designed to remain open during a design-basis accident).

b. Confinement: a radioactivity-containing area that is enclosed by or associated with one or more passive or active barriers whose purpose is to control radioactivity (i.e., to confine it to the area or to direct it to another desired control location, even when an access opening is made in a passive barrier) either by ensuring that the active system functions or by providing one or two other associated confinements in a layered fashion.

[Note that DOE 6430.1A states that a confinement area is "an area having structures or systems from which releases of hazardous materials are controlled. The primary confinement systems are the process enclosures (gloveboxes, conveyors, transfer boxes, other spaces normally containing hazardous material), which are surrounded by one or more secondary confinement areas (operating area compartments)."]

c. Enclosure: DOE 6430.1A defines this in one place as "a primary confinement such as process systems, gloveboxes, conveyors, hot cells, and canyons" and elsewhere includes cubicles, fume hoods, and conveyor tunnels. However, open-face hoods are not included. Thus, contrary to other common usage, an enclosure is essentially a primary containment that is not a portable container.

d. Containment system: a containment together with its associated barriers.

[Note that DOE 5430.80 states that a containment system is "a structurally closed barrier and its associated systems (including ventilation) between areas containing hazardous material and the environment or other areas in the facility that are normally expected to have levels of hazardous material lower than allowable concentration limits. A containment barrier is designed to remain closed and intact during all design-basis accidents."]

e. Confinement system: a confinement together with its associated barriers.

[Note that DOE 5480.30 and DOE $6430.1 \mathrm{~A}$ both state that a confinement system is "the barrier and its associated systems (including ventilation) between areas containing hazardous material and the environment or other areas in the facility that are normally expected to have levels of hazardous material lower than allowable concentration limits."] 
f. Primary confinement: the barrier or set of associated barriers most intimately in contact with the radioactivity; this might be an irradiation capsule, a pipe, a glovebox wall, or reactor fuel cladding, for example.

g. Secondary confinement: the barrier or set of associated barriers that encloses the primary and receives and controls any leakage from it; this might be the room or vault containing a tank or the outer wall of a double-walled tank, for example.

h. Tertiary confinement: the barrier or set of associated barriers that encloses the secondary and receives and controls any leakage from it; this might be the building containing the room containing a single-walled tank, or it might be the room containing a double-walled tank, for example.

i. Passive barriers: a barrier whose function is performed in a static, nonactivating fashion so that it confines radioactivity even when an active system is shut off; examples include room and duct walls, floors, filters, etc.

j. Active barriers: barriers whose function must be performed in a dynamic or activating manner, at least initially or under some conditions, for radioactivity to be confined; examples include valves, fans, and dampers.

2. All states of operation and system configurations shall be considered in defining confinements and containments; that is, dynamic situations as well as static or steady-state situations shall be considered.

As an illustration of this principle, consider a tank containing radioactive liquid. The tank itself is the primary confinement, together with its intake and outlet piping up to the nearest isolation valves. When these valves are open, the primary confinement extends to the next closed valve(s). When the next set of valves is opened, the primary extends out to them, and so on. When the valves are closed, a tank downstream of the first tank may constitute its own primary confinement. But when the valves between it and the first tank are open, the primary effectively extends from the first tank down through the piping and valves to and including the second tank.

3. In general, confinements shall be as independent as possible. However, secondary and tertiary barriers, where required, may exist in common in a form such as a single structural envelope (e.g., roof slab), provided that the barrier can withstand the effects of relevant DBAs and manmade events that it is designed for (6430.1A). An accessway(s) into the interior of the single structural envelope is allowed, provided that entrance into the accessway is gained from another level of confinement and the accessway does not allow the routine transfer of personnel, equipment, or materials directly to or from the exterior of the facility (6430.1A, clarified).

4. In general, confinement systems with widely differing levels of actual or potential radioactivity content should be isolated from one another by barriers such as walls and check valves or other reverse flow control devices. (See also Sect. 10.) 


\subsection{SPECIFICATION OF CONFINEMENTS AND CONTAINMENTS}

1. For a specific nuclear facility, the number and arrangement of confinement barriers and their required design features and characteristics shall be determined on a case-by-case basis (6430.1A). They shall be chosen so as to function to prevent or limit the release of radionuclides during normal operation and during AOOs and postulated accidents (6430.1A).

2. For large Category A reactors, a reactor containment and associated systems shall be provided. The containment design should meet the requirements of 10 CFR 50, Appendix A, Criteria 50-57 and 38-43, in an appropriately graded manner (5480.30). For reactor facilities that do not require a containment, confinement barriers and associated systems shall be provided considering normal operations, AOOs, and DBAs (5480.30).

3. Reactor confinement and containment

a. The primary confinement system shall include all equipment that is part of or serves to maintain the primary pressure boundary: the reactor vessel, the primary coolant system (including all pumps, tanks, valves, pressurizers, heat exchangers, and piping), etc.

b. The secondary confinement system shall include all equipment that is part of or serves to maintain the reactor inner reactor building boundary: the inside walls of the reactor building structure, the ventilation system, air seals, etc.

c. The tertiary confinement system shall include all equipment that is part of or serves to maintain the reactor building outside (annular) boundary: the outside of the reactor building structure, the annular purge ventilation system, etc.

"Reactor containment," as used in DOE $\mathbf{5 4 8 0 . 3 0}$ and as apparently required for ANS, is thus all or part of the secondary and tertiary confinements taken together. (This area must be determined for ANS.)

4. Auxiliary equipment systems (when isolated from the primary coolant boundary)

a. The primary confinement system shall include, in general, all equipment that serves to contain radioactivity, i.e., that is part of or maintains a boundary between the radioactive gas or liquid and the operating area: collection tanks, process vessels, pumps, valves, etc.

b. The secondary confinement system shall include, in general, all equipment that is part of or serves to maintain the barrier between an operating area (limited access area or confinement cubicle) and general access areas: the operating area walls, the operating area ventilation system, etc.

c. The tertiary confinement system (which may be optional, depending on the operation) shall include, in general, all equipment that is part of or serves to maintain the barrier between the general access area(s) and the outside of the building housing them: the outside wall and roof of the building, the building ventilation system, etc.

5. Liquid and gaseous radwaste systems (including off-gas)

a. The primary confinement system shall include all equipment that serves to contain radioactivity, i.e., that is part of or maintains a boundary between the radioactive gas, liquid, or slurry and the operating area: collection tanks, process vessels, pumps, valves, etc. A primary confinement consisting of a primary storage vessel or treatment system equipment shall be provided for high-level liquid waste, or consisting of a storage vessel or treatment system for low-level or transuranic liquid waste $(6430.1 \mathrm{~A})$. The primary storage 
vessel or treatment system equipment for high-level waste should be double-walled; if it is, it counts as both primary and secondary (6430.1A). The off-gas system capacity (i.e., the capacity of the primary confinement of this system) shall be consistent with the need for handling off-gas from components and systems during normal operations, AOOs, and DBAs.

b. The secondary confinement system shall include all equipment that is part of or serves to maintain the barrier between an operating (limited access) area and general access areas; it may include the operating area walls, the operating area ventilation system, etc. A secondary confinement consisting of a secondary storage vessel or process cell shall be provided for high-level liquid waste, of a dike or berm around the vessel or treatment systems for low-level liquid waste, and of a storage building or process building for transuranic liquid waste (6430.1A). Secondary spill containment shall be provided for mixed waste applications also (40.35).

Spills, overflow, or leakage from storage vessels or other primary confinement structures shall be collected and retained within the secondary confinement structure $(6430.1 \mathrm{~A}, 55.6)$; the secondary shall be capable of retaining the maximum radioactive liquid waste inventory that may be released from the primary (6430.1A). The capability shall exist to transfer all such collected liquid from the secondary confinement siructure to a suitable storage location (6430.1A), such as by means of drains to the liquid radwaste processing system (55.6).

c. The tertiary confinement system, the necessity for which depends on the operation, shall include all equipment that is part of or serves to maintain the barrier between the general access area(s) and the outside of the building housing them; it may include the outside wall and roof of the building, the building ventilation system, etc. (6430.1A). A tertiary confinement consisting of a soil barrier or process building shall be provided for high-level liquid waste; no tertiary is required, in general, for low-level or transuranic liquid waste (6430.1A).

6. Solid radwaste systems

a. In general, the primary confinement system for the treatment stage of processing shall be the radioactive solid waste process systems equipment and associated off-gas or vent systems $(6430.1 \mathrm{~A})$. For cases in which the process or storage includes corrosive or noxious materials, the radioactive solid waste process or storage system shall be totally enclosed and provided with its own ventilation system and off-gas cleanup system $(6430.1 \mathrm{~A})$. In such cases, the radioactive solid waste process or storage system shall be treated as the primary confinement system (6430.1A). However, depending on the waste being processed and stored, the primary confinement and secondary confinement shall consist of a site-specific engineered system of barriers (e.g., drums, liners, concrete casks) when the primary confinement described above is not required (6430.1A).

b. During treatment, secondary confinement shall consist of a process cell or building and its ventilation system; during interim storage, a storage building or enclosed structure shall be used (6430.1A). Process cells shall be provided with exhaust ventilation with sufficient capacity to ensure an adequate controlled ventilation flow as required in the event of a credible breach in the secondary confinement barrier (6430.1A).

c. A tertiary confinement is not required in most cases for radioactive sold waste during the treatment or interim storage phase $(6430.1 \mathrm{~A})$. 
7. Tritium-handling systems (in the reactor building and the detritiation plant)

a. The degree of confinement required at an individual tritium facility should depend on the form and quantity of tritium that could potentially be released (6430.1A, MLM-3719, TSHC). In general, tritium gas shall be contained in tanks and piping systems that are enclosed in a secondary confinement building or totally within primary confinement enclosures such as gloveboxes and fume hoods; gloveboxes are to be preferred to hoods for work with tritium (6430.1A). Simple confinements, such as using a single glovebox to contain more than one component, are to be preferred to more complex ones (MLM-3719). The secondary should have sufficient passive relief capacity to deal with a large leak from the primary (MLM-3719); when pressure or missile-producing accidents within a glovebox are credible accidents and would result in failure of the glovebox or process room, consideration shall be given to using an alternative confinement technique (6430.1A).

b. The primary confinement system shall include all equipment that serves to contain radioactivity, i.e., that is part of or maintains a boundary between the tritiated stream and the operating area; for the relevant detritiation plant systems, this would include collection tanks, process vessels, pumps, valves, gloveboxes, etc., and for relevant reactor and radwaste systems, these would be as given in Items 3 and 4 above.

c. The secondary confinement system shall include all equipment that is part of or serves to maintain the barrier between an operating (limited access) area and general access areas; for the relevant detritiation plant systems, these would include the operating area walls, the operating area ventilation system, etc., and for relevant reactor and radwaste systems, these would be as given in Items 3 and 4 above. It should be possible to perform maintenance and inspection of the primary confinement system of a tritium-containing system without breaching the secondary, in particular those parts most susceptible to failure (MLM-3719). Consideration should be given to, e.g., building the primary system so that it can be disassembled through the gloves of the secondary and parts can be moved in and out through pass-through ports in the secondary (MLM-3719). Where parts of the primary system are too large to allow this procedure, the secondary should be designed so as to allow for extension of the secondary by building a tent around or coming off a glovebox (MLM-3719) or by construction of large walk-in or reach-in hoods as at the Savannah River Plant (Reinig).

d. The tertiary confinement system (which may be optional, depending on the operation) includes all equipment that is part of or serves to maintain the barrier between the general access area(s) and the outside of the building housing them; for the relevant detritiation plant systems, these would include the outside wall and roof of the building, the building ventilation system, etc., and for relevant reactor and radwaste systems, these would be as given in Items 3 and 4 above.

e. Double-walled pipe within a secondary confinement structure (encasement) shall be used in all areas where the primary pipe leaves the facility; in areas within the facility, the use of double-walled pipe shall be considered (6430.1A).

f. Transfer lines between gloveboxes should be secondarily contained and have the same integrity as the gloveboxes (MLM-3719). For cryogenic processes involving tritium, a vacuum dewar may be used as secondary containment (MLM-3719).

8. Hot facilities, including hot laboratories, hot cells, gloveboxes, hoods, and similar enclosures Confinement requirements for hot facilities shall be determined on a case-by-case basis (6430.1A). The following are typical requirements for enclosures in which loose radioactive 
material may be handled, objects containing radioactive material may be opened, or material with a high potential for external contamination may be handled or stored.

a. The primary confinement shall be the hot cell, glovebox, process piping, tank, hood, etc. (6430.1A). The primary confinement volume and isolation systems, as appropriate, shall be compartmentalized to isolate high-risk areas and minimize the effects of the DBAs they are required to withstand $(6430.1 \mathrm{~A})$. (Note that if a sealed container is not likely to have significant levels of external contamination and is not to be opened in the enclosure, then the container is the primary.)

b. The secondary confinement shall usually be the facility operating compartment and associated ventilation systems; that is, the secondary confinement houses the hot cells, gloveboxes, fume hoods, etc. (6430.1A).

c. The tertiary confinement shall usually be the building housing the facility operating compartment and its associated ventilation system (6430.1A).

\subsection{VENTILATION AND PURGING}

It is to be understood that in the requirements below, the specifications for ventilation systems apply to both air and off-gas and purge gas venting and cleanup where appropriate; specifications for off-gas and purge gas venting and cleanup do not apply to air venting and cleanup.

1. Engineering controls are preferred to administrative controls for the prevention and control of airbornes (10CFR835, 10CFR20, RCM, 5480.11, RG8.8).

2. Primary confinement ventilation systems shall be separate from secondary and tertiary ones (6430.1A). Secondary and tertiary confinement ventilation systems may be shared if safety analysis indicates that this type of design is acceptable (6430.1A). DOE 5480.30, Attachment 3 , specifies that guidance for confinement systems from DOE 6430.1A, Section 1550.99, is to be used (see also 6430.1A, Section 1300-7.2).

3. The most important design objective for primary confinement systems shall be leaktightness (6430.1A; the TSHC says it is the second most important, after tritium recovery). When the associated ventilation system(s) is operating, the interior of an enclosure shall be at the proper negative design pressure (see below); when it is not, the enclosure should be leaktight. The exception is open-face hoods, which shall provide filtered confinement (6430.1A).

4. Confinement features shall function so as to maintain a controlled, continuous airflow pattern to, through, and out of the confinement; the design of a confinement ventilation system shall ensure the ability to maintain desired airflow characteristics when access doors or hatches are open (6430.1A, 5480.30, TSHC). In particular, gloveboxes shall have the ability to contain in-box contaminants safely when an access port is opened or a glove ruptures (6430.1A).

5. Air flow should be from clean areas to areas of progressively more (or potentially more) contaminated areas (6430.1A, 5480.30, RG8.8), with care taken to protect against backflow (6430.1A, 5480.30). Air flow may be constant or may be switched on (automatically or manually, as required) as needed (RG8.8). The use of portable or temporary ventilation is encouraged where it may assist in the reduction or control of airbornes (RCM, MLM-3719, RG8.8), but such ventilation should be adequate for the proposed use of the cubicle or area. 
Care must be taken for ducts used intermittently (e.g., an air system cycling on and off) that flow does not reverse.

6. HVAC equipment and openings should be sized and placed so as to effect proper air flow. Ducts shall be sized for the transport velocities needed to convey, without settling, all particulate contaminants (6430.1A). Within a room, air shall be exhausted within $4 \mathrm{ft}$ of an airborne radiation source. Cleaner air shall generally circulate across the cleaner or most accessed portions of the room, such as doorways and walkways; supply air diffusers may be required to minimize stale spots that can become airborne "hot spots" (6430.1A). Sufficient separation of supply and return ducts for ventilation and, where present, purge flows shall be made to ensure that adequate ventilation of the room is achieved; efforts should be made to avoid channeling the flow from supply to exhaust (6430.1A, TSHC). Diffusion of the air supply should be considered (TSHC).

7. Hood faces should not be located within $10 \mathrm{ft}$ of the nearest air supply or exhaust point, nor along normal traffic routes $(6430.1 \mathrm{~A})$. A hood shall not be located where there may be room air currents of greater than $50 \mathrm{lin} \mathrm{ft} / \mathrm{min}$ at the hood face (6430.1A).

8. In some cases the normal ventilation flow must be greater than the required cleanup flow because of the need to cool equipment. Where the cleanup and normal ventilation systems are separate, the need for auxiliary equipment cooling during cleanup and the need for an interlock system to cut off normal flow when the cleanup flow starts should be considered (TSHC). Purge or ventilation flows must be carefully designed in the case of large open areas; the opening of exterior doors, thermal sources, and the direction ventilation louvers must all be considered (TSHC).

9. Primary confinements shall be negative with respect to secondaries and other external areas, secondaries with respect to tertiaries and other external areas, and tertiaries with respect to the outside (6430.1A; RG8.8, in general). The reactor building, the reactor operations building, the reactor support building, the guide hall, the experimental support building, and the interface building shall be at negative pressure with respect to the office building and the outside. The reactor water upgrade and detritiation building(s) should also be at negative pressure with respect to the outside. The reactor building shall be at negative pressure with respect to the buildings connected to it, and the reactor containment proper shall be at the most negative pressure, in general.

10. In the case of the (primary) containment, ANSI/ANS-56.6 states that it assumes that there is a purge supply and a purge exhaust system for normal operations and shutdown and that these systems normally have no postaccident functions except for containment isolation. Further, each system is assumed to consist of a high volumetric flow rate subsystem and a low volumetric flow rate subsystem. However, it notes, a single volumetric flow rate subsystem may be provided where design conditions permit. The ANS containment ventilation design will depend on some design parameters that have not yet been determined; thus the design criteria given here that draw from ANSI/ANS-56.6 may not be entirely applicable to the eventual ANS design, although the principles that underlie them are.

a. The purge system may be used in conjunction with a (nonaccident) containment cleanup system, e.g., by sharing components; the high volumetric purge flow rate subsystem may be used as a containment cleanup system by the provisions of ducts, valves, dampers, and 
exhaust filters (if not already provided) to connect the supply plenum to the exhaust plenum. Two 50\%-capacity filter assemblies may be provided for the cleanup system in either case.

b. The design of the high volumetric flow rate and low volumetric flow rate subsystems, or their ANS equivalent(s), shall be such that containment and effluent airborne activity concentrations are kept below ANS design limits. (ANSI/ANS-56.6 says "at an activity level that permits normal access" for the containment and "within the offsite dose objectives of ANS-51.1-1983" for the effluent. The "objectives" of ANS-51.1 are not subscribed to in these design criteria because they are not necessarily in accordance with DOE limits and guidance.)

c. In general, the supply portion of both volumetric flow rate subsystems should distribute air to and the exhaust portion should exhaust air from inside containment as uniformly as is practicable (56.6); however, the need for localized areas to have a higher air flow than the general area shall be considered.

d. Filters should be provided at the supply intakes to remove particulates from the air.

e. The high volumetric purge flow rate subsystem, or ANS equivalent, should generally be used during refueling and maintenance outages and shall be capable of performing its design function(s) during cold shutdown and refueling operations. It should have the capacity to provide between one and one and a half complete containment air changes per hour. The exhaust section shall be designed such that the dose to an individual outside containment from a refueling accident inside containment when the high volumetric purge flow rate subsystem is operating shall be within ANS design limits (56.6 says "within ANS-51.1-1983 exposure guidelines" for the effluent).

f. The low volumetric flow rate subsystem, or ANS equivalent, should generally be used, and shall be capable of performing its design function(s), during normal plant operation. It should have the capacity to provide one complete containment air change every $40 \mathrm{~h}$. The exhaust section shall be designed such that any release of airborne radioactivity from the containment, together with other releases, is such that offsite exposures from normal operations are within ANS design limits (56.6 says "the objectives of 10 CFR 50, Appendix I," which, as has been discussed earlier in these design criteria, are not in accordance with the most current radiation protection philosophy). The exhaust section shall be designed such that the dose to an individual outside containment from an event corresponding to a frequency of $10^{-1}$ to greater than $10^{-6}$ per year when the low volumetric purge flow rate subsystem is operating shall be within ANS design limits (56.6 says "shall not result in off-site radiological exposures [exceeding] ANS-51.1-1983 criteria"). The low volumetric flow rate subsystem shall include iodine and particulate filters in its exhaust portion as necessary to meet the requirements above; there should be two filter assemblies, which may each have 50\% capacity, and valves to isolate one assembly from the other.

11. Ventilation shall be specially designed for any large open pools, such as the spent fuel pool. In the case of the spent fuel pool area(s), ANSI/ANS-57.2 specifies the following. Note that these apply to either a spent fuel pool in containment or a separate spent fuel storage area outside containment.

a. The normal fuel storage area ventilation system shall provide for air flow across the pool surface and shall generally direct the area from areas of low airborne concentration to areas of high airborne concentration. 
b. Incoming air should be filtered to remove particulates that might be deposited on and around the pool area. Normal air flow shall be filtered as necessary (at least on high airborne concentration indication) prior to being exhausted through the stack.

c. Air from the fuel storage area shall exhaust to a redundant safety-grade filtration system designed to limit appropriately the release of iodine and other filterable radionuclides during events corresponding to a frequency of $10^{-2}$ to greater than $10^{-6}$ per year, if safety analyses indicate the necessity for such a system. Such an emergency filtration system shall actuate automatically and isolate the normal ventilation system, if separate from the emergency system, on appropriate high airborne concentration indication; the actuation system for the emergency filtration system shall be redundant if the emergency system is separate from the normal ventilation system.

d. The fuel handling area should be maintained at negative pressure with respect to surrounding areas, in general.

12. For tritium facilities, the following pressure differentials are recommended (MLM-3719). (Notwithstanding this requirement, note that TSHC states that some people like to operate tritium gloveboxes at a slightly positive pressure to prevent the ingress of air (usually to prevent oxidation of tritium), with a liquid bubbler providing pressure protection. This approach is likely to be rejected at the ANS, but might be worthwhile to consider for certain applications.)

a. Office and other uncontrolled areas should be between 0.0 and -0.01 in. (of "water column") relative to the outside.

b. Main access corridors outside the area where radioactive material is present should be between -0.01 and -0.025 in.; main access corridors inside the area should be between -0.01 and -0.05 in.

c. Individual rooms in the process area should generally be between -0.1 and -0.15 in.

d. Gloveboxes should generally be between -0.25 and -1.0 in., although there may be cases in which this rule does not apply. However, note the 6430.1A statement below regarding the minimum pressure differential with respect to operating areas.

13. For gloveboxes, hoods, etc., the minimum pressure differential with respect to operating areas should be -0.3 in. of "water," except for open-face hoods (6430.1A).

14. Ducts carrying clean air should be at a positive pressure when passing through an area of potential contamination, and ducts carrying potentially contaminated air should be at a negative pressure when passing through a clean area.

15. Conservative $\mathrm{AOO}$ and accident airborne source terms shall be calculated for each cubicle and area to which access is required during or after the event. On the basis of these, air flow shall be provided in each cubicle or area as appropriate for the purpose and occupancy of the cubicle or area. Auxiliary ventilation provisions may be made, but these must be adequate for the proposed use of the cubicle or area and must be practicable given the anticipated postaccident condition of areas in which the auxiliary equipment may be stored or through which it may be transported.

16. Conservative normal operating airborne source terms shall be calculated for each cubicle and area; leakage terms may be based on ANSI N199-1976 (except for the tritium terms) or other guidance or on conservative estimates of leakage or other radioactivity loss for the equipment 
or other sources in the cubicle or area. On the basis of these estimates, air flow shall be provided in each cubicle or area as appropriate for the purpose and occupancy of the cubicle or area. These levels shall generally be as given below. The minimum air flow for any . cubicle or other small area with serious potential for airbornes shall generally be $500 \mathrm{cfm}$.

a. For general access areas, the design level shall generally not exceed 0.05 times the overall DAC applicable to the area.

b. For Radiological Areas that are not expected to be Airborne Radioactivity Areas more often than once or twice a year and that may require frequent access, the design level shall generally not exceed 0.1 times the overall DAC applicable to the area. For Radiological Areas that are not expected to be Airborne Radioactivity Areas more often than once or twice a year and that are not expected to require frequent access, the design level shall generally not exceed 1-3 times the overall DAC applicable to the area.

c. For Radiological Areas that are expected to be Airborne Radioactivity Areas more often than once or twice a year and that may require frequent access, the design level shall not exceed 1-3 times the overall DAC applicable to the area. For Radiological Areas that are expected to be Airborne Radioactivity Areas more often than once or twice a year and that are not expected to require frequent access, the design level shall not exceed 1-5 times the overall DAC applicable to the area.

d. For Radiological Areas that are expected to be Airborne Radioactivity Areas typically but that are not expected to require frequent access, no numerical restriction is made, but the design level should be as low as is practical.

17. With respect to tritium, the choice of purge ventilation or some other form of vapor recovery should depend on the size and frequency of occurrence of the source term and on limitations on emissions (TSHC). In general, all equipment areas with a potential for chronically contributing $10^{-3}$ to $10^{-2}$ of the facility emission targets should be placed within dried confinement, and any area with a chronic contamination potential of greater than $10 \mu \mathrm{Ci} / \mathrm{m}^{3}$ (equivalent to $0.5 \mathrm{DAC}$ because $1 \mathrm{DAC}$ is $2 \times 10^{-5} \mu \mathrm{Ci} / \mathrm{ml}$ for tritium oxide vapor) should be placed within a simple confinement (TSHC).

18. The face velocity through the doors of cubicles or areas of potential airborne contamination shall generally be 50 lin $\mathrm{ft} / \mathrm{min}$ (6430.1A).

19. The guidance of the American Conference of Governmental Industrial Hygienists (ACGIH) Industrial Ventilation Manual shall generally be followed in the selection of hoods, gloveboxes, etc., and of their ventilation rates (6430.1A). The minimum exhaust rate from a glovebox depends on the types and quantities of radionuclides and other hazards present, but in general 35-50 cfm should be adequate (6430.1A). For all such enclosures, the design should ensure adequate inflow of air through an opened access port or a postulated design breach (e.g., glove rupture), generally $125 \pm 25 \mathrm{lin} \mathrm{ft} / \mathrm{min}$ or as given in the ACGIH Industrial Ventilation Manual (6430.1A). The linear flow (face velocity) through the front of a hood, in general, shall be at least 125-150 lin ft/s (6430.1A).

20. For (fume)hoods in which tritium-containing samples are to be processed or counted, 100-150 lin ft/s shall be provided (MLM-3719). (Note: Although DOE 6430.1A specifies $150-200 \mathrm{ft} / \mathrm{s}$ for tritium hoods, MLM-3719 is held to be more authoritative and also has the backing of the DOE. The reason MLM-3719 gives for not going higher in most cases is the problem of the greater eddying encountered with higher flows, which can result in a higher 
worker intake than with lower flows. This possibility must be evaluated on a case-by-case basis.) Where large walk-in or reach-in hoods are used, the Savannah River Plant recommends the use of $180 \mathrm{lin} \mathrm{ft} / \mathrm{min}$ for the hood openings; an anemometer should be used to measure the air flow rate through the opening when the hoods are opened (Reinig).

21. The air change rate in areas containing tritium should generally be 10 air changes per hour (MLM-3719). The air change rate in associated offices and other nonradiological areas should generally be 4-6 air changes per hour (MLM-3719). If a room detritiation system is used, a lower air change rate shall be considered in order to contain tritium more easily following a release (MLM-3719). Even if there is no room detritiation system, a lower air change rate could be permitted when conditions allow, if in case of a tritium release a higher air change rate could be initiated (MLM-3719).

22. The design of accessways and transfer ports shall consider the control of airborne radioactivity. For containments and primary confinements, transfer ports for passing items in and out should, in general, be airlocks or mini-airlocks, with purging capabilities; this approach should be considered for secondaries where appropriate. In particular, airlocks shall be provided in confinement barriers (e.g., the reactor containment) $(5480.30,6430.1 \mathrm{~A})$. Also, primary confinement systems in hot and tritium facilities shall provide features to ensure safe introduction and removal of materials from process confinements (6430.1A). Such accessways shall not inhibit emergency exits, however (6430.1A).

23. Ventilation design shall consider planned breaches of confinement systems, such as the repair of pumps or the replacement of viewing windows or gloves; the need for in-place maintenance shall be considered (6430.1A).

24. Installed special or auxiliary ventilation systems should be considered in areas where contaminated equipment must be opened frequently or in areas of significant occupancy where airbornes are expected to be generated (RG8.8). Portable auxiliary ventilation systems featuring blowers, high-efficiency particulate air (HEPA) filters, and activated charcoal filters on carts should be considered for areas where contaminated equipment must be opened infrequently (RG8.8). For the latter, dampers and fittings should be provided in ventilation ducts to permit the attachment of flexible tubing or "elephant trunks" (MLM-3719) without causing an imbalance in the ventilation system (RG8.8), or alternatively, dedicated air supply ports can be provided. Also, space for the portable systems should be allotted. Special or auxiliary ventilation systems should be considered as given below.

a. The use of downdraft ventilation within occupied process areas (6430.1A) shall be considered. The use of canopy hoods should be considered for enclosing glovebox pass-through port operations (MLM-3719) and for housing process equipment too large to fit into a fumehood.

b. The use of fumehoods should be considered as the exhaust points of once-through ventilation systems where capture of contaminants is essential and high general area flow rates are impractical (MLM-3719).

c. The provision of special (supplemental or alternative) ventilation to maintain air flow and direction during fuel handling operations shall be considered (57.2).

d. Auxiliary ventilation shall be considered for sampling stations for primary coolant or other fluids with potentially high levels of radioactive material (Regulatory Guide 8.8 says "should"). 
e. Auxiliary ventilation should be considered for any area in which welding, grinding, sanding, scaling, and other machining or decontamination of contaminated surfaces may take place (RG8.8).

f. Purge ventilation for rooms or areas that may contain significant amounts of airborne tritium should be considered (TSHC). The use of a room air detritiation system shall be considered for areas where it is necessary to minimize a potential release of tritium to the environment (MLM-3719, TSHC). In general, this system should be a recirculation loop with a special tritium-removal system and with ducting into and out of the room that is separate from the normal operation ducting (MLM-3719). (See also Item 30 below.) Where collection systems and tritiated vapor recovery are infeasible, segregated plant layout coupled to local ventilation control may be considered (TSHC).

25. Dampers shall be located so that cross-contamination will not occur in case of a localized release of material (6430.1A). For the detritiation and upgrading building(s), design shall provide the capability of completely isolating from areas normally occupied by personnel those areas containing tritium processing and handling systems or containing systems with a substantial tritium content; consideration should be given to further isolating the tritium source itself (6430.1A).

26. The space between a duct, piping, conduit, door, etc., and the inside of the penetration through which it passes shall be filled with an airtight sealing material where necessary and appropriate to provide proper HVAC control and to preclude the spread of contamination (6430.1A). Sealing of entire wall faces or doors or caulking of joints shall be considered where appropriate; in particular, doors shall be well-sealing where tritium (6430.1A) or other airborne radioactivity (RG8.8, 40.35) may be present in significant quantities. Gaps between the tops of walls and the soffits of the floors above them shall generally be filled, if not offset, to satisfy applicable HVAC requirements (6430.1A). Covers shall be provided to be placed over glove ports when not in use, if there is a potential for airborne leakage should the seals or gloves fail (6430.1A, TSHC). Permeation of tritium and other radioactive substances through penetration seals and covers should be considered.

27. Atmospheric tanks, vessels, and sumps shall be provided with vents to prevent tank overpressure or vacuum conditions and, where appropriate, to allow for complete drainage (55.1). Displaced air from process systems and contaminated areas shall be vented to a ventilation or off-gas system for filtering and treatment, as appropriate (6430.1A, 40.35, 55.1). Vent design shall prevent liquids and solids from entering the facility ventilation system (55.1); however, consideration should be given to hard-piping the vents from the container to the HEPA filter rather than having the vented gas go to the room air first. Vents from liquid components shall be provided with traps and drains to prevent inadvertent flooding of off-gas systems (6430.1A). Primary storage tanks for liquid waste shall have condensers or filters or both in their vent streams. The annular space in double-walled components should be ventilated and the exhaust filtered (6430.1A).

28. Exhaust from contaminated areas or enclosures should be filtered, either locally or in the exhaust stack, as appropriate (6430.1A); effluent gases shall be recycled or routed to an appropriate gas cleanup system (40.35). The number of air filtration stages required for any area of a facility shall be determined by safety analysis based on the quantity and type of radioactive material to be confined (6430.1A). Redundant or standby filters shall be provided 
if changeout of one filter causes a loss of a required confinement barrier during changeout; this requirement is particularly true of hot cells (6430.1A). The design and provision of filter units should follow the guidance of ERDA 76-21 (according to 6430.1A) or of ANSI N13.1, as applicable.

29. HEPA filters shall be provided on the exhausts of areas where there is a significant potential for airborne radionuclides in particulate form (6430.1A). Either HEPA filtration or fail-safe backflow prevention for process area intake ventilation systems shall be provided (6430.1A). HEPA filters shall generally be provided for the following specific cases.

a. Hoods, gloveboxes, and other enclosures

b. Vents on radioactive radwaste and like tanks that have compressed air introduced into the tanks (55.1)

c. Any volume reduction process to filter the expelled gas, either in the system itself or in the building ventilation system (55.1)

d. In dewatering of spent resins and the like, if air is used for drying (55.1)

e. Change-room exhausts (in special facilities), if dispersible radionuclides are handled in the operating or process areas served (6430.1A)

f. Portable air-handling equipment and vacuum cleaners used in Radiological Areas, except for uncontaminated radiation areas (RCM)

30. Where required for enclosures, HEPA filters shall generally be provided at the interface of the enclosure outlet and the ventilation system to minimize the contamination of ductwork and also at the enclosure inlet to prevent movement of contamination within the enclosure to the operating area in the event of a flow reversal (6430.1A). Where required for other systems or subsystems, HEPA and other filters shall generally be provided as close to the source(s) as possible to minimize the contamination of ductwork (6430.1A). Standby filters for a hot cell shall be installed outside the cell and sealed in an acceptable enclosure for direct maintenance (6430.1A).

31. Each system employing HEPA filters shall have a minimum removal efficiency of $99.95 \%$ for particles in the size range from 0.3 to $1.0 \mu \mathrm{m}$ based on the dioctyl phthalate (DOP) test; if any stage or the whole train has an efficiency less than $99.95 \%$, justification of the lower efficiency shall be made (HPM).

32. Charcoal filters shall be provided on the exhausts of areas or enclosures where there is a significant potential for airborne iodine or other appropriate radionuclides (6430.1A).

33. Where appropriate, roughing filters or prefilters shall be provided near the intakes of clean air directed at potentially contaminated areas, to minimize radioactivity buildup on dust particles, and before HEPA and charcoal filters, to reduce loading on them (6430.1A). Corrosive gases or particles shall be neutralized before they reach HEPA filters (6430.1A).

34. Tritium traps or other appropriate capture devices shall be provided on the exhausts of process systems and enclosures and on other exhausts where there is a potential for significant airborne tritium (6430.1A, MLM-3719, TSHC). 
35. The use of systems for tritium collection and recovery, such those with dryers, shall be considered for appropriate areas (TSHC). The choice of air treatment mode (e.g., total recirculation, once-through flow with vapor recovery, high purge flow with limited recovery) associated with dryers shall generally be made on the basis of personnel access and emissions limitation considerations (TSHC), considering that air detritiation systems for tritium-handling facilities are mainly for emergency cleanup following tritium release and emissions controls, rather than for coping with chronic leakage and related personnel protection (TSHC). Portable dryers should be considered for certain areas (TSHC).

36. The sizing of tritiated-air-drying systems shall be based on factors including the maximum credible event (DBA), room or area volume, emission limits, and time available for cleanup (TSHC). The effect of dryers on plant reliability shall be considered, especially where vapor recovery may allow continued operation even in cases of acute seal leakage (TSHC). Other important parameters for any air cleanup system include the efficiency of the recombiner and the efficiency of the dryers, where included (THSC).

Thus, in the case of a large area, in general, a once-through system should not be considered because of the large dryer size required to process large amounts of moist air and the large volumes of slightly contaminated water that would be recovered in dryer regeneration (TSHC). In such a case, partial recirculation from the exhaust back to the area should be considered, with sufficient discharge to the environment to maintain a negative pressure in the area (TSHC). However, the possibility of recycling tritium to the room or depressurizing the room if the cleanup system fails or suffers degraded performance should be taken into account (TSHC). It should also be ascertained if there is a requirement for hot standby in the once-through mode (TSHC).

37. A mist eliminator may be required to prevent filter plugging if there is a filter bank serving a tritium-handling or tritium-contaminated area (MLM-3719). Humidity in areas of potential airborne tritium should be measured for purposes of evaluating the efficacy of tritium sweeping and capture (MLM-3719).

38. Recirculation of air in a single area may be considered (6430.1A) for both normal operation and postaccident functions if air is sufficiently filtered and directed to satisfy other applicable conditions in this section.

39. Recirculating systems should be used to reduce background levels of tritium in a glovebox, or once-through cleanup systems should be used to reduce emissions to the environment (TSHC). Oxygen and moisture should be removed as appropriate to prevent the formation of the oxide (TSHC). Inert gas atmospheres shall be considered for enclosed hoods and gloveboxes when tritium or tritiated material is being handled, especially if the atmosphere is recirculated (6430.1A, MLM-3719), because of the potential for tritium oxide production; otherwise argon or nitrogen is recommended (but note that nitrogen can react with tritium to form ammonia) (MLM-3719). Valve operators and other gas-operated equipment inside gloveboxes should be vented with the same gas that provides the glovebox atmosphere and should be vented with the same care (MLM-3719). 
40. Energy conservation shall be taken into consideration in ventilation (6430.1A). However, energy conservation features shall be incorporated only where they do not compromise the safety and health of personnel (6430.1A). In particular, air-to-air heat exchangers are not recommended with untreated air between, e.g., laboratory hood exhausts or other local exhaust systems for hazardous materials and "comfort air" systems (6430.1A).

41. Double-vented gloves or ventilated glove port covers should be considered (MLM-3719).

42. A purge system using inert gases shall be considered for gloveboxes and other secondary containments (MLM-3719). If tritium is present, the purge should be monitored for tritium leakage and should be sent to a tritium capture system (MLM-3719). The tritium capture system may be common to several secondaries (MLM-3719). The purge may be sent to the stack if a reliable, rapidly responding monitor is provided to send the stream to the capture system in case of leakage and if the leakage from the primary is released slowly

(MLM-3719). Provision of both a normal purge rate and a second, higher purge rate for use if leakage is detected shall be considered (MLM-3719). A bubbler system should be used in conjunction with the purge control system; valves in the bubbler line should be avoided if possible (MLM-3719).

43. Hazardous gases should generally not be part of a general gas manifold system. Supplies should be kept adjacent to the areas where they are used, and jacketed lines should be provided to convey them to fumehoods or gloveboxes (MLM-3719).

44. Overpressurization relief shall be provided where appropriate; in particular, rupture disks, pressure relief valves, seal pots, and bubbler traps vented to an appropriate effluent-handling system should be considered for primary and secondary confinement systems $(6430.1 \mathrm{~A}$, MLM-3719). For tritium-handling systems, rupture disk protection is preferred to relief valves because of the potential for valve seat leakage (MLM-3719). Venting of such disks to an evacuated catch tank also protected with rupture disks to allow recovery of tritium should be considered, particularly in the case of high-pressure transfers between gloveboxes (MLM-3719); the catch tank rupture disk should vent to the normal tritium capture system (MLM-3719) or to an appropriate effluent system. In the case of small enclosures with positive-pressure supplied gases, positive-acting pressure relief devices discharging to the exhaust system shall be employed (6430.1A).

45. Flow-limiting devices are recommended for any gas or vacuum source entering a glovebox (MLM-3719).

46. Safety-class air filtration units shall be designed to remain functional throughout DBAs and to retain collected radioactivity after the event (6430.1A).

47. The design of facilities that handle large quantities of tritium shall include an emergency tritium gas cleanup system to reduce tritium releases to the environment and to mitigate the consequences of an accident involving a failure of a tritium system pressure boundary, unless a safety analysis demonstrates that the system is not required $(6430.1 \mathrm{~A})$ or is more adverse to safety than an alternative accident-handling system, including, for example, the case of gloveboxes used as secondary confinements (6430.1A). Each secondary confinement area or compartment shall be supplied with ventilation air with sufficient capacity to ensure an 
adequately controlled ventilation flow as required in the event of a credible accident breach in a secondary confinement barrier (6430.1A).

48. An elevated stack shall be used for confinement exhaust discharge (6430.1A). Provisions shall be made to ensure an adequate ventilation exhaust discharge path in the event of stack failure (6430.1A).

49. Counting rooms should have a separate clean air supply to minimize Xe-133 interference. Laminar flow room ventilation shall be considered for each counting room in order to reduce background.

50. A personnel decontamination area should not share ventilation with a clean area (RG8.8).

51. Other sources or airborne reduction methods that should be considered are as follows.
a. Dust and other emissions from waste shredders (40.35)
b. Wet transfer or storage of potentially contaminated components (RG8.8)
c. Controlled venting of gases to reduce emission hazards (40.35)
d. The use of glovebags, tents, or temporary gloveboxes (MLM-3719) 


\section{DOSE MONITORING, PERSONAL PROTECTION, AND HUMAN FACTORS CONSIDERATIONS}

\subsection{PERSONAL DOSE MONITORING DEVICES}

1. Occupational workers shall be monitored for external dose to demonstrate compliance with radiation protection requirements and to determine the dose equivalents received from occupational sources of radiation, as given below.

a. At a minimum, personnel dosimetry shall be provided to radiation workers whose annual dose may exceed 100 mrem to the whole body, 5 rem to the skin, 5 rem to any extremity, $1.5 \mathrm{rem}$ to the lens of the eye, or 50 rem to any organ (10CFR835, 5480.11). (Note that 10 CFR 20 states that dosimetry should be issued if the annual external dose may exceed $10 \%$ of the annual limits for an occupational worker, that is, 500 mrem to the whole body, 5 rem to the skin, 5 rem to any extremity, 1.5 rem to the lens of the eye, or 50 rem to any organ.)

b. Minors, members of the public, and pregnant females shall be provided dosimetry if they may receive a annual (or term-of-pregnancy) dose of $50 \mathrm{mrem}$ (10CFR835). (10CFR20 says the same for minors and pregnant women, but restricts this to external dose.)

c. Dosimetry shall be provided to individuals entering High or Very High Radiation Areas (10CFR835, 10CFR20, RCM).

d. Neutron dosimetry shall be worn in appropriate areas also (RCM).

e. Supplemental dosimeters (e.g., self-reading dosimeters) shall be issued to personnel prior to entry into a High or Very High Radiation Area, when an individual could exceed $10 \%$ of an Administrative Control Level in a single day (i.e., 100 mrem at ORNL), and as otherwise required; use of electronic dosimeters is encouraged in these circumstances (RCM).

f. Supplemental dosimeters should be considered for all pregnant females who may enter Radiological Areas (RCM). (Note that 10 CFR 835 and 10 CFR 20 do not address neutron or supplemental dosimetry.)

g. Personal nuclear accident dosimeter units shall be worn by all personnel who enter those areas required to be covered by a criticality monitoring and alarm system (10CFR835, 5480.11).

2. Occupational workers shall be monitored for internal dose to demonstrate compliance with radiation protection requirements and to determine the dose equivalents received from occupational sources of radiation, as given below.

a. Participation in a bioassay program is required for each worker exposed to surface or airborne contamination from which the worker could receive an annual internal dose of 0.1 rem, or 5 rem to any tissue or organ (5480.11), from all occupational intakes of radioactivity (RCM, 5480.11). A baseline bioassay monitoring for those who could receive an annual internal dose of $0.1 \mathrm{rem}$ is required before work begins (RCM). (Bioassay is required by 10 CFR 20 for adults likely to "receive, in 1 year, an intake in excess of 10 percent of the applicable ALI(s) in Table 1, Columns 1 and 2, of Appendix B," corresponding to a committed effective dose equivalent of $5 \mathrm{rem}$.)

b. Minors, members of the public, and pregnant females shall be in a bioassay program if they may receive an annual (or term-of-pregnancy) internal dose of 50 mrem (10CFR835). 
c. Personnel whose routine duties may involve exposure to surface or airborne contamination or to radionuclides readily absorbed through the skin, such as tritium, should be included in a bioassay program (RCM). A baseline bioassay monitoring for those who could receive an annual internal dose of $0.1 \mathrm{rem}$ is required before work begins (RCM). (Bioassay is required by $10 \mathrm{CFR} 20$ for minors and declared pregnant women who may receive an annual or term-of-pregnancy internal dose of $50 \mathrm{mrem}$.)

d. In the absence of ORNL- or DOE-specific guidance on tritium bioassay, the guidance from Regulatory Guide 8.32 shown in Table 6.1 of this document shall be used to assess, for design purposes, the potential for restrictions on access because of requirements for tritium bioassay (material has been added from the text of the Guide, for clarity).

\subsection{BREATHING AIR AND RESPIRATORY PROTECTION}

1. The routine use of respirators shall generally not be relied on in design to meet the dose limit for normal operations (6430.1A, RG8.8). The use of air-line suits in areas with high potential airborne tritium content is an exception; however, provisions should be made to minimize the necessity for such use.

2. The use of respiratory equipment should be considered for entries into Airborne Radioactivity Areas, breaches of contaminated systems, and work in High Contamination Areas (RCM). However, consideration should also be given to worker safety, comfort, and efficiency, especially where there is a potential for heat stress or for high external dose rate (RCM). Respirator use may also be appropriate in nonroutine or ernergency operations when the application of engineering controls is not feasible or while controls are being installed (RG8.8). For design purposes, the Ontario Hydro guidelines should be assumed: HTO respiratory protection shall be worn when the airborne level is greater than $1 \mathrm{DAC}$, and ventilated clothing (supplied-air or bubble suits) shall be worn when airborne levels exceed 100 DAC or when exposure will exceed 10 DAC-hours (TSHC).

3. Self-contained breathing apparatus (SCBAs) shall be considered as appropriate for use in airborne areas without significant airborne tritium or tritium surface contamination, except where tritium is virtually all in the elemental form (TSHC). Air-supplied suits shall be assumed to be required for normal operational use in areas with significant airborne tritium or tritium surface contamination (MLM-3719, TSHC). Although SCBAs provide no protection against uptake of tritium (e.g., as tritium oxide) through the skin, SCBAs should be provided for emergency use in such areas to protect against uptake by inhalation (MLM-3719).

4. In areas where there is a significant potential for airborne tritium or where particulates may exist and where remote or enclosed maintenance is not practical, connections to a compressed-air breathing system for use with bubble or other supplied-air suits shall be provided (6430.1A, TSHC). Breathing-quality air should be continuously supplied; the rate of 8-10 L/s used by the Savannah River Plant should be considered (Reinig).

5. Air supply stations for bubble suits should be strategically located in corridors adjacent to the glovebox areas (MLM-3719, TSHC, Reinig); hose lengths should not exceed $100 \mathrm{ft}$ (50 ft is preferable) (MLM-3719, TSHC). However, hoses should be long enough to allow the donning and removal of suits in locations free of tritium (Reinig). Provisions should be made to 
provide air supply hoses with quick-connect fittings (MLM-3719, Reinig) in both the corridor and the operating areas (MLM-3719). Hoses should not be routed through partly open doors (MLM-3719).

6. Air supply stations for bubble suits should generally contain pressure regulators, flow meters, valves, pressure gauges, filters, a water removal trap, and quick-connect fittings that are for bubble suits only; low-pressure regulators may be on the air supply hoses themselves, however (MIM-3719). Gas bottles, tube trailers, or reliable oil-free pumps should be used to provide breathing air from these stations (MLM-3719). The air should be dried to enhance personnel comfort (MLM-3719).

\subsection{OTHER PROTECTIVE CLOTHING AND EQUIPMENT}

1. Gloves shall be assumed to be worn whenever workers are handling or working near tritium-contaminated surfaces (TSHC).

2. Disposable gloves should be worn inside glovebox gloves if tritium is handled or contained in the glovebox (TSHC).

\subsection{HUMAN FACTORS}

1. Communication

a. A loudspeaker system should be provided in areas where personnel may need immediate oral warnings or information. In particular, such a system should be provided in the (primary) containment and in any separate fuel storage for communications from the control room (57.2).

b. Communications not susceptible to loss of on-site or off-site power, such as sound-powered telephones or two-way radios, shall be provided between the fuel-handling machine, the refueling machine, the control room, and any transfer mechanism or upender control stations, as applicable (57.2). These communication devices shall operate on a channel different from the remainder of the ANS in order to minimize or preclude interference with the fuel-handling operation (57.2).

c. Communications links should be adequate when tent operations take place, considering both the possibility that the workers will be wearing respiratory protection and the interference with sound and sight because of the tent wall (MLM-3719).

d. Consideration should be given to integrating communication headsets into air-supplied suits (TSHC). (The explanation of this recommendation is the Ontario Hydro example given by the TSHC. At Ontario Hydro, where the communication wires are built into the air supply hoses, manifold connectors and connectors on the suit are combined air and communication connectors. The wiring for the headset bridges the suit wall so that the headset remains entirely inside the protection of the suit and hood and mounts on the hard hat. Up to 10 people can be accommodated on each circuit, and circuits can be connected. Personal alarming devices such as integrated gamma dose and dose rate warning devices may also be coupled into the headsets so as to alert the user.) Voice-activated two-way radios should also be considered for communication with workers wearing plastic suits (Reinig). 
e. Consideration shall be given to the inclusion of built-in noise suppression features in air-supplied ("plastic") suits to reduce the noise level produced by the air supply to less than 73 dBA (Reinig).

2. Lighting

a. Adequate lighting should be provided in all equipment areas $(55.4,55.6)$, generally as per DOE Order 6430.1A, and elsewhere when good visibility is important for safety and accuracy. An adequate emergency lighting system shall also be provided (RG8.8).

b. In particular, a minimum intensity of $1076 \mathrm{lux}(100 \mathrm{ft}-\mathrm{c})$ shall be provided for the fuel cask handling facility (57.2), if applicable, and the new fuel inspection station, measured at the surface of the fuel in the latter case (57.3).

c. Emergency lighting shall be provided in areas of potential personnel access (57.3).

3. Physical Considerations

a. Reduction of worker agility and mobility by the use of multiple layers of gloves and clothes shall taken into account in design (56.6).

b. Correct sizing of garments, tools, etc., shall be considered. (Note that according to the TSHC, an Ontario Hydro study indicates that the extra time spent if an air-supplied suit is used is more because of the clumsiness when ill-fitting gloves are worn than because of the wearing of the suit itself.)

c. For considering reach areas in gloveboxes, it may be assumed that typical maximum reach arcs are in the 20- to 22-in. range (MLM-3719).

4. Comfort

a. Temperatures that will be experienced by workers in radiological areas should be carefully evaluated for their impact on work efficiency and thus on stay times.

b. A system used for containment atmosphere cooling shall maintain localized areas to which personnel access is required during power operation or hot shutdown conditions at a temperature that permits access for inspection and maintenance, unless as-needed supplemental cooling is provided as part of this or another system (56.6).

c. Breathing-quality air can be cooled using a vortex tube (Reinig). 
Table 6.1. Activity levels or concentrations above which tritium bioassay programs should be provided

\begin{tabular}{|c|c|c|c|}
\hline Types of operation & $\begin{array}{l}\text { HTO, other } \\
\text { tritiated compounds } \\
\text { (Ci) }\end{array}$ & $\begin{array}{l}\text { Tritium gas, sealed } \\
\text { process vessels } \\
\text { (Ci) }\end{array}$ & $\begin{array}{c}\text { HTO mixed with } \geq 10 \\
\text { kg inert } \mathrm{H}_{2} \mathrm{O} \\
\text { (per kg water } \\
\text { or other substance) }\end{array}$ \\
\hline $\begin{array}{l}\text { Potential skin contact } \\
\text { with, ingestion, or } \\
\text { absorption into the body }\end{array}$ & & & $0.01 \mathrm{mCi}$ \\
\hline $\begin{array}{l}\text { Process in open room or } \\
\text { bench }\end{array}$ & 0.1 & 100 & $0.01 \mathrm{Ci}$ \\
\hline $\begin{array}{l}\text { Process carried out in a } \\
\text { well-designed fume } \\
\text { hood }\end{array}$ & 1 & 1,000 & $0.1 \mathrm{Ci}$ \\
\hline $\begin{array}{l}\text { Process carried out in } \\
\text { glovebox that is } \\
\text { ordinarily closed }\end{array}$ & 10 & 10,000 & $1 \mathrm{Ci}$ \\
\hline
\end{tabular}

Note: It is assumed that possible escape of tritium can occur. Quantities less than $10 \mathrm{~kg}$ of substances that contain tritium and are present during operations may be considered to be either the amount processed by an individual at any one time or the amount of activity that entered the process during any one month. The last column also applies for workers in nuclear reactor facilities; the lowest value in the column should be used where employees may be exposed to the air in a room or area where more than $10 \mathrm{~kg}$ of water containing this or a greater concentration, or a total of more than $0.1 \mathrm{Ci}$, is in contact with the air (e.g., a storage pool). 


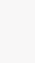




\section{LAYOUT, READY ACCESS FEATURES, AND SHIELDING}

\subsection{LAYOUT}

1. Installation, operation, testing, inspection, maintenance, decontamination, and decommissioning shall be considered in the choice of location and arrangement of equipment and components, with the aim of minimizing radiation exposure to facility personnel (55.4; 55.1 and 56.6 for all but installation and decommissioning). The layout should be such as to optimize the movements of personnel, material, and equipment to accomplish desired functions safely under both routine and accident conditions. The layout should also be such as to reduce the contaminated area of the facility, the extent and cost of vapor recovery, purge-ventilation requirements, and cleanup time following spills or prior to extended personnel access (TSHC). Wherever possible, areas for work with radioactivity shall be located together to simplify ventilation design, waste disposal, and contamination control (6430.1A).

2. The principle of segregation, that is, the physical separation of two or more components by difference in source strength or leakage potential, shall be applied in layout. Segregation may be provided by distance where appropriate (RG8.8). Segregation by use of physical barriers (rather than distance), such as a separating wall(s) or berm, should be considered in the following cases. The radioactivity may be in the form of a contained source or an uncontained solid, liquid, or gaseous source.

a. Between two pieces of equipment (e.g., tank, pump, valve) or areas, when one contains a markedly higher amount of radioactivity, a radioactive source of substantially different composition, or a significantly higher leakage potential than the other (RG8.8)

b. Between two pieces of equipment or areas, when one has no potential to contain radioactivity (is clean) and the other does ( $R G 8.8,55.1)$

3. The principle of separation, that is, the physical separation of two or more identical or comparable components in order to reduce the dose rate at one from the other, shall be applied in layout. In particular, separation by use of physical barriers (rather than distance), such as a separating wall(s) or berm, should be considered in the following cases.

a. A separate cubicle or a separating shield wall should generally be placed between two pieces of equipment (e.g., tank, pump, valve) when one or both potentially contain sufficient radioactivity to produce a significant dose rate at points near the other (RG8.8).

b. A separate cubicle or a separating shield wall for a piece of equipment requiring more frequent access (e.g., for maintenance or inspection) than a nearby piece of equipment that potentially contains sufficient radioactivity to produce a significant dose rate at the other. In particular, active and passive equipment should generally be separated.

4. Access to an area or cubicle should be to the (sub)area of lowest dose rate; the progression into the area should be from lower dose rate areas to higher dose rate areas. Areas of high dose rate should be physically isolated (55.4).

5. Tritium process systems should usually be segregated in layout according to the tritium concentration contained, system temperature and pressure, and the degree of personnel access desired (TSHC). 
6. In general, operation of systems, manipulation of components such as valve operators, the taking of readings, inspection, etc., shall take place from low dose rate areas (RG8.8, 40.35, and many other references). (For completeness, this is reiterated elsewhere in this set of criteria where specifically applicable to individual components or systems.)

7. Field-routing of pipes is to be avoided wherever possible (RG8.8). Piping containing highly radioactive gases (55.4) or liquids shall not be field-run, but shall be designed and routed within shielding when necessary. Piping chases should be considered (40.35). Systems containing fluids that could chemically affect or react with fuel shall not be routed through the fuel storage or handling areas unless double-walled pipe is used or the fluid is otherwise restricted from contact with the fuel (57.3).

8. For highly radioactive systems, shield walls between motors and pump bodies should be considered.

9. In the location of components, attention should be paid to the potential increase in local radiation levels as radioactive sources build up (RG8.8).

10. Locations for instruments should be chosen considering the required frequency and duration of personnel access, the estimated service life, ease and frequency of maintenance and calibration, and crud accumulation (RG8.8). Primary measuring elements shall, insofar as is practicable, not require location in a tank or equipment cell $(40.35,55.6)$. Instrument elements and transmitters in piping systems should be located in the lowest dose rate area practical (40.35, 55.1). Local controls and readouts should be located in low dose rate areas (RG8.8, 55.1). MLM-3719 states that a central tritium monitor readout system and a "counting monitor room" (see also Sect. 14.2) should be accessible from both the associated Radiological Area and the Controlled Area(s).

11. Manual valves and valve operators shall be located in low dose rate areas $(40.35,55.1,55.4$, 55.6) or be provided with an extension handle that is so located (55.1).

12. Valves and pumps associated with tanks or process equipment containing radioactive materials should be located outside the shielded area in which the tark or process equipment is located $(40.35,55.1)$.

13. No area containing liquid radwaste processing equipment shall be lower than the sump serving that area (55.6). To ensure reliability, pumps should be located such that leakage from the failure of any nearby tank or process equipment would not disable the pump or its drive $(40.35,55.6)$.

14. Gears, motors, and drives shall be located as much as practicable in a low radiation area (55.1). Required lubrication, chemical, or solidification addition and hydraulic fluid fill points should be located in low dose rate radiation areas $(40.35,55.1)$.

15. MLM-3719 states that a desirable arrangement for gloveboxes is in two rows with a maintenance access corridor common to the backs of the boxes. This allows maintenance tents 
to be set up and torn down without interfering with the operational side of the gloveboxes. Useful rules of thumb from MLM-3719 are as follows.

a. A standard glovebox line $3 \mathrm{ft}$ deep requires approximately $7 \mathrm{ft}$ of space on each side or a minimum room width of $17 \mathrm{ft}$.

b. Two parallel rows of standard gloveboxes with a maintenance access corridor $6 \mathrm{ft}$ wide between them can be installed in a room with a minimum width of $26 \mathrm{ft}$.

c. To install a single glovebox and associated equipment, $17 \mathrm{ft}^{2}$ of floor space per linear foot of glovebox front is necessary; $13 \mathrm{ft}^{2}$ is required to install parallel rows of gloveboxes and associated equipment.

d. The total Radiological and Controlled Areas ("radiation control area" in MLM-3719), including adjacent corridors and support areas, require 1-1/2 to 2 times the room space estimated above (MLM-3719). The uncontrolled area in a tritium facility requires approximately the same amount of floor space as the controlled area (MLM-3719).

16. Standby filters for a hot cell shall be installed outside the cell in a maintenance enclosure (6430.1A). Resin traps shall be located outside the associated ion exchanger cubicle (55.6).

17. Storage for protective clothing, masks, etc., and for change rooms should be provided near or at the entrance to a potentially contaminated area or building for use as necessary. Space for friskers, step-off pads, and bins to receive dirty clothing and masks should be provided at the exit. The distance between the area of contamination and the step-off point should be minimized. Space for temporary access points in smaller areas known to be potentially frequently contaminated should be allowed (e.g., at the entrance to a radioactive pump room).

18. Truck access for delivery shall be provided in an uncontaminated low dose rate area (55.1).

19. Equipment laydown requirements shall be considered in sizing cubicles (RG8.8).

20. Change rooms that connect with the personnel decontamination area and a control point equipped with sufficient lockers, etc., to accommodate both permanent and contract (outage) workers shall be considered (RG8.8).

\subsection{READY ACCESS FEATURES}

1. Design and arrangement shall provide unobstructed access to and adequate working space around equipment requiring manipulation, removal, maintenance, or inspection (RG8.8, 40.35, $55.1,55.4,56.6,57.2)$, including the removal and replacement of internals and parts (40.35). Piping, tubing, conduit runs, and ducts should be arranged to facilitate access and maintenance (40.35).

2. Equipment that may be removed to remote locations for maintenance should be readily removable and installable (RG8.8, 55.4, 55.6, 56.6). Thus special tools and instruments (RG8.8); readily removable and replaceable shielding, insulation, and other material (RG8.8, 55.1); and modular components (RG8.8) shall be considered for use where they would permit remote or quicker inspection or maintenance. 
3. Platforms, walkways, stairs, and ladders that permit prompt and safe accessibility for servicing or inspection of components in hot areas shall be considered (RG8.8, 40.35, 55.4, 57.1).

Ladders shall be provided to the top of all tanks where top-entry manholes are provided (55.6). Permanent anchor points for removable access ladders should be installed in the cask-handling pool and fuel-transfer canal (57.2), if appropriate.

4. The use of labyrinths shall be considered where personnel access is needed to potentially high dose rate areas, but allowance shall be made for ready removal of components from the area for repair or replacement (RG8.8, 55.4, 55.6)..Adequate space should be provided for the installation of temporary or portable shielding, where appropriate (40.35).

5. Access shall be provided, preferably to the tops of tanks and with top-entry manholes (40.35, $55.1,55.6)$. Manholes should be a minimum of $24 \mathrm{in.}(60 \mathrm{~cm})$ in diameter $(40.35,55.1,55.6)$. Ample space should be provided to facilitate cleaning and internal inspection from the tank manway $(40.35,55.1,55.6)$. Two manholes may be provided if space permits $(40.35)$. In the case of doubly contained tanks containing tritium, the secondary tank shall normally have a removable port to allow access to the primary tank (MLM-3719).

6. Accessibility to heat exchanger tube sheets shall be provided by means of a removable channel cover.

7. Access shall be provided to all sumps to allow maintenance (55.6).

8. Access to all new fuel storage cells shall be provided for operating handling tools without requiring personnel to walk on stored components (57.3).

9. Instrument transmitters in piping systems should be located so they are accessible for calibration and maintenance $(40.35,55.1)$.

10. Equipment inside a glovebox should be laid out so that it can be reached and seen when necessary, both for normal operations and for maintenance (MLM-3719). Allowance must be made for reaching into pass-throughs and passboxes; these should be provided where frequent movement of material is required (MLM-3719). If routine use of a pass-through or passbox is not anticipated, a port suitable for trash removal and maintenance is acceptable (MLM-3719). A clear area should be left toward the front of a glovebox to allow tools and material to pass down the boxline (MLM-3719). If a large quantity of material or equipment is to be routinely moved through the glovebox, a conveyor system should be considered; it is preferable that the conveyor surface be level with the glovebox work surface (MLM-3719). Care should be taken to anchor items appropriately to the floor of the glovebox, especially for measurement equipment (MLM-3719), so that they are not easily tipped over or jostled.

11. Consideration should be given to compartmentalizing tritium-containing process equipment (as at the Savannah River Plant) with large walk-in or reach-in hoods constructed with lexan or lucite panes and doors to provide visual access to the equipment (Reinig). Glove ports with butyl rubber gloves should be provided in many locations of such enclosures to allow operation of the equipment or minor adjustments without personnel entry into the hoods (Reinig). It should be possible to perform major maintenance and replacement of equipment by removal of the panels or by entry of personnel through the doors in the hoods (Reinig). 
12. Handwheels, chain, or extension handle operators shall be located a distance of $6 \mathrm{ft}$ or less above the floor or above a permanently installed platform $(40.35,55.1,55.4,55.6)$.

13. Lifting provisions, such as lifting eyes or beams, or both, should be provided for the removal and transfer of heavy equipment or parts from the installed area to such areas as may be required for maintenance activities to be performed $(40.35,55.1,55.4,55.6)$.

14. Extended-service lamps in high-radiation areas, with features that permit the servicing of the lamps from lower-radiation areas, shall be used (RG8.8).

\subsection{SHIELDING}

The provisions of this section apply to radiological areas with potential or actual sources requiring shielding. In general, this category includes all equipment, structures, and areas producing significant external dose rates (e.g., the reactor itself, tanks, pumps, valves, filters, evaporators, and sumps).

1. General shielding requirements

a. Concrete radiation shielding design shall comply with ANS 6.4 and should comply with ANS 6.4.2 where applicable (6430.1A).

[Note that when it is desired to use the "new" neutron quality factors, i.e., those that were produced as a result of the reevaluation of the Hiroshima and Nagasaki dose data and other neutron dose information, then a set consistent with the neutron quality factors given in NCRP 116 and ICRP 60 (see the reference list) should be used. However, according to the RCM, Revision 1, "(a) neutron quality factor of 20 for conditions of unknown spectra (or doubling of the neutron quality factor of associated with known neutron energies) should be used for design purposes. Design analyses based on these neutron quality factors are intended to be used to estimate the additional construction cost that would result if the neutron quality factor was increased. The results of these analyses should be used to ascertain the economic feasibility for incorporating such modifications in the final design." Thus it appears that in ANS design, the single factor of 20 will not be used, on the grounds that at present there does not appear to be a reason to estimate what the additional cost would be if the new quality factors were used. Also, the neutron energies would be at least roughly known and the corresponding new factors would thus be used. ANS shielding designers have stated that calculations using the old factors will likely give results that are conservative compared to those using the new factors because the methodology used with the new factors is not quite the same as that used with the old factors. Thus the new dose rates not only do not turn out to be twice the old dose rates; they may even be lower than the old ones, depending on the case.]

b. Shielding shall generally be based on access requirements $(55.1,55.4)$.

c. For continuously occupied (general access or unrestricted) areas, the HPM gives a value for design of $0.25 \mathrm{mrem} / \mathrm{h}$ as the average dose rate (based on an occupancy time of $40 \mathrm{~h} /$ week). This is more limiting than the corresponding dose rate of "less than $0.5 \mathrm{mrem} / \mathrm{h}$ " given by 5480.11 .

d. For controlled areas not continuously occupied, the design objectives for exposure rates are not to exceed $20 \%$ of the annual occupational external exposure limits given in 5480.11 $(5480.11,6430.1 \mathrm{~A})$. The interpretation of this rule given in $6430.1 \mathrm{~A}$ is that shielding should 
be designed with the objective of limiting the total effective dose equivalent to less than 1 rem per year, based on the predicted exposure time for any individual in the normally occupied area. According to the HPM, the dose rate at the surface of a shield in an operating area (or restricted area of substantial or frequent occupancy) should not exceed $2.5 \mathrm{mrem} / \mathrm{h}$, and the average dose rate in the working area should not exceed $0.5 \mathrm{mrem} / \mathrm{h}$. However, since the dose is the real principal constraint in radiological control, consideration of the dose (e.g., the annual, weekly, and daily dose limits, as given in Sects. 2.1 and 2.2 of this set of design criteria, and the ALARA process) shall supersede dose rate specifications that are not set up on the basis of an assumed dose apportionment and related occupancy factors or, where warranted, on the basis of radiation zone or radiological area dose rate boundaries set for control purposes.

e. Appropriate shielding must be provided to minimize doses to the skin and the lens of the eye (6430.1A).

f. Appropriate shielding must be provided to minimize doses to sensitive equipment (e.g., microprocessors) that cannot survive the doses that would be incurred in a normal operating lifetime.

g. Shielding shall be provided for appropriate areas to allow personnel entry postaccident. Shielding shall be provided as needed to reduce doses to equipment required to function postaccident.

h. The design of shielding and work spaces (e.g., gloveboxes, countertops) should permit the later installation of additional temporary or permanent shielding to accommodate anticipated increases in workload or production of hot spots by crud accumulation (6430.1A). This includes consideration of size and weight of shielding and of such provisions as hooks, racks, portable shielding, and the like.

i. Fortuitous shielding by structural materials and equipment (that is, shielding by items not designed for that purpose, such as columns) should be considered (RG8.8). However, such fortuitous shields shall not be removable in circumstances in which their presence is necessary for shielding purposes.

j. Water shields, such as that used in the spent fuel pool, shall be of such depth or thickness as to allow for a reasonable inadvertent loss before actuation of safety mechanisms.

k. In general, piping shall not be embedded in shielding (e.g., in concrete floors, walls, or columns or in earthen foundations) $(40.35,55.1,55.6)$, in spite of Regulatory Guide 8.8's statement that advantage should be taken of this opportunity. However, embedment of pipe sleeves in concrete, from which the primary piping could be removed, may be acceptable in some cases (55.1), such as possibly for floor drain piping to sumps $(40.35,55.1,55.6)$.

1. Specialty shielding, such as polyethylene for neutrons, lead and leaded glass for gammas, lucite for betas, etc., shall be provided where appropriate.

m. Gamma heating (57.2) and thermal heating of concrete shall be taken into account in the design of shielding (because of the resultant heat production, which may affect cooling requirements and the functions of equipment and structures, and because of the potential resultant loss of water and thus hydrogen over time, which may affect neutron-shielding effectiveness).

2. Removable, temporary, and portable shielding

a. The use of temporary (RG8.8, 55.1, RCM), auxiliary (RG8.8, 55.4, 55.6), and portable (RG8.8, 55.4, 55.6) shielding should be considered, where appropriate, including the case in which hot equipment must be removed (55.1).

b. Modular construction and mobility of shielding shall also be considered where feasible. 
c. Removable shielding should be provided for large, infrequently moved pieces of equipment. In general, removable block may be used if access is required less than once a year. If access is required at more frequent intervals, steel doors, removable concrete panels, or the like should be used.

d. Blocks in removable block walls should be staggered both horizontally and vertically. For unmortared joints the maximum joint width shall generally be 1/16 in. and for mortared joints, $3 / 16$ in. This criterion may be relaxed if the mortar or grout density is close to that of the wall, if the dose rate on the source side is fairly low, or if the geometry is favorable.

e. Portable shields may be used to shield adjacent radiation sources or to minimize exposure to personnel doing contact maintenance (40.35).

3. Local shields, labyrinths, and plugs

a. Local shielding shall be considered where appropriate $(40.35,55.4,55.6)$, including for shielding-adjacent radiation sources or for minimizing exposure to personnel doing contact maintenance (55.1). The use of shadow shields should be considered (RG8.8).

b. The criteria for which a hot spot shall generally be shielded (including radiation sealing or elimination, as appropriate) are given in the following table. Exceptions may be made on a case-by-case basis where (1) the hot spot is of a very limited physical extent, (2) it is not near any location that personnel are likely to occupy for a significant fraction of the time spent in the general area, (3) pipe expansion or clearance requirements preclude it, or (4) the hot spot shielding (or sealant or elimination) would interfere with operations to the degree that dose from other sources would offset the dose saved by the shielding. Hot spots producing dose rates below the criterion levels below shall be considered for shielding (e.g., with extra stay time in the area).

\begin{tabular}{ll}
\hline $\begin{array}{c}\text { General area dose rate } \\
\left(\mathrm{D}_{\mathrm{G}}{ }^{\prime}\right) \text { in } \mathrm{mrem} / \mathrm{hr}\end{array}$ & $\begin{array}{c}\text { Hot spot dose rate, } \\
\text { in } \mathrm{mrem} / \mathrm{h}\end{array}$ \\
\hline$\leq 0.5$ & $\geq 1$ \\
$0.5-5$ & $\geq 5 \times \mathrm{D}_{\mathrm{G}}^{\prime}$ up to 10 \\
$5-100$ & $\geq 5 \times \mathrm{D}_{\mathrm{G}}^{\prime}$ up to 200 \\
$100-1000$ & $\geq 5 \times \mathrm{D}_{\mathrm{G}}^{\prime}$ up to 200 \\
$1000-5000$ & $\geq 5 \times \mathrm{D}_{\mathrm{G}}^{\prime}$ up to 10 \\
$\geq 5000$ & $\geq 2 \times \mathrm{D}_{\mathrm{G}}^{\prime}$ \\
\hline
\end{tabular}

c. The use of labyrinths shall be considered for entryways to areas or cubicles containing a source producing a potentially high dose rate $(55.4,55.6)$. Labyrinths shall generally be double where a significant percentage of the gamma rays from the source are of low energy (less than $0.3-0.5 \mathrm{MeV}$ ), and single where they are generally of higher energy (0.5-3.0 MeV); however, this decision also depends on the magnitude of the potential dose rate and the actual angle(s) of scatter. If the labyrinth top is lower than the height of the ceiling in the room served, the labyrinth shall generally be supplied with its own roof. Entrances with shield doors generally do not require a labyrinth. 
d. An access hole for inserting a telescoping detector through a shield plug shall generally be provided in the plug; it shall have a shielding plug or cap to cover it when not in use. Similarly, such an access hole shall be considered for the roofs or labyrinth walls of cubicles containing equipment producing high dose rates.

4. Shielding requirements for penetrations and voids

a. Penetrations should generally be located as high up on a wall as possible. Penetrations should not line up directly with the source (RG8.8, 55.4, 55.6) or with any area or space that may be potentially occupied (55.1) (e.g., stairways and platforms).In particular, doors should be located or shielded so that personnel standing in front of a closed door are not exposed to direct radiation from the hot equipment within $(55.4,55.6)$.

b. The number of penetrations should be minimized, particlularly in primary (57.2) and secondary confinements. However, several smaller and dispersed penetrations are preferred to one large one.

c. Penetrations should have the minimum diameter necessary.

d. The radiological effects of voids (partially-penetrating openings or areas of lesser density) shall be considered.

e. The selection and design of penetrations shall include consideration of the need for the penetration to be sealed for radiation reduction, air flow or airborne control, fire protection, or flooding.

f. A radiation seal or shield shall generally be provided for a penetration or void if:

1. There is otherwise a direct shine from the source to a general access area through the penetration.

2. It creates a hot spot in a frequently or continuously occupied area.

3. It exceeds the hot spot criteria in an infrequently but regularly occupied area (e.g., stairways, platforms, etc.).

4. The penetration is into a filter/demineralizer or like cubicle of varying but possibly high dose rate.

5. The penetration is in a floor or roof slab.

6. It would create an area of unacceptably high dose rate postaccident in an area where people or equipment must perform an accident mitigation or recovery function.

g. A radiation seal or shield shall be considered for a penetration or void if:

1. Eventual crud buildup in a pipe passing through it might cause it to exceed the hotspot criteria.

2. The centerline is less than $8 \mathrm{ft}$ above the floor and the penetration diameter is greater than 2 in. (except for filter/demineralizer or like high dose rate cubicles).

3. The void is a glove port in a glovebox potentially containing, even when not in use, radioactivity producing a high dose rate outside the box.

4. It is a gap between the top of a wall and the soffit of the floor above the wall. If offsetting is not adequate to satisfy applicable shielding requirements, such a gap shall generally be filled with material that provides shielding equivalent to that of the wall or that provides a lesser degree of shielding that is acceptable based on access and related requirements.

h. Exception is taken to the requirement in DOE 6430.1A (Section 1300-6.2) that "Straight-line penetration of shield walls shall be avoided to prevent radiation streaming"; this is too broad and dogmatic a statement to be adhered to in every instance, particularly when other measures, such as sealing and optimization of location, can adequately 
compensate for the straightness. Zigzag or angled penetrations shall be used where sealing is not possible or practical (6430.1A and IAEA Safety Series No. 50-SG-D9) and where a change of location is not feasible.

i. There shall be no penetrations through the spent fuel pool structure below the minimum water level required for cooling. All penetrations, except for isolation gates, shall be above the minimum water level required for shielding (57.2).

5. Requirements for shielding specific components or areas

a. Equipment such as filters and ion exchangers should be individually shielded or located in shielded cells, as appropriate and necessary $(56.6,57.2)$.

b. Viewing windows for hot cells shall be as small as practicable; provisions for shielding during window replacement shall be considered (6430.1A).

c. Sample valves shall be shielded from adjacent equipment (55.4).

d. Local shielding of monitors shall be provided as needed (55.4).

e. Where there is a mixer on a tank or vessel, provisions for the addition of shielding, as necessary and when feasible, between the vessel flange, and the motor should be made so that motor and bearing maintenance may be performed while the tank contains radioactive material (40.35) (otherwise, lubrication may be done remotely).

f. The requirement for shielding of new fuel shall be determined based on the highest anticipated level of radioactivity associated with the type of fuel to be stored assuming worst-case conditions (57.3). (57.3 states that "shielding shall be such that personnel exposures are ALARA," but does not make it clear what "worst-case conditions" are for new fuel, and ALARA is incompatible with accident exposure reduction.)

g. Shielding for areas adjacent to the spent fuel pool, including the overhead operating floor, shall be based on the maximum spent fuel inventory, with the minimum water depth over the inventory (57.2). Design shall ensure that loss of shielding due to reduction in water depth does not preclude personnel access to areas in which emergency makeup procedures must be performed (57.2). [57.2 also states that the shielding, with the maximum inventory and minimum water depth, shall not produce a dose rate exceeding $2.5 \mathrm{mrem} / \mathrm{h}$ in accessible areas under normal conditions or AOO events corresponding to a frequency of greater than $10^{-1} /$ year, or a dose rate exceeding $100 \mathrm{mrem} / \mathrm{h}$ during recovery operations for AOO conditions corresponding to a frequency of $10^{-1}$ to greater than $10^{-2}$ per year. Since the specifications are for dose rates and not projected doses, they are not necessarily consistent with application of the ALARA principle (see Sect. 16), and thus these specifications should not be applied to ANS.]

h. Regulatory Guide 1.97 states that "the design envelope for shielding, handling, and analytical purposes should assume 30 minutes of integrated sampling time at sampler design flow, an average concentration of $10^{2} \mu \mathrm{Ci} / \mathrm{cc}$ of radioiodines in gaseous or vapor form, an average concentration of $10^{2} \mu \mathrm{Ci} / \mathrm{cc}$ of particulate radioiodines and particulates other than radioiodines, and an average gamma photon energy of $0.5 \mathrm{MeV}$ per disintegration." 



\section{REQUIREMENTS FOR MATERIALS AND COMPOSITION SELECTION}

Specifics of some materials are discussed in appropriate other sections, e.g., sample lines and sampling equipment in in Sect. 14.

\subsection{GENERAL REQUIREMENTS}

1. Ease and efficiency of maintenance, decontamination, alternative uses, and decommissioning are to be considered in selection of materials (RCM, 6430.1A, HPM, RG8.8, THSC).

2. To the extent practicable, materials with low nickel and low cobalt contents shall be specified for components in contact with primary coolant, such as primary coolant piping, tubing, internal vessel surfaces, heat exchangers, wear materials, etc. (RG8.8). Alternative materials for hard facings of wear materials of high cobalt content should be considered if these high-cobalt materials may contribute (significantly) to overall exposure levels; account should be taken of potential increased service, repair requirements, and overall reliability of the old and new materials (RG8.8).

3. Corrosion effects during normal and possible off-normal operation shall be considered in the selection of materials for radioactive service $(40.35,55.1,57.1)$, e.g., the effects of galvanic or chemical corrosion. Continuously monitoring and adjusting bright hydrogen-annealed tubing and piping in the primary coolant and feedwater systems should be considered for the reduction of the loss of material by corrosion (RG8.8).

4. Use of favorable geometries and lubricants, where practicable, and controlled leakage purge across journal sleeves to prevent entry of particles into the primary coolant should be considered for reducing the erosion of load-bearing hard facings (RG8.8).

5. Lubricants, sealants, and protective coatings shall be compatible with their intended service and environment (57.1). If immersion of components is required, lubricants and rust-inhibitive coatings shall be chosen that are compatible with expected wear conditions and water chemistry (57.1).

6. Only materials compatible with fuel assembly function and integrity shall be used for the construction of surfaces in contact with fuel elements (57.3). Where materials to be used are susceptible to corrosion in the fuel storage environment, a suitably tough protective coating shall be used (57.3). All material in contact with pool water shall be compatible with the wetted materials of the primary reactor coolant system (57.1); all materials of construction shall be capable of withstanding expected cumulative radiation exposures and shall be compatible with pool water chemistry (57.2). Sulfur, mercury, and their compounds and alloys shall not be used (57.1). Lead, cadmium, halogens, and their compounds and alloys shall not be used unless encapsulated or otherwise prevented from coming into contact with the pool water (57.1).

7. Radiation-damage-resistant materials shall be selected for use in areas of high dose rate or high radioactivity deposition potential, especially seals and gaskets (RG8.8). 
Radiation-resistant seals shall be provided on the pressure faces of spent fuel pool gates (57.2). Stainless steel should be used where compatible with the process or the area (e.g., the degree to which it might become activated should be considered) (RG8.8).

8. Design shall ensure the adequacy of rail wearing surfaces during facility lifetime (57.1). This may be accomplished by providing replaceable rails or wearing surfaces, or by providing wearing surfaces for which the prevention of in-service failures can be ensured (57.1).

9. Materials used for valve packing shall have adequate radiation resistance for the intended application and the desired maintenance interval and service life and shall be compatible with the process stream $(40.35,55.1,55.6)$. If valve packing or soft seat inserts are required, the use of nonhalogenated plastics $(6430.1 \mathrm{~A})$ or teflon $(55.1,55.6)$ shall be considered, except in cases where tritium may be present in the stream (see below).

10. In general, plastic (including fiberglass-reinforced plastic) shall not be used for radioactive service $(55.1,40.35)$, although fiberglass-reinforced plaslic tanks may be used if done in accordance with the American Society of Mechanical Engineers (ASME) Boiler and Pressure Vessel Code (55.1).

11. For off-gas filter adsorber materials, consideration should be given to materials in the gaseous effluent that may inhibit adsorption performance and to monitoring the effectiveness of the adsorber (40.35).

12. Low-background materials shall be used for the walls, ceilings, and floors of counting rooms (e.g., concrete made from coal fly ash may be unsuitable).

\subsection{MATERIALS REQUIREMENTS WHEN TRITIUM MAY BE PRESENT}

Special materials considerations for equipment that may contain or come in contact with tritium are as follows.

1. The compatibility of materials with tritium should be considered, taking into account the need for containment, gas purity, and mechanical integrity in the application (TSHC). The potential for helium embrittlement should be considered (TSHC); primary confinement barriers used in tritium facilities shall avoid the use of materials that are subject to hydrogen embrittlement (6430.1A). Outgassing of materials and degradation effects due to tritium decay, such as loss of ductility, should also be considered (TSHC).

2. The diffusion (and permeation) of tritium into and through other material shall be taken into account. In the case of gloveboxes handling tritium or tritiated components, material resistant to hydrogen diffusion should be used to the maximum extent possible (6430.1A). For reduction of the tritium inventory in materials, materials should be selected that have low solubilities for hydrogen or that dissolve it as atoms rather than molecules (TSHC). Tools with rubber or plastics should be avoided whenever possible, since the rubber and plastic show an affinity for tritium (Reinig). 
3. The possibility of He-3 leakage shall be taken into account in the choice of any transducer (MLM-3719) or other such component.

4. In general, all-metal components are preferred (MLM-3719, TSHC), particularly for the primary confinement (MLM-3719). Nonhydriding metals shall be preferred to hydriding metals for tritium work (MLM-3719); the metal should be as little susceptible to hydrogen embrittlement or radiation damage as possible (MLM-3719). Hydriding metals shall not be used for pipelines or vessels that serve as primary containments for tritium gas (MLM-3719).

5. In general, austenitic stainless steel is recommended, especially 304 or 316 , with a low carbon content (MLM-3719). Copper and aluminum may be used in some cases for low-pressure systems (MLM-3719).

6. The exchange of tritium for hydrogen on the surfaces of material shall be considered in design, particularly for oxide layers on nonhydriding metals (MLM-3719); selection of impermeable materials with thin or nonexistent oxide layers is preferred (MLM-3719). UHV treatment of metal surfaces should be considered where appropriate, since metals without such treatment tend to bond large quantities of water at their surfaces, and then protium-tritium exchange can occur (TSHC, which notes that removal of the tritiated oxide layer is difficult). The bakeability (TSHC), immersibility, and other relevant properties of materials for decontamination purposes shall be considered.

7. Stainless steel is to be preferred to silica glasses, which are hard to decontaminate (MLM-3719). Ceramics may also be considered (MLM-3719), where their use is appropriate.

8. Pressure transducers for tritium-containing gas generally require all-metal construction (MLM-3719). Sensors and transducers inside tritium gloveboxes should generally be made of 316 or 316L stainless steel (MLM-3719). All strain-gauge transducer parts that will be exposed to tritium should be made of 316 stainless steel (MLM-3719).

9. Consideration should be given to the interior materials of all kinds of instruments. In particular, consideration should be given to the provision of smooth inner surfaces, especially of metal (TSHC). Piping should have a smooth interior finish, electrolytically polished if appropriate (TSHC). Aluminum or stainless steel interiors for Kanne chambers should be considered (as at the Savannah River Plant, according to Reinig). Tritium sample containers should generally be of 304 or 316 stainless steel with the inside surface polished (mechanically or electropolished) to minimize surface area (MLM-3719).

10. The use of tools with polished metal surfaces is encouraged because they are easiest to clean (Reinig).

11. Tritium process and handling systems shall use, wherever appropriate, nonflammable hydraulic, lubricating, and cooling fluids (6430.1A), particularly where elemental or flammable forms of tritium are present.

12. Oils should be avoided wherever possible (TSHC) and carefully selected where used (MLM-3719). For vacuum pumps, polyphenyl ether oils are preferred (MLM-3719, TSHC), especially where it is necessary to avoid frequent changeout of oil (MLM-3719). Saturated 


\section{8-4}

hydrocarbon mineral oils and silicone oils are generally to be avoided (MLM-3719; TSHC says hydrocarbon oils may be considered). Oils containing halogens (e.g., fluorinated pump oils) should not be used, to avoid the formation of tritium fluoride and like substances (MLM-3719, TSHC) (note that MLM-3719 qualifies this rule by saying they should not be used for tritium gas or water vapor service). Vacuum pump oil is preferable for use in bubblers, but glycol or other fluids may be acceptable (NILM-3719).

13. The use of organics in tritium work must be carefully considered in light of potential damage to gaskets, valve tips, O-rings, elastomer seals, and the like (MLM-3719). The use of polymers such as Teflon, Viton, and Kel-F must be carefully considered because of the potential for production of the acid TF; in particular, since radiation damage to Teflon is thought to be more severe than to all other thermoplastics, Teflon should not be used in concentrated tritium streams (MLM-3719). Polyimides should be considered for tritium work, especially if gamma radiation is also present. (Note that TSHC advises the avoidance of plastics and (presumably rubber) O-rings in general and of elastomers, halogens, and organic lubricants in the process region.) However, glovebox windows may be sealed to the box with silicone rubber channel gaskets or other appropriate seals (MLM-3719).

14. Tritium gloveboxes should be of stainless steel, preferably 304 , or weldable aluminum alloy, as appropriate (MLM-3719). Tritium gloveboxes should have enough rigidity (7- to 11-gauge thickness) to provide good surfaces for sealing gaskets (MLM-3719). The metal surface should be smooth (2B mill finish) with no pockets (MLM-3719).

15. For vacuum pumps, all-metal types with no lubricants are best for tritium service (e.g., scroll, metal bellows); pumps having elastomer seals or using lubricants should be used only on systems containing low levels of tritium (TSHC).

16. All-metal valves are preferred, in general (TSHC). However, it shall be taken into account that all-metal valves typically require higher sealing forces than those utilizing elastomers or plastics at the sealing surfaces (TSHC).

17. For valve stem tips, stellite is acceptable for high-purity applications and manual operation where neutron activation is not expected to be high or where the reliable seal it provides (because of seat rather than stem deformation in forming the seal) is more essential than prevention of activation (TSHC). Stainless steel valve tips may be acceptable where the use of copper could induce electrolytic or corrosion problems; copper valve tips may be acceptable for infrequent automatic operation and manual operations (TSHC). Polyimide (e.g., Vespel) valve tips may be acceptable for valve applications where some contamination can be tolerated (TSHC), where good resistance to tritiurn is needed (TSHC), where a long-lasting component is highly important (TSHC), and where the sealing force is adequate (MLM-3719). See the summary table below (TSHC). [Note: polyamide (nylon) should not be confused with polyimide; the former has a much lower radiation resistance than the latter.] 


\begin{tabular}{ccccccc}
\hline & \multicolumn{2}{c}{ Gaseous environment } & & \multicolumn{2}{c}{ Aqueous environment } \\
\cline { 2 - 3 } \cline { 5 - 6 } Application & Auto & Manual & & Auto & Manual \\
\hline High-purity & Copper & Stellite & & Stainless & & $\begin{array}{l}\text { Stainlesss or } \\
\text { Stellite }\end{array}$ \\
& & & & & \\
Low-purity & Vespel & Vespel & & Vespel or & & Vespel or \\
& & & & Elastomer & Elastomer \\
\hline
\end{tabular}

18. An acceptable glovebox window material for tritium work is laminated safety plate glass, 3/8-1/2 in. thick; Lexan may be used where glass may crack (MLM-3719). For walk-in or reach-in tritium hoods or similar enclosures, Lexan or Lucite panels may be used for doors and windows (Reinig).

19. High-density polyethylene should be considered for containers intended for storage of tritiated aqueous waste where the waste is solidified into or sorbed onto a solid form (as a safety precaution in case of rupture) (TSHC). High-density polyethylene may be used for containers intended for storage of tritiated oils and other organic liquids, where these have been solidified into or sorbed onto a solid form (as a safety precaution and for protection of the container against organic attack) (TSHC). High-density polyethylene may be used for metallic waste, where this has been backfilled with a high-water-content material (TSHC). (Note that the statements in this item are subject to approval by the ORNL group handling solid waste, since the acceptability criteria for tritiated waste from ANS is uncertain at present.)

20. Surfaces should be free of oils and wash residues that must be removed from surfaces to maintain gas purity (MLM-3719; TSHC, inferred), e.g., to prevent formation of $\mathrm{CH}_{3} \mathrm{~T}$. 


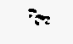




\section{GENERAL EQUIPMENT DESIGN AND SELECTION}

\subsection{GENERAL REQUIREMENTS}

1. The design and selection of equipment for all radioactive systems (those that contain, transport, collect, store, or process radioactive materials in whatever form) or for all nonradioactive systems that significantly affect or support radioactive systems must be appropriate for the intended function of the equipment, including consideration of environmental conditions, maintenance, inspection and testing requirements, and the like.

2. In particular, equipment design shall facilitate removal and replacement or ease of in-place maintenance (55.1), as appropriate.

3. Equipment design shall minimize leakage (6430.1A) and the presence of crevices and pockets where contaminants could accumulate $(40.35,55.1,55.6,57.1)$.

4. Equipment should be designed to require minimum lubrication (40.35).

5. Reliability (RG8.8, THSC), serviceability (RG8.8, THSC), and long operating life (40.35) shall be important considerations in the design, selection, and location of equipment. Decontamination, alternative uses, and decommissioning are also to be considered (RG8.8).

\subsection{TANKS, VESSELS, AND HEAT EXCHANGERS}

1. Tanks and vessels should be fabricated with all braces and reinforcing structures on the exterior of the tank or vessel (to eliminate crevices and pockets) (40.35).

2. Tank and vessel drainage shall provide for complete drainage $(40.35,55.1,55.6, \mathrm{RG} 8.8)$, with drain lines located in the low point (55.4).

3. Cone-bottom tanks (RG8.8, 40.35, 55.1) or dished-bottom tanks (40.35) should be used for liquid radioactive service.

4. Mixers should be designed to be mounted on top of the tank or vessel (40.35). Built-in spray or surge features should be provided (RG8.8). Tank design shall provide for purging or inerting of the tank gas activity or potentially combustible gases (55.4).

5. Provision of spare connections on tanks or other components located in higher radiation zones should be considered, where appropriate to promote flexibility (RG8.8).

6. Whenever possible, internal vessel or tank components should be designed for remote replacement. 
7. Plugging of any heat exchanger tube shall be possible when the removable channel cover is removed.

8. The use of directly buried storage tanks should be avoided if possible (6430.1A).

\subsection{PUMPS, THEIR ASSOCIATED SEALS, AND FANS ANID BLOWERS}

1. Pumps and associated piping connections shall be designed for ease of decontamination, replacement, and repair of seals $(40.35,55.1,55.6)$.

2. Progressive cavity-type pumps may be used for slurry pump applications (55.1). When used, they should be designed for ease of decontamination and replacement of pump stator (55.1). Solenoid-operated valves may be used for slurry applications (55.1). Magnetically coupled pumps should be considered (40.35). Sealless-type pumps may be considered for some applications of nonsiurry use (e.g., decanting or dewatering) $(55.1,55.6)$. Canned pumps should be used where compatible with process and service needs (RG8.8).

3. Tritium pumps should have as many of the following characteristics as is practical: positive displacement, reliability, convenience, the ability to pump over a wide range, no moving seals, and no liquid or organic lubricants or seals (MLM-3719). According to MLM-3719, pumps that may be acceptable, depending on the applicalion, include rotary vane pumps with magnetic drives and low-vapor polyphenylether oil; metal diaphragm pumps; metal bellows pumps; scroll pumps; mercury-displacement pumps; cryogenic compression pumps; magnetically suspended turbomolecular pumps; and molecular drag pumps (MLM-3719). The removal of heat generated by the induced eddy currents from magnetic couplings must be considered, however (THSC). According to the TSHC, pumps that may be acceptable, depending on the application, include metal bellows pumps (which must be protected against water vapor, particulates, and dead-heading); metal diaphragm pumps (all-metal, no lubricants in the process region, typically uses check valves); cryopumps (no moving parts, but must be regenerated periodically by warming), getter pumps (cannot pump inert gases), and dry roots and claw pumps (oilless, inert gas purge used).

4. For tritium high-vacuum pumping, compound cryopumps and turbomolecular pumps shall be considered (TSHC). Scroll, bellows, and wobble plate pumps that are all-metallic and do not require oil for lubrication or sealing shall be considered for forevacuum use; hermetically sealed canned and magnetically-driven pumps should also be considered, the latter especially when lower eddy current losses, oil-free operation, and enhanced pump control are desirable (TSHC). Roots and rotary-vane pumps may be used where higher throughput or capacity is needed, if the use of lubricants can be minimized (TSHC) or the tritium concentration is low (inferred from TSHC).

5. For high-pressure tritium applications, oil-driven diaphragm compressors with triple diaphragm containment should be considered (MLM-3719).

6. Metal hydride beds should also be considered for use as tritium pumps (MLM-3719). However, care should be taken to provide metal getters (especially for $U$ ) with a filter to remove broken-off getter particulates so as not to degrade valve seats, pumps, etc., downstream (TSHC). 
7. Where avoiding oil contamination is critical, dry rotary pumps (such as multistage roots or claw pumps) should be considered for tritium service (MLM-3719).

8. For general-purpose, small-volume tritium vacuum support, direct-drive or belt-drive rotaryvane vacuum pumps may be appropriate (MLM-3719). Oil may be fed to the pump from outside a glovebox and then go to a spent oil receiver tank in the glovebox (MLM-3719).

9. Pumps should generally have wear-resistant double (40.35) mechanical seals or other appropriate provisions to minimize leakage of radioactive liquids $(40.35,55.1,55.6)$.

10. The use of seals and seal water should be considered on a case-by-case basis, including the pump manufacturer's recommendation (55.1). Seal water injected into the interior of the seal should prevent abrasive material from entering the seals and eroding the seal material (55.1). If mechanical seals are used on a pump in slurry service, features that permit the use of flush water to clean the pump seals shall be provided (RG8.8, 40.35, 55.6).

11. Compressors and regeneration blowers on gas dryers shall be equipped with reliable, high-quality seals; if diaphragm-type compressors are used, they should be provided with leak-detection capability (55.4). Magnetic couplings should be considered for blowers; the removal of heat generated by the induced eddy currents from magnetic couplings must be considered, however (THSC).

12. Consideration shall be given to the potential presence of catalyst debris carried into relevant dryers, since tritium not recombined may react with it in the dryers (TSHC).

\subsection{VALVES AND THEIR ASSOCIATED PARTS}

1. Straight-through valve configurations should be provided wherever possible (RG8.8). In resin and sludge treatment systems, full-ported valves shall be used such that the slurry will not interfere with the opening or closing of the valve and such that the valve has minimal cavities (RG8.8, 40.35, 5.1, 55.6).

2. Valves and associated piping connections shall be designed for ease of replacement; valve design should particularly avoid crud traps (RG8.8, 40.35, 55.1).

3. Valves should be oriented so as to promote complete drainage $(40.35,55.1)$. It shall be possible to install valves in the "stem-up" orientation (RG8.8). For tritium getter storage beds, valves should be oriented so that the flow direction is away from the bed (TSHC).

4. The use of packless (e.g., metal diaphragm or bellows) valves shall be considered (6430.1A, 55.6). For primary coolant, packless or live-loaded-packed valves shall be used (RG8.8). For gaseous radwaste, valves with bellows-sealed stems, diaphragm valves, or similar leaktightness characteristics shall be used; if packed valves are used, double-stem packing leakoff connections shall be provided (55.4). Valve back seats should be considered (RG8.8). Valves used in tritium work should be packless (metal diaphragm or bellows) (MLM-3719, THSC), with metal stems and valve seats for manually-operated valves (MMM-3719). Torque-limiting handles should be used on manual valves (to avoid damaging valve seats) 


\section{$9-4$}

(MLM-3719). Magnetically-coupled valves should also be considered (THSC).

Bellows-sealed valves, in general, should not be used as control valves due to their tendency to fail after a relatively short number of cycles (TSHC). Bellows-sealed valves with replaceable stem tips and bellows may be considered, however, where appropriate (TSHC). High-pressure metal diaphragm valves should not be used where downstream pressure might exceed upstream pressure under some conditions, because in such cases they tend to act as reverse check valves (TSHC). Rubber diaphragm valves may be considered for low-pressure applications with discharge to the environment, if it is practical to replace the diaphragm every few years (TSHC). Magnetic couplings on butterfly valves should be considered, as appropriate, where low leakage is essential. Where stem-sealed valves must be used, live-loading and optimal design of the stuffing box should be provided (TSHC). Lantern rings inserted in the middle of the packing and connected to a closed-loop leakage collection system should also be considered for appropriate valves (TSHC).

5. For reliability in tritium work, valves and fittings should be disassembled when possible, cleaned, reassembled, function-tested, and leak-tested at operating pressures before being installed in the system (MLM-3719). Fail-safe valves should be used where feasible (TSHC).

6. The use of check valves should be considered where it is important to prevent backflow. However, because they have been known to leak when closed and thus may not provide reliable confinement, consideration should be given to providing pairs or even trios of check valves, check valves combined with other kinds of valves, or leak detection in conjunction with a check valve(s).

\subsection{PIPING AND TUBING}

1. Piping shall be designed to minimize entrapment and buildup of solids in a system (6430.1A).

2. Slurry piping shall provide a free-flowing, minimum pressure drop path between the slurry source and the slurry receiver $(40.35,55.1,55.6)$, such as by appropriately sizing the piping (55.4, RG8.8) and continuously sloping it $(55.4,55.6)$. Bends with radii of at least 5 times the pipe diameter or long-radius elbows shall be used; bends are preferable $(40.35,55.1,55.6$, RG8.8). Slurry piping design should consider minimum settling velocities (40.35).

3. Tubing used in a tritium system should be precleaned or treated so as to achieve a surface reduction inside the tubing of at least 90\% (MLM-3719).

\subsection{CONNECTIONS AND WELDS}

1. In general, all process connections and fittings to tanks containing radioactive materials shall be welded $(40.35,55.1,55.4,55.6)$, except for lined or fiberglass or other nonmetallic tanks $(40.35,55.1,55.6)$. Pressure-retaining components shall also be welded $(55.4,55.6)$.

2. Joints made by brazing or welding are preferable; no dead spaces should be left in joints (TSHC). Regarding flange joints, the TSHC holds that most leakage occurs as a result of 
temperature and pressure changes during system startup and shutdown, when there is a nonuniform distribution of seal compression. In such cases, seal-welded flanges or live-loaded studs should be used wherever possible (THSC). Similarly, mechanical couplings are especially prone to leak when subjected to temperature cycles, so the connection should be welded if possible (THSC).

3. The tube-to-tube-sheet joint in a heat exchanger shall be seal-welded, if leakage would result in a release of radioactive material to the environment.

4. Unless confined within a recirculating glovebox, tritium process system component connections shall be welded to the fullest extent practicable (6430.1A). Tritium piping and tubing should generally be welded at the joints (MLM-3719). In the case of double-walled piping inside gloveboxes, the interannular space should be seal-welded inside the gloveboxes; in the case of transfer lines between gloveboxes, these lines should be secondarily contained, have the same integrity as the gloveboxes, and have welded connections (MLM-3719).

5. Butt welds should generally be used wherever deposition of radioactivity is likely. Butt welds with consumable inserts should be used in place of socket welds and backing rings for slurry piping (RG8.8, 40.35, 55.1, 55.6), except that for lines other than slurry lines $3 / 4$ in. nominal size and larger but less than 2-1/2 in. nominal size, socket-welded or mechanical joints may be used $(55.4,55.6)$. For tritiated streams, welds on the inside of pipes (i.e., in contact with the stream), etc., are always preferred; thus butt welds are preferred to socket welds for tritium piping (TSHC). The pipe should be cleaned prior to assembly (TSHC).

6. Rapid-disconnect fittings shall be used only where maintenance or operational requirements clearly indicate such construction to be preferable (RG8.8). Where disassembly of joints is required for valves, pumps, etc., in tritium work, engineered couplings with demountable metal gasket seals should be used (MLM-3719). Compression-type fittings such as Swagelok should be used only on systems containing small amounts or low concentrations of tritium (THSC). Screwed connections in which the threads provide the only seal shall not be permitted otherwise $(55.4,55.6)$ except for instrumentation connections or pump casing vents and drains where welded connections are not suitable $(55.4,55.6)$. Threaded or flanged connections may be used for instrumentation (40.35), backed up by seal-welding as appropriate (55.4). The exception is that pipe-threaded joints shall not generally be used for tritium work (MLM-3719).

7. Flanged manways on pressurized gas storage tanks should be seal-welded or provided with an underlying seal-welded diaphragm (55.4).

8. Glovebox windows should be sealed to the box with channel gaskets or other appropriate seals (MLM-3719). Doors to passboxes should seal well (MLM-3719). A flange or metal surface can be provided where a plastic tent can be taped to the box for performing maintenance inside the box (MLM-3719). 


\subsection{INSTRUMENTS}

For most criteria relating to monitors, see Sect. 14.

1. Instruments shall be designed, selected, and specified so as to provide for easy maintenance and calibration and for low crud accumulation (RG8.8). Operating experience shall be considered in the selection of instrumentation (RG8.8).

2. Instrumentation should be selected that contains minimal quantities of contaminated working fluid (e.g., pressure transducers rather than bellows-type pressure gauges) (RG8.8).

3. In general, active control and limit equipment shall be accessible for routine maintenance without equipment removal (57.1).

4. Sensors and transducers inside tritium gloveboxes should be of high-quality construction (MLM-3719). Pressure transducers for tritium-containing gas require welded construction (MLM-3719). Strain gauge transducers with all parts that will be exposed to tritium should have a metal gasket fitting for attachment to the volume (MLM-3719). In addition to the pressure transducers on tank volumes, it is usually necessary or desirable to have pressure transducers on process lines to monitor upstream and downstream pressures on pumps or the evacuation level of a line (MLM-3719).

5. Thermocouple pressure gauges with stainless steel construction and ceramic electrical feedthroughs should generally be chosen (MLM-3719, on the grounds that these usually have a high pressure rating).

6. For capacitance manometers in tritium systems, the capacitance electrodes should be on the reference side and the tritium must be exposed to a welded chamber and diaphragm (MLM-3719).

\subsection{TOOLS}

1. The provision of special tools should be considered, where it would be appropriate (RG8.8).

2. Handling tools shall be provided with a positive means of latching to preclude inadvertent release and with means to indicate visually whether the tool is in the "latched" or "unlatched" condition (57.1). Handling tools shall be designed to remain in a safe condition upon loss of actuating power or force (57.1).

3. Tools should be designed so they can easily be disassembled, if, necessary, to facilitate decontamination, handling, and storage (57.1).

\subsection{MISCELLANEOUS}

1. In order to reduce the tritium inventory in a given area or object, the face area exposed to the tritiated gas or liquid and the material thickness should be reduced (TSHC). 
2. HEPA filter cartridges should be mounted with vertical upflow (55.4). The vessel or canister should be furnished with guides to position the filter cartridge in the vessel (55.4). The filter should be designed for removal of the cartridge from above (55.4). The filter vessel shall be designed to allow complete drainage and vessel piping shall be arranged for easy disassembly of the filter for cartridge removal (55.4).

3. If filters are installed in a tank for dewatering, they shall be designed for remote backflushing or for removal and cleaning or disposal (55.1).

4. In-place testing shall not be required of filters upstream from charcoal or catalysts where DOP could damage the media and where a set filter efficiency is not required (55.4).

5. In a tritium facility, consideration should be given to compartmentalizing appropriate equipment in large walk-in or reach-in hoods with some transparent panels or doors to provide visual access (Reinig). Glove ports with butyl rubber gloves should be provided in several locations in these to allow operation of the equipment or minor adjustments without personnel entry (Reinig).

6. Glove ports in gloveboxes shall allow the user to change gloves readily (MLM-3719). Glove ports shall be adequate in number and size for the intended work (MLM-3719).

7. Doors to glovebox passboxes should exit into a fumehood if routine use is anticipated (MLM-3719). 



\section{SYSTEM, PROCESS, AND OPERATIONAL DESIGN}

\subsection{GENERAL REQUIREMENTS}

1. DOE 6430.1A shall be used to provide general design criteria $(5480.11,5480.30, \mathrm{HPM})$. Reactor-specific general design criteria shall be provided by DOE 5480.30. PNL-6577 should be used as guidance for determining the ALARA radiological design criteria (5480.11, HPM).

2. The design of all radioactive systems (those that contain, transport, collect, store, or process radioactive materials in whatever form) and of all nonradioactive systems that significantly affect or support radioactive systems must be appropriate for the intended function of the system, including consideration of environmental conditions, maintenance, inspection and testing requirements, and the like. Ease and efficiency of maintenance and decontamination shall be considered in system design (RCM, 6430.1A, HPM, THSC); alternative uses and decommissioning should be considered in facility design and thus also in system design (RCM, 6430.1A, HPM).

3. The principle of isolation (i.e., physical separation of radioactive streams from components or from nonradioactive or other radioactive streams within a system or between connecting systems) shall be applied. The potential for contamination of nonradioactive systems by leaking radioactive systems shall be considered (RG8.8).

4. Note that DOE 5480.30 states that "There shall be no interconnections between liquid effluent streams, such as streams containing radioactive or hazardous waste, and potable water streams, other incoming nonpotable streams, and other outgoing streams." The RCM states that "Design should preclude the connection of nonradioactive drains with radioactive ones." These statements appear to be overly dogmatic and restrictive, however. The question of interconnection should surely be addressed on a case-by-case basis, and the best interpretation of DOE 5480.30 and the DOE RCM is that interconnections should be minimized and no nonisolable interconnections should be made.

5. All components should generally be isolable from the streams they carry. Redundant components, cross-connections, backup systems, etc., should be provided as necessary; provision of redundant components shall be considered (RG8.8) where it might allow for greater operational flexibility or reduce dose. The need for use of temporary components in the event of an extended outage of critical components should be considered in design (57.2). Redundant equipment should generally ( 57.2 says "shall") be individually testable and maintainable without loss of system function.

6. To prevent cross-contamination of clean streams by radioactive ones or of less radioactive streams by more radioactive ones, check valves should be provided as necessary and where appropriate. Temporary connections, such as hose connections, should be provided instead of welded connections only where appropriate and necessary.

7. Process lines should be carefully installed so that no backflow occurs (MLM-3719, 57.2). Flow-limiting devices should be considered for these lines (MLM-3719). Any permanently 
installed piping that could serve as a siphon to lower spent fuel pool water below the minimum required for shielding shall be equipped with passive antisiphon devices (57.2). Drains installed in the cask-handling pool and transfer canal, if such a pool and canal are present, shall be provided with double valves (57.2). The cask-handling pool, if present, should be connected to the spent fuel pool by gates and a weir (57.2).

8. Isolation arrangements, such as certain valve arrangements, that produce "islands" of radioactivity (e.g., dead legs) should be avoided or should be such as to minimize the "islands."

9. It is stated in the TSHC that prudent tritium control design should be based on a residual level of chronic tritium escape plus infrequent acute releases due to component failure, human error, and system maintenance; reference conditions should be estimated for various operating modes and system process parameters based on operating experience. It is also stated that the most fundamental barrier to escape of tritium as vapor or liquid is tritium removal, provided that the transfer, tritium removal, and storage systems do not in themselves contribute appreciably to the total tritium emissions. Thus, it is concluded in the TSHC, system leaktightness, "with essentially zero leaktightness," should be a major design aim. Achieving this requires the application of the following principles.

a. Design should be simplified as much as possible. In particular, the number of components with leakage potential and the number of mechanical joints should be reduced as much as possible.

b. Components where leakage may occur (e.g., seals) should be carefully designed and selected. Special attention should be paid to pumps, blowers, fans, mechanical couplings, static seals such as flanged joints, and dynamic seals in valves. Consideration should also be given to the potential for leakage provided by flow and pressure transmitters, temperature probes, and sight glasses.

c. The use of freeze plugs to isolate systems for maintenance purposes without valves should be considered.

d. Methods with sufficient sensitivity to measure down to a specified leakage should be available.

10. Instrumentation, wiring, cooling connections, or miscellaneous piping runs shall be attached, mounted on equipment, or located in a manner that results in minimum time for maintenance (55.1).

11. Design should support, where practical and appropriate, remote repair or maintenance for maintenance operations offering a potential for significant exposure (6430.1A). Thus, consideration should generally be given to removal of equipment to remote, lower-dose-rate locations for maintenance (RG8.8, 55.4, 55.6).

12. Adequate clean services, including breathing air, service air, nitrogen, and demineralized water, shall be provided at points appropriate for and convenient to work locations (5480.30, RG8.8).

13. The use of traps in radioactive liquid waste lines (6430.1A) or in spent fuel pool water cleanup system(s) (57.2) shall be avoided (6430.1A) to the extent possible. To the extent possible, piping shall be designed to minimize loops, flanges, and other areas in which radioactive materials may accumulate (57.2). 
14. Positive operator action shall be required to effect any controlled discharge to the environment $(55.4,55.6)$. As a normal method, controlled discharges from storage tanks shall not be accomplished by gravity or siphoning flow (55.6). Valves used to control the discharge of radioactive liquid waste to the environment shall fail closed when actuating power is lost to the valve $(55.4,55.6)$.

15. An appropriate surveillance system shall be provided to monitor the integrity of all process piping, tanks, and other containment equipment, including those used for liquid effluents, and other primary confinement components (6430.1A).

16. Systems containing tritium shall be designed, to the extent practical, to minimize the conversion of elemental tritium to tritium oxide, where a significant release may occur (6430.1A). In particular, air should not generally be used for the atmosphere of a recirculating tritium glovebox because of the potential for tritiated water production; argon or nitrogen is recommended (6430.1A).

\subsection{FLUSHING, PURGING, AND CLEANING}

1. Flushing should be performed with a minimum amount of water (55.1).

2. All slurry piping $(40.35,55.1,55.6)$ and spent fuel pool cleanup piping (57.2) shall be provided with provisions for flushing and mechanical cleanout $(40.35,55.1)$; automatic flushing after each transfer should be considered $(40.35,55.1 ; 55.6$ says "shall be performed"). In particular, valves and piping that contain concentrated chemical solutions shall have provisions for flushing and shall be designed so as to preclude solidification of the solutions in the lines (55.6).

3. Cleaning by remote flushing, rapid replacement, etc., should be provided for screens, filters, or other traps for solids from tank overflows and vents (RG8.8) and by remote flushing from resin traps (55.6), where present.

4. Cleanup systems (e.g., using graphite or magnetic filters) for removal of crud from the primary coolant during operation should be considered (RG8.8).

5. Equipment interior and exterior surfaces that may come in contact with radioactive materials should permit, when appropriate, cleaning or decontamination, or both, by flushing, purging with inert gas, chemical treatment, or mechanical means (40.35). When seal water is used for flushing, the flow to the seals shall be coordinated with pump operation $(40.35,55.1,55.6)$.

6. Pressurized gas storage tank systems shall have a means of purging individual tanks with an inert gas (55.4).

7. Purge connections should be double-valved to reduce leakage (55.4).

8. Preheaters for gaseous radioactive waste shall have drain traps with strainers located upstream that are removable for cleaning (55.4); they shall be of a type without small, easily plugged orifices and shall have a remotely operable bypass line around the drain trap and 
strainer (55.4). These provisions should apply to other kinds of systems also, where appropriate.

9. If an inert atmosphere is used for a glovebox passbox (or pass-through port), then a flushable passbox with an evacuation and fill cycle should be used (MLM-3719).

\subsection{UNPLUGGING, SPARGING, AND MIXING}

1. The tendency of slurry lines to plug shall be considered; pressurized gas to blow out lines shall be used only with caution (RG8.8).

2. Water, air, or nitrogen should be used for sparging and fluidizing resins or sludges in storage tanks, but the resulting production of airbornes and the potential for overpressures shall be considered (RG8.8).

3. Tanks containing slurries shall have means to mix tank contents $(40.35,55.1,55.6)$, especially preceding sampling (55.6); tank circulation by pumping the tank's contents back to the source tank should be a design consideration $(40.35,55.1)$.

4. Dewatering of sludge or resin tanks shall be considered (55.1). Decanting may also be used, provided the tank is of sufficient capacity to allow for the settling of sludge or resins prior to decanting (55.1).

\subsection{HEAT TRACING AND MISCELLANEOUS MEASUREMENTS}

1. Tanks, piping, sample tubing, or equipment that processes or contains liquid shall have heat tracing if concentrates are likely to precipitate, solidify, or become too viscous to pump adequately at ambient temperatures $(55.1,40.35)$.

2. When practical, tritium glovebox temperature and pressure sensors should be calibrated in place; if calibration lines are run outside the glovebox, extreme care should be taken (MLM-3719) in routing and penetrations. Hermetically sealed bulkhead connectors should be used for all power and signal cabling entering or exiting the glovebox; the feed-throughs should be gasket-mounted (MLM-3719).

3. The location of a pressure transducer with respect to the volume on a tritium pressure-volume-temperature system should be chosen with care (MLM-3719). A transducer to be calibrated in place should generally be placed on the line connected to the tank, with an isolation valve between the tank and the transducer, to avoid having to fill the tank during calibration (MLM-3719). When it is desirable to allow direct pressure reading at random times by opening the valve yet still provide protection from leakage if the transducer diaphragm leaks, the alternative method of attachment for the pressure transducer (installing it directly on the volume) with an isolation valve between the transducer and volume should be considered (MLM-3719). 
4. Thermocouple pressure gauges used as auxiliary indicators preferably should be located both near the pump and on the lines being pumped, at the farthest practical location along the pumping path (MLM-3719). A fitting should be welded onto the gauges for attachment to the tritium process system (MLM-3719). Thermocouple gauges attached to process lines should have isolation valves to minimize long-term exposure of the ceramic-to-metal seal to tritium (MLM-3719). Thermocouple gauges on storage tanks should have isolation valves that need be opened only for vacuum measurements (MLM-3719).

5. For flow rate measurements of gases containing low tritium concentrations, flow meters based on temperature profile measurements along the heated flow tube should be considered (MLM-3719). For higher concentrations, the tendency of tritium to permeate through the tube and raise glovebox concentrations should be considered (MLM-3719). Capacitance manometer-based flow meters may also be considered, provided the design of the manometer does not expose the capacitance electrodes to tritium (MLM-3719).

6. If only one temperature probe is to be used in a tritium-containing tank, it should generally be located on the axis near the center of the tank (MLM-3719). It should generally have a stainless steel sheath and be long enough to be inserted into a thermal well, with a reasonably tight fit (MLM-3719). The temperature well arrangement is preferred to direct insertion of the probe into the gas, because in the latter case the volume must be emptied and a contaminated probe handled whenever the probe is calibrated (MLM-3719).

7. For some calibrations in gloveboxes, a well-type arrangement may be used in the form of a stainless steel block welded to the inside of the glovebox; this would have one well opening to the exterior of the glovebox for entry of the clean reference probe and another well opening into the interior of the glovebox for entry of the potentially contaminated process temperature probe (MLM-3719).

8. Tritiated-water-leak detectors and gas-leak detectors shall be provided as appropriate (6430.1A, TSHC). Instruments should monitor for tritium and as necessary for oxygen, moisture, and temperature (TSHC).

9. Loss of ventilation alarms shall be provided in process areas that use radioactive materials (6430.1A). When large walk-in or reach-in hoods are opened in tritium areas, air flow through the opening should be measured with an anemometer to verify the rate (Reinig).

\subsection{PIPING SYSTEMS}

1. Process subsystems shall be arranged to minimize tees, elbows, dead legs, low points, and the length of piping runs (40.35, 55.1, RG8.8). If a tee must be used, the flow should be through the run (straight section) of the tee and the branch should be oriented above the run or at least horizontally (RG8.8).

2. It is recommended that gravity be used to ensure proper flow where applicable (55.1, RG8.8).

3. The number of fittings and flow restrictions shall be minimized (RG8.8). 


\subsection{EVACUATION AND RECOVERY}

1. Evacuation of tritium-containing pumps and lines should first be done using metal getter, vane, or metal bellows pumps to preserve the tritium contained in the gas (MLM-3719). To evacuate to lower pressures, a forepump or even a turbomolecular or diffusion pump backed by a forepump should be used (MLM-3719).

2. Tritium vacuum pumps should exhaust to the tritium capture system (MLM-3719). Forepump exhaust recovery may or may not be desirable from an economic and accountability standpoint. Not in the case of capillary sampling pumps, this recovery may be worthwhile, but it is probably not worthwhile for mass spectrometers and their inlet systems (MLM-3719).

\subsection{VENTS, DRAINS, AND PRESSURE RELIEF}

1. Atmospheric tanks and sumps shall be provided with vents routed to a suitable collection point $(40.35,55.6)$. In general, purge and vent connections should be piped into a closed building exhaust ventilation system or to another vent with provisions for monitoring of releases (55.4).

2. Tanks that use compressed gas and contain radioactive wastes or that contain pressurized radioactive gas shall be vented directly to a facility exhausi system that includes suitable filters [40.35, 55.4 ("should"), 55.6] and provision for monitoring of releases (55.4), or to another system capable of containing the discharge (55.4). Pump casings and housings (RG8.8, 55.6), ion exchangers (55.6), filter vessels (55.6), and both the tube and shell sides of heat exchangers (55.4) shall be provided with vent connections to suitable vent and drain systems. Loop seals shall vent to a controlled vent system (55.4).

3. Vent design shall prevent liquids and solids from entering the facility ventilation system (40.35, 55.6); screens, filters, or other features shall be used to collect and retain solids from tank overflows and vents (RG8.8). In particular, a resin trap shall be provided downstream of ion exchangers to trap resins in the event of failure of an internal screen (55.6). Vent connections should be double-valved to reduce leakage (55.4).

4. Drains shall be piped to an appropriate sump (RG8.8, 55.6) or backwash receiving tank (55.6). Tanks shall be provided with overflows routed to a suitable collection point depending on the physical, radiological, and chemical characteristics of the tank contents $(40.35,55.1,55.6)$. Pump casings and housings (RG8.8, 55.6), ion exchangers (55.6), filter vessels (55.6), and both the tube and shell sides of heat exchangers (55.4) shall be provided with drain connections to suitable drain systems.

5. Provisions shall be included for collection and handling of seal leakage (55.6). For gaseous radwaste, valve leakoff connections shall be piped to a sealed collection system or shall be supplied with an external source of clean oil-free gas at a pressure higher than the system pressure (55.4). If dewatering is performed, dewatering filter vessels shall be provided with drain connections to allow for complete drainage (55.1). 
6. In areas containing tritium or into which tritium may leak, special provisions should be made to collect released sprinkler water in holding tanks until the water can be evaluated for possible tritium contamination (MLM-3719). A location should be selected within a Radiological Area for a sump collection pit, and a pump equipped with aboveground piping should be used to move the potentially contaminated water into the holding tanks (MLM-3719).

7. Flow-indicating devices should be installed in the leak-off lines in radioactive drain systems (RCM). In gaseous radwaste systems, tank drain lines shall have provisions to verify that the system is drained without permitting escape of contained gases, unless the drain line is designed to accept the gases (55.4).

8. In gaseous radwaste systems, equipment drains shall be closed (55.4).

9. The use of stack-vented rupture disks, pressure relief valves, seal pots, or bubbler traps shall be considered to prevent overpressurization and subsequent explosive disruption of primary and secondary tritium confinement systems (6430.1A). In particular, thermocouple gauges on storage tanks should have rupture disk protection (MLM-3719).

10. For tritium systems in which the vacuum pump pumps directly on a tank, a pressure switch and automatic valve that will close if a set pressure is exceeded should be used on the pump inlet; an alarm should be included (MLM-3719). Double valves should be considered for major components (MLM-3719).

\subsection{MISCELLANEOUS PROCESS REQUIREMENTS}

1. For transporting samples containing tritium, a transport container or line designed to function as a secondary confinement may be required (MLM-3719). For less qualitative tritium assay, a transport container may be used. For highly qualitative tritium assay, metal capillary tubing to transport gas samples from a tank or line to a mass spectrometer should be considered (MLM-3719) where the typically smaller volume of contamination compared to a portable sample and the capability of direct insertion of the capillary (either into the volume to be sampled or into a connection to an appendage valve on the tank) are important factors. Another method for transporting a sample to an analytical instrument that may be considered for dedicated process operations is a process bypass flow loop that pipes process gas through a gas chromatograph sample loop and returns it to the process stream farther down (MIM-3719). Potential leakage from this method must be taken into account, however (MLM-3719).

2. The location of a central analytical system and common house vacuum systems should be carefully considered (MLM-3719). Any transfer lines that handle gaseous tritium should be as short as possible, must be secondarily contained, and should be located in areas protected from large equipment that could accidentally damage the lines (MLM-3719).

3. Regarding gloveboxes, it is recommended that routine operations be carried out from a remote control panel to limit exposures via gloves (6430.1A). Remote shielding operations 
(i.e., with remote-handling equipment such as remote manipulators) shall be considered where it is anticipated that exposures to hands and forearms would otherwise approach the limits of 5480.11 (6430.1A, HPM).

4. If cooling is required for glovebox systems and equipment for pumps and other heat-generating systems, the cooling water should be in a loop that is isolated from the general plant cooling system and has a limited volume (MLM-3719). Water sensors on the glovebox floor should be provided as necessary to detect leaks and to shut off flow to the glovebox (MLM-3719).

5. Design of processes and systems shall take account of the fact that, while conversion from the elemental form to the oxide form proceeds fairly slowily, it will proceed faster if there is a flame or if there are hot metals (TSHC).

6. Consideration should be given in the design of tritium storage beds to allowing room for the helium that will be generated in the decay of tritium (TSHC)

\subsection{OPERATIONAL AND RELIABILITY REQUIREMENTS}

1. Redundant instrumentation may be required for some cases of component failure (40.35). Adequate redundancy shall be provided (55.4). Controls not normally used but installed for backup of other automatic or remotely-operated equipment may be "local control and manual" (55.1).

2. In rooms that are tritium confinements, room exhaust must continue during a loss of primary power (MLM-3719). All electrical equipment should be designed to go into a safe mode if the power fails (fail-safe). An uninterrruptible power supply may be required for computers (e.g., for tritium accountability), tritium monitors, and other critical systems in the facility (MLM-3719).

3. Capability should be provided to move a fuel assembly (57.1), a control component (57.1), or other hot object manually in the event of equipment malfunction or loss of power, in particular the freezing of a crane.

4. In general, normal operator controls shall be designed for manipulation with gloved hands (57.1). Placement of controls shall be such as to enable the operator to use the controls while observing operations or instruments monitoring the functioning of the equipment controlled (57.1).

5. In a system used for containment atmosphere cooling, electric heating coils are preferred to hot water or steam systems because measures do not have to be taken to prevent corrosion or freezing, because cabling and conduit are preferable (presumably because they are easier to install and modify) to piping and supports, and because maintenance requirements are reduced (56.6).

6. Switches should be installed on the lights in glovebox rcoms to permit dimming of the lights outside the gloveboxes and thus improve viewing for personnel working inside the gloveboxes with the glovebox lights activated (MLM-3719). 
7. The fire hazards of performing operations involving welding, grinding, etc., in tents shall be considered (MLM-3719).

8. Consideration should be given to standardizing filters and using other measures to permit remote removal, installation, and servicing of equipment (RG8.8). Standardized handling equipment should be considered (55.6).

9. The preferred option for treatment of all forms of tritium is capture and recovery (MLM-3719). The following methods of capture and recovery of tritium should be considered (MLM-3719).

a. Converting gas to oxide in a reaction chamber and removing the oxide in a drying bed

b. Adsorbing tritium gas on to a reactive bed such as charcoal, followed by the regeneration of that bed at room or cryogenic temperature

c. Hydriding an active metal surface with tritium and subsequently regenerating or storing the resulting metal

10. Regarding vapor recovery, molecular sieve dryers offer performance and economic advantages over simple chilling condensers and freezer dryers (TSHC). This principle is especially true at low partial pressures or at low relative humidities, where the water capacity of molecular sieves is much higher than that of silica gel or activated alumina; therefore, when drying to low dew points is desired, molecular sieves shall be preferred (TSHC). In general, molecular sieve dryers used for confinements should be optimized for operation at low moisture loadings and exhaust dew points (TSHC).

11. The method generally used (at Sandia, Mound, Princeton, and Los Alamos) for removing (gaseous) tritium from air, that of oxidizing it on precious metal catalysts and then removing the oxide vapor on molecular sieves, shall be considered when appropriate (TSHC). (Note that the TSHC states that such systems are typically designed for a flow rate of around 1000 scfm.)

12. Regeneration of molecular sieve shall be considered (TSHC). 


\section{FUEL AND FUEL POOLS}

This material is in addition to specific criteria in previous sections (e.g., ventilation).

\subsection{POOL AND RELATED SYSTEM DESIGN REQUIREMENTS}

1. The spent fuel pool and its associated cooling system, etc., shall be designed such that pool water is not inadvertently released and is maintained above the top of the stored fuel under all conditions (57.2, which also states that the pool(s) shall be designed for "zero leakage"). In particular, failure of a valve in a transfer tube shall not result in reduction of water shielding to a level that would cause unacceptable exposure rates at the pool surface (57.1). A system shall be provided to detect water loss and maintain the minimum pool water depth (57.2). A permanently installed redundant or emergency spent fuel pool makeup shall be provided, unless it can be shown that the time required to set up and operate a temporarily installed one is less than the time required for the pool to reach boiling temperature with complete loss of cooling or than the time required for the pool water to drop below the minimum cooling depth as a result of other pool water losses (57.2).

2. A stainless steel or other suitable liner shall be used in meeting the "minimum leakage" requirements; the liner surface finish shall be such that accumulation of radioactive material is minimized and decontamination can be readily performed (57.2).

3. The pool water cleanup system shall be such as to ensure the adequate collection of radioactive material from the pool water and to control, retain, and dispose of this material (57.2). Design decontamination factors for pool water shall be maintained for normal conditions or AOO events corresponding to a frequency of greater than $10^{-1} /$ year (57.2). Piping design shall preclude siphoning and freezing for all plant conditions (57.2). Provision shall be made for isolation and flushing of the pool water cleanup system; in particular, filters shall be capable of being either backflushed remotely or removed directly into a shielded container (57.2).

4. Intake and discharge points for the treatment systems should be located so as to provide for enhanced mixing and to avoid stagnation areas in the pool (RG8.8).

5. Pool water overflows and skimmer tanks should be provided (RG8.8).

6. Fluid jet or vacuum-cleaner-type agitators should be considered for reduction of crud settling on surfaces of the pool system (RG8.8).

7. Sealed bearings or provisions for waterproofing shall be utilized to prevent contamination of components and pool water (57.1). Where cavities are unavoidable, parts should be designed to be disassembled to facilitate decontamination (57.1).

8. Spent fuel handling area(s) shall be provided with controlled sumps and drains interfacing with the radwaste system (57.2). 


\subsection{FUEL-HANDLING EQUIPMENT, CONTROLS, RACKS, AND CASKS}

1. Construction of fuel-associated equipment and structures shall be such that it will not be possible to place fuel elements closer to one another than the minimum specified separation $(57.1,57.2)$.

2. Equipment shall be designed to permit removal and replacement or repair of all functional components, including underwater components (57.1). Active components [such as air motors, power cylinders, hydraulic cylinders, limit switches (including their electrical leads), and position measuring devices] of elevators, fuel transfer carriages and upenders, tools, etc., that are underwater shall be removable and reinstallable without requiring the water level to be lowered below that necessary to maintain minimum shielding and cooling capability, unless they are located in an area of a pool that can be isolated by valves or gates (57.1; 57.2 includes all underwater components in this requirement).

Also, provisions should be made for mounting equipment such as TV cameras, boroscopes, and radiation monitors on the fuel-handling machine and the refueling machine (57.1); if remote viewing apparatus is attached to fuel-handling machines (elevators, fuel transfer carriages and upenders, tools, etc., that are underwater), the apparatus and its associated lights shall be removable and reinstallable without requiring the water level to be lowered (57.1). The carriage or basket used to raise and lower fuel assemblies shall be removable from the elevator rails without requiring the removal of the entire elevator assembly from the pool (57.1); the carriage inspection fixtures should be remotely removable from the base without requiring the removal of the fuel-preparation machine assembly from the pool or requiring the pool water level to be lowered below that necessary to maintain minimum shielding and cooling capability, unless these fixtures are located in an area that can be isolated by valves or gates (57.1).

3. Drive cables and chains for fuel-handling machines shall be accessible and maintainable (57.1). Drive motors for fuel-handling systems shall be accessible for routine maintenance without equipment removal (57.1), if possible.

4. Control panels should be located to afford the operator a full view of the upender (if any) he is operating (57.1). Fuel transfer control mechanism control stations should be located at both ends of the fuel transfer system travel (57.1).

5. Controls, interlocks, or other features shall be provided to minimize the potential for dropping or jamming fuel assemblies or control components during all handling operations (57.1). Fuel upender(s) (if any) and refueling-machine controls shall be interlocked to ensure proper equipment position during each phase of fuel assembly transfer operations to prevent damage to the fuel assembly (57.1).

6. Provision should be made to permit withdrawal of the fuel transfer carriage with auxiliary equipment such as an overhead crane in the event it becornes jammed in the transfer tube (or analogous feature) or if it cannot be moved by the normal method (57.1).The transfer tube assembly (if applicable) and associated appurtenances shall be designed to ensure the capability to remove a fuel assembly following a design-basis seismic event ("safe-shutdown earthquake") (57.1). 
7. Bridge travel should be automatically annunciated (57.1).

8. If applicable, means should be provided to handle parts of the transfer tube assembly required to be disassembled for operation, maintenance, and inspection (e.g., the use of a davit for handling the blind flange) (57.1).

9. Parts of the transfer tube assembly (if applicable) required to be disassembled for operation, maintenance, and inspection shall have associated access openings and test connections (57.1). If a blind flange is used on the transfer tube assembly, the seals should be replaceable (57.1). Provisions shall be made for either removal or in-place maintenance of the valve(s) of the transfer tube assembly (57.1). Devices used to indicate the position of the transfer tube assembly valve(s) shall be removable and reinstallable without requiring the water level to be lowered (57.1).

10. All surfaces contacting fuel assemblies, shall be free of all burrs, sharp corners, edges, and weld beads or splatter that could mar or damage a fuel element, and there shall be no projections of rivets or bolt heads into the interior of the fuel cell $(57.2,57.3)$. Handling tools shall be free of all burrs, sharp corners, edges and weld beads that could damage fuel assembly or control component surfaces (57.1).

11. Handling tools used underwater shall be vented to permit filling with water and draining; buoyancy chambers may be used if adequate shielding is provided (57.1).

12. Handling tools to be used in or over a pool should have provisions for attaching a safety line (57.1).

13. The arrangement and design of the storage racks in the pool shall be such as to facilitate natural circulation cooling of the stored fuel in the event of a loss of forced cooling (57.2).

14. Provision may be made for storage of defective fuel elements in canisters or other suitable containers (57.2).

15. Provisions shall be made for the receipt, inspection, monitoring, decontamination, venting, flushing, moving, and loading of casks that are received at or are to be shipped from the facility under normal conditions (57.2).

16. If there is a cask-handling facility, it shall be designed to allow receipt of a cask that is on a transportation vehicle; cleaning of the exterior; radiation and contamination monitoring; inspection; and venting (57.2). This requirement includes a cask decontamination area and laydown space for removed and possibly contaminated parts (57.2). The cask coolant flush system should have the capability of monitoring for the presence of radioactive contaminants (57.2). The cask coolant flush system, cask decontamination fluids, and any other potentially contaminated flush or spray liquids associated with cask handling shall drain to a radioactive liquid waste system (57.2).

17. Casks shall not be moved so as to pass over or affect stored fuel directly or indirectly, in any plant condition (57.2). Electrical or mechanical controls shall be provided to limit the height to which the cask can be raised (57.2). 


\subsection{LOOSE PARTS CONTROL}

1. Parts that are removed from fuel-handling systems to perform normal maintenance and operations, such as access covers and handwheels, or that could fall into the reactor vessel or spent fuel pools shall be attached with suitable retaining devices (57.1). Suitable fastener locking devices (such as tack welds, bent metal tabs, or lock wires) shall be used to prevent parts from falling from equipment (57.1).

2. All handling equipment above or adjacent to pools, canals, or cavities and having electrical hardware using screw-tightened wiring connections shall use nonremovable screws to permit safe disconnection required for module replacement or other maintenance operations (57.1). Cotter pins, lockwashers, and spring-type pins shall not be used where there is a potential for their falling into a fuel assembly (57.1), cooling channel, etc.

3. Underwater lights shall be completely enclosed to prevent foreign material from falling into the pool (57.1).

\subsection{MISCELLANEOUS}

1. For new fuel, if dry storage is used, a drainage system sized to accommodate the maximum flow from rupture of the largest water-carrying pipe in the area shall be provided to prevent accumulation of water or other neutron-moderating media (57.3).

2. It shall be possible to observe fuel identifiers clearly while the fuel is in its stored position, for normal conditions or AOO events corresponding to a frequency of greater than $10^{-1} / y e a r$ (57.2).

3. Fuel-handling communications shall operate on a channel different from the remainder of the facility to minimize or preclude interference with the fuel-handling operation (57.1). 


\section{RADWASTE HANDLING AND STORAGE}

Radwaste handling as covered here does not include effluent (discharge) control, which is covered in Sects. 2.2 and 2.3 above; venting and cleanup aspects of gaseous radwaste systems, which are covered in Sect. 5.3; or specifics of sampling lines and equipment and monitoring, which are given in Sect. 14. (It is assumed that the ANS will not have a fluid bed dryer/incinerator, extruder-evaporator, or thin-film systems, such as are referred to in 55.1.)

\subsection{GENERAL REQUIREMENTS}

1. The design of special facilities (e.g., the detritiation plant, hot cells) shall include adequate provision for the safe collection, packaging, inventory, and loading for transport of solid waste that is contaminated with radioactive material (6430.1A). The same shall be assumed to apply to reactor facilities.

2. A waste minimization program shall be in effect (RCM); radwaste shall be handled on a current basis and shall not be allowed to accumulate excessively (HPM). Waste reduction efforts shall be based on techniques such as process modification, process optimization, materials substitution, and decontamination (5820.2A). In particular, DOE low-level waste shall be managed using the most appropriate combination of waste generation reduction, segregation, treatment, and disposal practices (5820.2A).

3. Nonradioactive solid waste and radioactive solid waste shall be kept segregated as they are generated. Hazardous waste shall be segregated from both radioactive and nonhazardous wastes. In addition, mixed waste shall be kept segregated from radioactive waste and hazardous waste (RCM, 6430.1A, HPM). Regarding temporary storage at the generating site, transuranic waste in storage shall be segregated or otherwise clearly identified to avoid the commingling of transuranic (TRU) waste streams with other low-level waste (5820.2A).

4. The design and operating requirements for radioactive waste treatment and handling (high-level, low-level, and TRU waste) found in DOE 5820.2A shall apply (RCM, 6430.1A). Wastes should be characterized by activity, half-life, and chemical toxicity (5480.30). Any material that is known to be or suspected of being contaminated with transuranium radionuclides shall be categorized as soon as possible in the generating process as recoverable material, transuranic waste, low-level waste, mixed waste, or nonradioactive trash; however, the determination as to whether the waste exhibits any hazardous characteristics may be based on knowledge of the waste-generating process when obtaining a sample and performing a chemical analysis would significantly increase the radiation hazard to personnel (5820.2A). Transuranic waste shall be evaluated to determine the kinds and quantities of transuranic radionuclides present prior to storage; additionally, hazardous waste components shall be estimated or analyzed, whichever is appropriate (5820.2A). Mixed transuranic waste shall be treated, where feasible and practical, to destroy the hazardous waste component (5820.2A).

5. Generators of waste shall assure that the waste-acceptance criteria for any low-level waste treatment, storage, or disposal facility used by the generator are met, including allowed quantities or concentrations; criticality safety requirements; the generation of external radiation 
dose rate levels, internal heat, and gases, vapors, and liquids; stability of waste packages with respect to radiation damage effects; and restrictions on chelating and complexing agents that may mobilize radionuclides $(5820.2 \mathrm{~A})$.

6. Engineering judgment and health physics judgment shall be used to govern the handling, packaging, volume reduction, encapsulation, and packaging of special dry radioactive components (e.g., large contaminated core components, activated charcoal, HEPA filters, and discarded equipment components) arising from maintenance and refueling operations (55.1).

7. Special consideration shall be given to the handling of wastes that may be contaminated with tritium, such as materials used to absorb liquid tritium waste and molecular sieve material (HPM). The potential pressure buildup because of radiolysis in sealed containers of tritium-contaminated waste shall be considered in the design of these canisters, waste storage areas, and waste-handling equipment (HPM).

8. Consideration should be given to centralizing system instrurnentation and controls where feasible to facilitate ease of control and observation of the system $(55.1,55.4,55.6)$. Some controls, such as container smearing and sample system controls, may be located at local control stations (55.1). Remote manual switches with status lights shall be provided on all frequently actuated valves and components $(55.4,55.6)$. Where automatic control of components is provided, manual override capability shall be provided where necessary to maintain system operability $(55.4,55.6)$. Gaseous and liquid radwaste processing systems shall have sufficient instrumentation and controls that they can be started, operated, monitored, and shut down from remote control areas $(55.4,55.6)$. Automatic waste feed cutoff should be considered (40.35).

\subsection{GASEOUS AND LIQUID RADWASTE, SLURRY, AND SOLIDIFICATION}

1. Pressurized gas storage tank systems shall have the means to transfer gas from one tank to another (55.4).

2. Equipment, waste routing, and spare storage volume shall be installed and available to transfer the contents of one tank to another if a tank shows indications of excessive leakage or other conditions that warrant taking the tank out of service (6430.1A). The capability shall exist to transfer liquid waste leaked from a secondary confinement structure to a suitable storage location (6430.1A).

3. Process tanks shall be oversized by an adequate amount to accommodate the maximum single batch input with an additional $20 \%$ safety factor and $10 \%$ fieeboard allowed; monitoring tanks shall be oversized by $10 \%$ freeboard $(55.4,55.6)$. The minimum spare storage tank volume shall exceed the maximum liquid content of any one normal storage tank (6430.1A).

4. Consideration should be given to the significant quantities of seal water that may enter the waste processing stream if a seal fails (55.1).

5. Evaporation (where applicable) may be preceded by filtration to minimize the deposition of particulate matter on evaporator components, such as sensory elements and heat exchanger 
surfaces (55.6). If discharged to the environment, waste shall be routed to a monitor tank for batch analysis prior to discharge (55.6).

6. Adequate meters and interlocks shall be provided to prevent overfilling of waste containers (55.1). There shall be no bypasses or drains in the liquid waste system by which waste may be released directly to the environment inadvertently (6430.1A).

7. 55.6 gives the following as liquid radwaste system input guidelines applicable to personnel decontamination in power plants; these should be used with caution in the design of ANS. This effluent is normally monitored and discharged without treatment (55.6).

a. Decontamination hot shower

Typical maximum per shower: 20 gal (75 l)

Maximum per day during shutdown: $400 \mathrm{gal}$ (1500 l)

Total (for a typical outage, apparently): 1200 gal (4500 1)

b. Decontamination hand wash

Typical maximum per wash: 1 gal (4 l)

Maximum per day during shutdown: 1500 gal (5700 1)

Maximum total per year (per typical outage): $45,000 \mathrm{gal}(170,000 \mathrm{l})$

8. For slurry or high-concentrates service, pump motors should be equipped with ammeters and high-current alarms where appropriate to detect abnormal slurry densities or partially plugged pipes indirectly $(40.35,55.1)$. Automatic pump shutoff on indications of source tank low level, loss of suction pressure, and receiving tank high level should be considered $(40.35,55.1)$.

9. All precoat and backflush operations should be designed to be automatic following manual initiation of each of these operations (55.1).

10. Radioactive liquid waste that cannot be discharged shall be solidified and disposed of as solid radioactive waste (RCM, 55.1). DOE 6430.1A states that volume reduction and waste solidification of liquid wastes shall be used "to the extent practical." Secondary waste streams from volume reduction should be eliminated or reduced to the extent practical (40.35).

12. Valves that are in routine service for solid radwaste handling (solidification) and volume reduction should be remotely operated from a control panel $(40.35,55.1)$. Liquid radwaste valves that in normal operation must change position shall be remotely operated from the control panel (55.6). Other valves may be manually operated with reach rods and position indication, where appropriate $(40.35,55.1)$. The need for lubrication, inspection, maintenance, etc., that can be the source of additional exposures associated with remote operators, reach rods, and indicators must be taken into account (RG8.8).

13. Appropriate valve position-indicating devices shall be used for all remote power-operated valves and shall be located on the control panel $(40.35,55.6)$, except potentially for valves in low-activity posttreatment sections of the system (55.6); control indication should be initiated by a valve-mounted position transmitter (40.35).

14. The operator shall be able to view remotely mixing and packaging, filling and capping, and container-handling operations (55.1). Filled radwaste containers shall be capped remotely 
(55.1). The container-handling system shall have the capability to be operated remotely when the container enters the shielded location of the fill station (55.1). The remote handling system shall be capable of moving the container after filling to a radiological monitoring and smear survey station and to the decontamination area if necessary (55.1).

15. The following methods of solidification of tritium should be considered: converting liquid tritium oxide into a stable waste form by solidification with concrete or other agents or hydriding an active metal surface with tritium and subsequently disposing of the resulting solid waste (MLM-3719). If shredding or other volume-reduction techniques are used to process tritiated waste, applying a surface coating to the material to help fix tritium that may be on or near the surface during reduction should be considered (MLM-3719).

16. Ventilation air dryers should be used to remove tritiated water vapor from the air (in radwaste processing areas) to reduce the amount of tritiated moisture in miscellaneous solid radwaste (TSHC). Dewatering ion exchange resins and spent filter cartridges should be done to reduce the amount of tritiated moisture in them (TSHC).

\subsection{SOLID RADWASTE HANDLING AND STORAGE REQUIREMENTS}

1. Volume reduction of solid waste shall be practiced where feasible (6430.1A, 5820.2A, $5480.30,55.1)$.

2. Low-range, low-level radwaste is to be segregated by the generator into compactible (paper, plastic, cloth, etc.) and noncompactible (metal, wood, concrete, etc.) segments (HPM). Compactible waste should be collected and stored dry in cans or drums lined with plastic bags; noncompactible waste should be drummed or boxed after it has been decontaminated as well as is feasible (HPM).

3. High-range and very-high-range low-level (solid) radwaste is to be packaged by the generator (HPM).

4. TRU wastes shall normally be packaged (sealed) and stored in stainless steel drums if the beta-gamma radiation level at the surface of the package is $\leq 200 \mathrm{mrem} / \mathrm{h}$, or in concrete casks or metal boxes if it is $>200 \mathrm{mrem} / \mathrm{h}$ (HPM).

\subsection{RADWASTE CONTAINER STORAGE AND HANDLING}

1. Appropriate shielded storage area(s) shall be provided for solidified waste and for compacted, dry solid waste (55.1). High-radiation waste storage area(s) shall have remote visual monitoring (55.1).

2. Provisions shall be made to enable radiation monitoring and smear surveying of radwaste containers prior to storage and loading on a truck (55.1).

3. The container-handling system shall have the capability to remove the shield cask cover and to load a shield cask located on a vehicle remotely (55.1). The system shall also be capable of 
loading low-level containers on an unshielded vehicle (55.1). If a shielded filter transfer vehicle is used, its mechanism shall be capable of transferring the disposable filter assembly into the vehicle remotely without direct visual monitoring, if the radiation level warrants this procedure (55.1).

4. High-range waste is to be transferred in lead-lined pans (similar to dumpsters); very-high-range waste is to be transferred in bottom-discharge carriers (HPM). When a reusable transfer carrier is used, an inner container is required (HPM). 


\section{CONTAMINATION CONTROL, DECONTAMINATION, AND DECOMMISSIONING}

\subsection{CONTAMINATION CONTROL}

See Sects. 3.2 and 4.2 for the definitions of the various radiological areas. "Contamination" is defined for skin and personal clothing in the DOE-ORO Order Contamination Control Policy (DOE-ORO CCP), Attachment 2.

1. Workplace surfaces outside Radiological Areas should be essentially free of contamination. At a minimum, removable and fixed contamination should not exceed the respective levels given as the RCM limits (10CFR835, RCM, 5480.11). Workplace surfaces inside Radiological Areas should be essentially free of contamination or must be posted and controlled as given in 10 CFR 835 and the RCM.

2. Engineered controls shall be preferred to administrative methods for the prevention and control of surface contamination (10 CFR 835, RCM, 5480.11, HPM).

3. Material and equipment in areas of potential surface or air contamination shall be treated as radioactive material and shall be controlled as such unless surveys show that contamination levels do not exceed the levels specified as the RCM limits (RCM). Under well-controlled conditions, materials and equipment exceeding the total or removable contamination levels specified as the RCM limits may be moved from one Radiological Area to another or to a location in the Controlled Area that is not a Radiological Area; storage of such items in any area must be such that the items are contained and identifiable as contaminated items (10 CFR 835, RCM).

4. In general, however, uncontaminated equipment and supplies and nonessential personal items shall not be stored in RBAs or contamination areas (RCM, HPM). Uncontaminated wastes, tools, work materials, supplies, and equipment shall not be combined with contaminated wastes, tools, materials, and equipment (RCM, HPM).

5. Consideration should be given to keeping contaminated special or frequently used tools and equipment in designated contaminated tool cribs (RCM, MLM-3719, Reinig). This recommendation includes tools that may be stored in a glovebox for use in maintaining components in the glovebox (MLM-3719).

6. Tobacco and food service vending machines, food storage, eating, smoking, tobacco chewing, and drinking are prohibited in Radiological Areas (RCM), with the exception of drinking fountains in RBAs and possibly in Contamination Areas. Locating office space in Radiological Areas (except RBAs) is discouraged (RCM); when this is necessary, occupancy should be minimized.

7. Persons entering RBAs, contamination areas, and Airborne Radioactivity Areas shall be provided with special instrumentation, protective equipment, and radiation protection 
surveillance as required (RCM, 5480.11, HPM). In particular, the following shall be provided (RCM, 5480.11).

a. Protective clothing (PCs) and respiratory protection shall be provided as necessary (10CFR835, RCM). PCs shall be worn only in contaminated and designated RBAs (including Airborne Radioactivity Areas, when required); they must be removed when exiting such an area (RCM, HPM).

b. Access control points at Contamination Areas shall be provided with a step-off pad area(s), a contaminated waste barrel(s) or the like, and a shoe or shoe cover exchange area, as applicable (RCM, 5480.11, HPM). Containers for used protective clothing should be adjacent to the step-off pad and should be clearly labeled to indicate what type of personal protective clothing is to be deposited (HPM, IGG1).

8. All persons shall have their clothing and bodies monitored for possible radioactive contamination upon exiting a (contamination-based) RBA, contamination area, or Airborne Radioactivity Area (10CFR835, RCM, 5480.11, 6430.1A, HPM); an exception is made in the case of areas containing radionuclides undetectable by frisking, such as tritium (RCM). (However, note that tritium-detecting friskers are starting to come onto the market and that these may eventually be required for the ANS.)

9. Personnel monitoring instruments shall be placed as close as possible to the exit of those areas requiring frisking (5480.11, RCM). If friskers cannot be placed at the exit because of high background, space, or other limitations, a sign shall be placed there informing personnel of the location of the nearest frisking station (5480.11, RCM). Frisking shall be performed in a background less than 300 counts per minute beta-gamma in order to achieve the sensitivity required to detect the (direct-reading) limits of the HPM, Appendix A. If background count rates below 300 counts per minute cannot be maintained at the desired monitoring location, frisking for gross contamination shall be performed and a final frisk shall be performed at a more remote location with acceptable background levels (HPM). Protective clothing, however, should still be removed at the exit to the work area (RCM). Hand-and-foot counters may be provided, where permitted, in addition to or instead of friskers.

10. Hoses, cords, and other equipment that cross from the Controlled or Radiological Buffer Area into a contamination area or Airborne Radioactivity Area should be marked as radioactive material and secured (RCM, HPM, IGG1).

11. Tools or equipment being removed from a contamination area or Airborne Radioactivity Area should be monitored for release or for retention in a contaminated-tool crib (10CFR835, RCM).

12. Solid barriers should be used to enclose contamination areas and Airborne Radioactivity Areas whenever possible (RCM). Containment devices such as glovebags, gloveboxes, and tents are also to be used where appropriate (RCM, RG8.8). Consideration should be given to doing work on some components underwater using diving techniques in order to contain radioactivity (RG8.8).

13. Measures that shall be considered for use to minimize the spread of contamination and to facilitate decontamination in the event that spillage or leakage occurs include appropriate ventilation (55.1); sumps and other drainage collection provisions $(5480.30,55.1, \mathrm{RG} 8.8)$ that 
direct the liquid to radwaste (5480.30); trenches and curbing (5480.30, 55.1, RG8.8); and floors sloped to local drains (5480.30, RG8.8). In particular, where tritium may be present, operating areas should be sealed at the perimeter walls and should be designed with raised thresholds at doors to contain leakage and sprinkler water and to drain it to appropriate sumps (MLM-3719). Also, to confine liquid spills, confinement rooms where liquid leakage may occur should be provided with a sealed entranceway with a curb and floor drainage going to a collection tank; the drain line should discharge below the minimum water level in the collection tank to ensure a water seal and to prevent moist air from other areas from being drawn into the confinement room (TSHC).

14. The interior finish of walls and ceilings should be smooth, easy to clean, and free of pinholes (MLM-3719). Inner surfaces of equipment should be smooth and as free of cracks, crevices, etc., as possible $(5480.30,40.35)$. Coatings and surface treatments that resist the incorporation of contamination, allow the drainage of liquids from them, or withstand any chemical solutions that might be leaked from equipment or used to decontaminate them shall be considered for the interiors of processing equipment and other potentially contaminated surfaces (5480.30, 55.1, RG8.8). Concrete block with fillers and epoxy paint should be considered for use in tritium (MLM-3719) and other areas. Continuous vinyl flooring is preferable in areas where tritium-contaminated liquids (water or oils) may be handled, but vinyl floor tile may be considered for appropriate areas (MLM-3719). Floor design should allow for frequent mopping and waxing of floors in areas with a potential for high contamination, because this method provides better control than shoe covers (MLM-3719).

15. The provision of laminar flow and smooth surfaces for the primary coolant and measures to minimize crud traps in the primary system shall be considered for the reduction of deposition of crud (RG8.8).

16. Perimeter cable trays and electrical ducts within operating or laboratory rooms should be considered as one method of routing and protecting wires and cables (MLM-3719).

\subsection{DECONTAMINATION}

1. Detectable contamination on personnel or their property shall be removed promptly by appropriate decontamination methods (RCM, 5480.11, RPM, THSC). In particular, personnel should change out of contaminated clothing and shower immediately if wetted by tritiated water (TSHC). Provisions for personnel decontamination must be made (5480.30). A decontamination area with showers, basins, and installed frisker equipment shall be considered; it should be located and designed to expedite rapid cleanup of personnel and should generally not be used as a multiple-purpose area. Personnel decontamination areas should be provided with proper cleaning, HVAC, drainage, shielding, and access provisions (5480.30). Services (breathing air, service air, electrical connections, etc.) should be provided as appropriate in all decontamination areas for anticipated future use (5480.30).

2. Consideration should be given to the necessity for decontamination: as pointed out in the TSHC, decontamination of, for example, many tritium-contaminated surfaces should be performed only where it will actually reduce exposures. Removal methods such as bathing in hot steam, washing with water and acid solutions, and flushing with moist air are 
"time-consuming and generate large amounts of low-level radioactive waste," so consideration should be given to whether it may be more cost-effective to discard and replace (TSHC). Contaminated materials that require only short-term handling at ambient temperature may require only surface decontamination (because bulk-to-surface diffusion in metals at room temperature is slow) (TSHC).

3. Consideration should be given to the timing of decontamination: as pointed out in the TSHC, spills should be identified and cleaned up promptly, and provisions for appropriate equipment and procedures for prompt cleanups must be in place if the cleanup is to be the most effective at eliminating the contamination.

4. Facilities and equipment to clean, repair, and decontaminate personnel protective equipment, monitoring instruments, hand tools, electromechanical parts, or other material should be provided (RG8.8). Dedicated decontamination areas with proper cleaning, HVAC, drainage, shielding, and access provisions and with sinks, workbench space, and decontamination supplies should be provided as appropriate (5480.30), where local decontamination is not feasible. Provision of one or more fumehoods for decontamination of tritium-contaminated items shall be considered; such fumehoods should be supplied with water or steam for cleaning (MLM-3719). Gloveboxes for repairing contaminated equipment can be an important feature if expensive contaminated equipment can be repaired and salvaged (MLM-3719). However, tools or other such equipment should not be decontaminated in the area used to clean respiratory equipment (RG8.8).

5. Provisions for cleaning contamination off the surfaces of buildings must be made (5480.30).

6. Provisions shall be made for isolating components and flushing with radioactivity-removing fluid, which may include clean water, a chemical solution, or inert gas, through physical or chemical action periodically and before maintenance or equipment replacement (RG8.8, 55.4, 55.6). Alternatively, mechanical means may be provided in appropriate cases (40.35).

Disassembly shall generally not be necessary to clean equipment surfaces by flushing or chemical treatment (55.1). Radioactivity-containing systems such as volume-reduction systems should be designed with provisions for proper decontamination, e.g., spray nozzles, flushing connections, and accommodations for brushes, plastic tarps, chemically compatible detergents, absorbents, scoops, and solvents (40.35).

7. Where practical, contaminated equipment, clothing, materials, and tools shall be decontaminated for reuse or for disposal as nonradioactive waste to achieve a net reduction in the volume of solid radwaste (RCM, HPM, both in part). Subsets of tools may be dedicated to a contamination area and kept there in order to reduce the potential for contamination of more tools (RCM, HPM).

8. Means for decontamination of the surfaces of containers prior to storage and shipment shall be provided, such as installed spray nozzles (55.1).

9. The eventual fate of decontamination liquids and gases shall be considered (RG8.8). Provisions shall be made to collect these appropriately (5480.30), e.g., for tritium decontamination fumehoods, draining to an appropriate water collection system (MLM-3719). 
10. Methods described in two EPRI studies of decontamination techniques, NP-6433, Source Book for Chemical Decontamination of Nuclear Power Plants, August 1989, and NP-2777, Comparison of Decontamination Techniques for Reactor Coolant System Applications, should be considered (5480.30). (These describe methods of "in-place" and "off-system" decontamination.)

11. The following methods for tritium decontamination shall be considered.

a. For decontamination, water, detergents, and sodium perborate bleach are "moderately effective" for decontaminating tools (Reinig).

b. Metal surfaces can also be decontaminated by heating to $300^{\circ} \mathrm{C}$ for $30 \mathrm{~min}$ and then using a water quench (Reinig). Detergents added to the water enhance the decontamination (Reinig). More commonly, metal surfaces are cleaned using freon or alcohol (Reinig).

c. Kanne monitors can be decontaminated by scrubbing with a detergent and, after rinsing with water, flushing the surfaces with freon (Reinig).

d. Tritium adsorbed onto metal surfaces can be rapidly liberated when the metal is heated whereas water, detergents, and certain solvents are only moderately effective in removing tritium contamination; this property should be considered in the design of decontamination facilities and in the planning of decontamination methods (6430.1A).

e. Acid dissolution of tritium oxide (on and beneath a surface) or exchange with normal water, possibly at an elevated temperature, is also a method to be considered for decontamination (MLM-3719).

f. The use of damp rags or, in cases such as gloveboxes, steam can be effective for decontamination of solid surfaces in tritium areas (MLM-3719).

\subsection{DECOMMISSIONING}

Note that many of the provisions given above for contamination control and decontamination apply also to the case of decommissioning, since many of the decommissioning activities of ANS will involve contaminated objects or areas. The most important of these are repeated below for emphasis.

1. Planning for facility decommissioning shall be initiated during the design phase for new facilities and prior to the termination of operations for existing operational facilities (5480.6, $5480.23,5480.30)$. Facilities in which radioactive materials are utilized shall be designed to simplify decontamination and decommissioning $(5480.30, \mathrm{RG8.8}, 15.10)$, to reduce the overall cost of decommissioning (15.10), and to increase the potential for reuse and recovery (5480.30 says "e.g., as identified in 6430.1A"; 5820.2A).

2. Features and procedures that simplify and facilitate decommissioning shall be identified during the planning and design phase, based upon a proposed decommissioning method or conversion to other use (5480.30). Such planning should anticipate the need for additional data, shielding, decontamination, and site and facility access (15.10). Design-phase engineering studies should verify the feasibility of dismantling and removing contaminated or activated components, systems, and structures (15.10). Facilities, equipment, and valuable materials shall be recovered and reused when practical (5820.2A). 
3. Measures providing for ease of decontamination and for the reduction of contamination potential and contaminated volumes before and during decommissioning shall be considered $(5480.30,15.10)$. Specific measures include localized liquid transfer systems, equipment design that minimizes the accumulation of radioactive materials, fully drainable systems, choices of materials and design that minimize the potential for activation, sealed nonporous insulation, enclosed cable trays (e.g., of solid sheet metal), and minimization of cable trays and motor control centers in contaminated areas (5480.30). In addition, nondrainable cavities in piping and components and inaccessible interstices on welded structures should be minimized (15.10), exposed concrete surfaces should have smooth finish coats and waterproof coatings (5480.30, 15.10), and remote chemical decontamination connections should be provided (15.10). Design of components exposed to neutrons should include materials that minimize the activation of long-lived isotopes; where this is not feasible, alternative designs should explore minimizing the incident neutron flux (15.10).

4. Reduction and facilitation of disassembly and dismantlement during decommissioning shall be considered $(5480.30,15.10)$. This includes such specific measures as bolted steel construction; flanged construction; quick-disconnect components; lifting lugs and anchor points; preplaced concrete core samples and blast holes; removable roofs, panels, and plugs; designs that facilitate the cutting up, dismantlement, removal, and packaging of contaminated items; and minimization of embedment of pipes, ducts, and equipment (5480.30). In addition, adequate cutting and removal space should be planned for and provisions such as sufficient platforms, doors, passageways, cranes, portable hoist supports or rails, lighting, and power supplies (pneumatic and electrical) in potentially high dose rate areas should be allowed for (15.10). For removal of radioactive materials from the facility, adequate equipment hatches and floor loading capacities for heavy packages and casks shall be provided (15.10).

5. Reduction of airbornes and air cleanup volumes before and during decommissioning shall be considered (5480.30). Specific measures include modular separable confinements and the location of exhaust air cleanup components as near to the ventilated area as possible (5480.30).

6. Specific measures shall be considered for the reduction of dose during decommissioning. These include the provision of appropriate radiation shielcling (15.10).

7. Consideration should be given to provision of services and equipment that could be used during decommissioning, such as a breathing air supply system, space for a tank to receive decommissioning waste liquids, tracks and supports for segmentation cutting devices, flushing and drying capability for contaminated systems, and so forth (5480.30).

8. NUREG/CR-3587, Identification and Evaluation of Facilitation Techniques for Decommissioning Light Water Power Reactors should be consulted for guidance in how to facilitate and optimize decommissioning (5480.30).

9. The DOE 5480.30 (p. 20 of its Attachment 3) statement that "The installation of a canal gate in the refueling canal would allow for parallel cutting of the reactor vessel and internals, resulting in a reduction in segmentation time and thus in exposure" (during decommissioning) should be considered, if applicable. 


\section{MONITORING AND SAMPLING}

Releases to the environment are covered in Sect. 2.

\subsection{GENERAL REQUIREMENTS FOR MONITORING}

Items here from $10 \mathrm{CFR} 50$ are those that apply to radiation-monitoring instrumentation, although they may apply to other monitoring instrumentation as well.

1. Instrumentation shall be provided to monitor variables and systems accurately over their anticipated ranges for normal operation, for AOOs, and for accident conditions as appropriate to ensure adequate safety (5480.30; 10CFR50, Appendix A, Criterion 13).

2. The radiation-monitoring system should measure at least the following parameters: reactor coolant reactivity, containment radiation level, off-gas radiation level, effluent radiation level, and process radiation level (10CFR50, Appendix E). Also, means shall be provided for monitoring the reactor containment atmosphere, spaces containing components for recirculation of LOCA fluids, and the facility environs for radioactivity that may be released in the course of normal operations, AOOs, and postulated accidents (5480.30; 10CFR50, Appendix A, Criterion 64). Other general guidance that should be considered is given in 6430.1A; 10 CFR 50, Appendix A, Criterion 24; and Regulatory Guide 1.97 (per 5480.30).

3. Instrumentation that is part of the protection system shall be designed to sense accident conditions and to initiate the operation of systems and components, where appropriate (10CFR50, Appendix A, Criterion 20). The protection system shall be designed to fail in a safe state or into a state demonstrated to be acceptable if conditions such as disconnection of the system and adverse radiation environments are experienced (10CFR50-Criterion 23). In process areas where activities will continue during a power outage, emergency power supplies shall be provided for alarm systems, or the activities shall be continuously monitored with portable instruments (8.3).

4. Instruments and alarms that may serve to minimize or preclude exposures outside the facility shall be provided, as appropriate (many references). In addition to radiation monitors, these should include instruments to measure meteorological parameters for use, with the radiation data, in calculating doses (10CFR50, Appendix E).

5. Where sources other than the one of interest may have a significant effect on a monitor, it shall be shielded as needed, or compensating techniques such as the use of anticoincidence counting shall be used (N42.18). The effects of high-intensity radiation fields of short duration (such as criticality spikes) on monitors not intended to detect them shall be considered (N42.18).

6. If an installed monitor is removed from service, a radiation-monitoring program or system providing at least equal detection capability should be maintained, consistent with the potential for unexpected increases in radiation dose rates (N320). 
7. Monitoring systems shall have means for calibration and operability testing (5480.30); functional testing should be performed preferably without removal from the instrument system (N320).

8. Units of similar function should be as modular as possible (e.g., power supplies, electronic modules, etc.) (N320).

\subsection{GENERAL REQUIREMENTS FOR DETECTORS, READOUTS, AND ALARMS}

1. Detectors shall be selected so as to provide ranges adequate to ensure readout of the highest anticipated radiation levels and to ensure positive readout at the lowest anticipated levels (RG8.8). Detectors shall be located so as to achieve optimum coverage of areas (RG8.8, 8.3). Unwanted shielding of the detector by equipment or structural components shall be considered and minimized (8.3).

2. A central monitoring system should be provided that has neadout capability at the main radiation protection access control point or other designated monitoring center (5480.30, MLM-3719, RG8.8) or in the main control room (5480.30, 55.4, 6.8.1, N320), or both (55.4), as appropriate. Local readout and alarm(s) shall be provided for the facility or area covered by the associated detector as well as in control or monitoring rooms outside, where applicable (5480.30, 6430.1A, IGE2, RG8.8, 6.8.1, 57.3, N42.18, N320). (MLM-3719 mentions a "counting monitor room" but not local readout.)

3. Monitors shall have clear and unambiguous readout, the capability to record the readout of all systems, and circuitry that indicates component failure (RG8.8).

4. Visual as well as audible alarms shall be provided when appropriate (6430.1A, IGE2, 6.8.1, N42.18), for example when background noise may be high (IGE2, 8.3). Visual and audible alarms should be distinctive so as not to be confused with other visual and audible alarms (IGE2). Alarms shall not reset without positive operator action (acknowledgement) (6.8.1, N320). If the audible signal is not acknowledged, in general, decrease of the detection signal below the trip setting shall not reset the visual alarm (N320); local audible bypass or reset switches shall not affect visual indications (6.8.1, N320).

5. Alarm panels shall be accessible after a DBA as necessary to evaluate "internal (facility) conditions" (5480.30).

\subsection{REQUIREMENTS FOR OCCUPATIONAL AIR MONITORING AND SAMPLING}

The statements below apply only to occupational air monitors and sampling for normal operation and AOOs; this category does not include effluent and accident (and postaccident) monitoring and sampling, although some monitors and sampling devices covered here may also serve during an accident. 
1. For the control of airbornes, the Derived Air Concentration (DAC) values given in Appendix A of 10 CFR 835 are to be used (note that similar tables appear in 10 CFR 20 and in Attachment 1 of 5480.11).

2. In general, air-monitoring equipment, including air monitors and portable and fixed air samplers, should be used in situations where airborne radioactivity levels can fluctuate and early detection of airbornes could minimize inhalation (RCM; TSHC, in general). Ambient air monitoring shall be performed in occupied areas, where, under typical conditions, an individual is likely to receive an annual intake of $2 \%$ or more of the annual limit of intake (ALI) values (i.e., 40 DAC-hours) (10CFR835; 10CFR20 says "10\% of the ALI"); 100 mrem committed effective dose equivalent (CEDE) (RCM) (the RCM uses the term "air sampling" rather than "air monitoring" and 5480.11 gives " $10 \%$ of any DAC value"); or whenever respiratory protective equipment is used to limit intakes (RG8.25). The need for air monitoring should be evaluated if unsealed or loose radioactive materials are processed or handled in quantities that during a year will total more than 10,000 times the ALI for inhalation (RG8.25).

3. The level of radioactive material in confinement exhaust systems shall be continuously monitored (6430.1A). Alarms shall be provided that will annunciate in the event that activity levels above specified limits are detected in the exhaust stream (6430.1A).

4. Real-time air monitoring using continuous air monitors shall also be performed in normally occupied areas where an individual is likely to be exposed to a concentration of airborne radioactivity exceeding $1 \mathrm{DAC}$ or where potentially exposed individuals need to be alerted to unexpected increases in airborne radioactivity levels (10CFR835, RCM) and in situations in which there is a potential for accidents to cause intakes exceeding 40 DAC-hours in a day (RG8.25). (However, continuous breathing-zone air monitoring should be performed in areas where workers are likely to exceed 40 DAC-hours in a year, according to IGE2). Such monitors shall have alarm capability (IGE2, RCM) and a backup power source (IGE2).

5. For real-time air monitoring, continuous air monitors shall normally be used (10CFR835, IGE2, RCM, RG8.8) unless high levels of contamination or other factors might prevent them from providing reliable results or unless high-volume air flow rates are needed (IGE2). In such cases, either periodic direct reading of fixed air samples by means of portable survey instruments or periodic grab samples with rapid analysis may be used (IGE2).

6. Air-monitoring systems shall comply with ANSI N13.1 (6430.1A, RG1.97), and air-sampling locations shall meet ACGIH/ASHRAE criteria (6430.1A).

7. Monitors should be capable of measuring 8 DAC-hours (5480.11, HPM) under laboratory conditions (IGE2, RCM). Where it is necessary to alert potentially exposed individuals that immediate action is necessary in order to minimize or terminate inhalation exposures, monitors should have alarm capability and sufficient sensitivity to detect the appropriate release level (10CFR835). Where continuous monitors with automatic alarms are used, the alarm setpoints should be set as low as practical for the work being conducted without causing excessive false alarms (IGE2) (e.g., more than once per quarter) (RG8.25). However, when continuous monitors are used during respirator work, the alarm setpoint can be adjusted to correspond to a point at which the respiratory protection factor might be exceeded (IGE2). 
8. Representative air-monitoring samples shall be taken at work locations (IGE2, RCM, 5480.11); if the worker's job activity will be the main source of airborne radioactive material, the sampling should be done during the activity (RG8.25). Air sampling shall be performed during all (remote) operations that have a potential for generating significant airborne concentrations before personnel are allowed to enter such areas (DOE-ORO CCP). Air sampling shall be performed as necessary during the startup of a new facility or operation and when special maintenance work must be done or when there is a loss of process controls (10CFR835).

Grab samples may be appropriate when operations are conducted on an intermittent basis (RG8.25) and should be used for appropriate temporary or nonroutine situations and as a backup for other types of air sampling in case of equipment failure (IGE2).

9. The following apply to the selection of a location for a fixed-location or portable air sampler (RG8.25, except as noted).

a. Air-sampling heads shall be located to provide a representative sample of potential airborne radioactive material being breathed (RCM, in spirit).

b. For verification of confinement effectiveness or providing warning of elevated concentrations, the sampling point should be located in the airflow pathway near the release point, rather than near the worker's breathing zone (RG8.8, IGE2).

c. For determining worker intakes, a sampling point should be placed at each frequently occupied work location, as close to the breathing zone of the worker as is practicable; the point should be downstream of the source and upstream of the worker. However, for hoods, gloveboxes, and other similar enclosures, air samplers may be installed slightly above head height and in front of the worker, or they may be installed on the enclosure front face, as appropriate.

d. For measuring workplace concentrations (e.g., to determine whether an Airborne Radioactivity Area exists), samplers shall not be located in or near exhaust ducts unless their purpose is to detect leakage from systems that do not leak during normal operation or to make only qualitative measurements of workplace concentrations. (Note that the RCM states that air sampling equipment should be positioned to measure air concentrations to which persons are exposed, or else breathing-air sampling should be done.)

e. Airborne radioactivity monitors used for the purpose of occupational monitoring shall be placed upstream of filters (RG8.8).

10. At least one continuous air monitor shall be located in the spent fuel area (57.2 says "should").

11. Consideration should be given to the following practices of the Savannah River Plant in the selection and placement of Kanne chambers for tritium monitoring (Reinig).

a. Kanne chambers may be used to monitor up to four locations cyclically, using automatic valving to allow each location to be monitored for one minute in each cycle. Manual valves should also provided so that a chamber can monitor a specific location. Recorders and alarms are located at a central station.

b. Kanne chambers on carts may be used as mobile air monitors, especially in the reactor process areas, where there are no stationary Kanne chambers because of the difficulty of covering large areas. However, in the reactor building these must be placed in low-background areas. Because of this latter difficulty (and presumably to reduce the potential for external contamination of a chamber and of a person checking a monitor), long hoses must often run from many work areas to the chambers. 
c. If a $110-\mathrm{V}$ power supply is not available, a portable air sampler must be used for air monitoring (Reinig).

12. Ionization chambers shall be considered for use in tritium monitoring, since these can provide an immediate indication of tritium concentration (TSHC). The response time should be consistent with the desired use (TSHC), especially in leak detection. A second identical but sealed ion chamber for gamma compensation should be used (TSHC). Consideration should be given to providing a molecular sieve cartridge preceding the monitor to take out the oxide form (to discriminate between oxide and elemental forms) and to providing a desiccant for high-humidity situations (TSHC).

13. Bubblers may also be considered for tritium monitoring, with the sample counted by liquid scintillation methods, for appropriate uses, such as an integrating device for counting chronic low levels of tritium (TSHC).

14. All air samplers to be used for quantitative measurements should have a means to determine the volume of air sampled (RG8.25). Checking for leakage of air into such samplers and their associated sampling lines should take place upstream of the flow measurement device (RG8.25). Air inleakage tests should be performed on continuous air monitors when they are calibrated, replaced, or have a seal changed, and ideally also when they are given a monthly or quarterly performance test (IGE2).

15. Continuous air monitoring equipment shall be routinely calibrated and maintained at a frequency of at least once per year (RCM; IGE2 says "real-time air monitors"). An operational check including positive-flow indication, nonzero response to background activity, and internal check sources (or equivalent) should be performed daily (IGE2, RCM). An instrument response check should be performed weekly (IGE2, RCM). Backup battery power for continuous air monitors shall be tested monthly (IGE2).

16. Components of air sampling and monitoring systems should be uniquely identified (IGE2).

17. NUREG-1400, which is essentially an elaboration on the air-sampling requirements of Regulatory Guide 8.25 and 10 CFR 20, should also be consulted regarding good design practices.

\subsection{REQUIREMENTS FOR AREA MONITORING AND “AREA MONITORING DOSIMETERS"}

The statements below apply only to area gamma radiation monitoring during routine operations, including AOOs; as in ANSI/ANS-8.6.1, this category does not include accident (and postaccident) monitoring and instruments used solely for monitoring various facility processes, although some area radiation monitors may also serve as accident monitors. Note that the RCM does not define "area monitoring dosimeters," so it is unclear what is meant by this term.

1. Area monitors appropriate to the source(s) should be placed in suitable locations (RCM, $5480.11,6430.1 \mathrm{~A}, 6.8 .1,57.2)$. Detectors shall be located in those normally accessible areas that require personnel entry or exit, or both, to be monitored or controlled for purposes of 
occupational radiation protection and in areas where changes in conditions (such as operational transients and maintenance activities) can cause significant increases in personnel exposure rate above that expected for the area (RCM, 6.8.1). In addition, detectors shall be placed in remote locations where there is a need for local indication of dose rates prior to personnel entry (RCM). Detectors shall be located so as best to measure the exposure rates in the area on the basis of information required to minimize exposure to personnel (6.8.1).

2. An area radiation monitor located within a High Radiation Area shall have local exposure rate indication and audible and visual alarm(s) and should also have remote exposure rate and audible and visual alarm(s) located so as to allow personnel to ascertain, from a point outside but adjacent to the monitored area, the associated exposure rate(s) (6.8.1).

3. In particular, area radiation monitoring with local and control room indications and alarms shall be provided to cover appropriate fuel-handling system areas $(6.8 .1,57.1,57.2)$, including one on the fuel-handling machine (or ANS equivalent) with audible alarm (57.2, but another location that provides equivalent warning may be considered), and failed fuel elements (57.1). Monitoring of fuel and radioactive waste storage should be guided by ANSI/ANS-57.2 (5480.30).

Other locations that shall be provided with area radiation monitors are the in-core instrument area (or the appropriate ANS analogue), personnel hatch(es) inside containment, the primary sample station area, areas containing HVAC filters serving the containment, and the control room (6.8.1).

Other locations that should be provided with area radiation monitors are significant solid radwaste storage and handling areas, the drumming or radwaste packaging control area, process waste control area(s), the hot machine shop, the hot radiochemistry laboratory, and equipment decontamination areas (6.8.1). All permanently established decontamination areas should be provided with locally alarmed radiation monitors near potentially high radiation level collection devices such as tanks, filters, and demineralizers (5480.30).

4. The response of monitoring channels shall be independent of gamma-ray energies to within $\pm 20 \%$ of the true exposure rate from about $100 \mathrm{keV}$ to $2 \mathrm{MeV}(6.8 .1 ; \mathrm{N} 320$ says $3 \mathrm{MeV}$; RG1.97 says $0.06-3 \mathrm{MeV}$ with a "dose rate response accuracy" within a factor of 2 over the entire range). The response to $\mathrm{N}-16$ gamma rays shall be considered when $\mathrm{N}-16$ may contribute significantly to personnel exposure (in an area) (6.8.1). The range shall be selected based on the anticipated range to be encountered, from the lowest dose rate that should be detected for personnel protection purposes to the highest dose rate under normal operating or AOO conditions. Postaccident area radiation monitors should be capable of measuring gaseous effluent radioactivity with compositions ranging from fresh equilibrium noble gas fission product mixtures to 10-day-old mixtures, within a factor of 2 accuracy (RG1.97).

5. In general, the reading shall be on-scale at all times under normal operating or AOO conditions (6.8.1 gives other options) and the upper end of the scale shall be high enough to ensure an on-scale reading for exposure rates that approach ten times the expected peak exposure rate (6.8.1). However, monitors whose indication may exceed 10 roentgen (R) per hour during routine operation or AOOs need not register exposure rates more than five decades below that for the sole purpose of providing an on-scale reading (6.8.1). Provision of an alert exposure rate alarm shall be considered (6.8.1). 
6. Where an area radiation monitor is incorporated into a safety interlock system, the circuitry shall be such that a failure of the monitor shall prevent either entry into the area or operation of the radiation-producing device (RCM). If an alarm common to more than one channel can be silenced by an acknowledge switch, the alarm circuit shall be designed to realarm if any other channel reaches its alarm setpoint (6.8.1).

7. Area radiation monitors should be calibrated at least annually (RCM, 6.8.1) and after maintenance or component replacement, except for normal battery changes (RCM). Area radiation monitors should be tested at least quarterly (RCM). Backscatter effects and personnel doses shall be taken into account if in-place calibration is to be performed (6.8.1).

8. "Area monitoring dosimeters" shall be used to record and document radiation levels in routinely occupied areas adjacent to areas where actually or potentially significant sources of radiation are present or where operations with or near such sources may take place (RCM).

\subsection{REQUIREMENTS FOR PROCESS AND EFFLUENT MONITORING AND SAMPLING}

The statements below apply only to process and effluent monitoring and sampling during routine operations, including AOOs; as in ANSI N42.18, this category does not include accident (and postaccident) monitoring and sampling, although some process and effluent monitors and sampling devices may also serve during an accident.

1. Process and effluent monitors appropriate to the source(s) should be placed in suitable locations (6430.1A, N42.18); for tritium-handling facilities and other appropriate facilities, these may include components of a surveillance system provided to monitor the integrity of all process piping, tanks, and other primary confinement components (6430.1A). On hot and tritium-handling facilities, all exhaust outlets that may contain radiological contamination shall be provided with two monitoring systems (6430.1A). All hot cell exhaust systems shall have monitors that provide an alarm if the concentration of the hazardous material in the exhaust exceeds specified limits (6430.1A). The fuel storage area effluent shall be continuously monitored (57.2).

2. In general, process and effluent radiation-monitoring devices shall be designed to monitor and record continuously all radioactive liquids released to the environment from the associated system (55.6). Ail normal and potentially significant pathways of releases to the environment shall be monitored (RG1.97, 40.35, 55.6). Sampling and monitoring systems should have the capability to sample or monitor effluents continuously as necessary to ensure that applicable discharge limits are not exceeded (40.35) and to allow detection of conditions requiring corrective or protective actions (6430.1A). Monitoring shall be designed to provide information on radioactivity concentrations (55.4), where appropriate.

3. Design and selection of process and effluent monitors shall consider preferential collection of the sample due to variations in particle sizes, nonuniform mixing, plateout, etc. (N42.18). Sample corrosiveness, sample absorption between the source and the detector, radiation absorption between the source and the detector, and delay time between sampling and measurement shall also be considered (N42.18). Detector contamination shall be considered 
and minimized (N42.18). Humidity in areas of potential airborne tritium should be measured for purposes of evaluating the efficiency of tritium monitoring.

4. Specific sampling requirements and recommendations for radwaste and associated equipment are given as follows. (These do not supersede any generic DOE requirements that may be applicable.)

a. Gaseous radwaste processing system (55.4)

Gaseous waste effluent: analysis required prior to release $(6430.1 \mathrm{~A}, 55.4)$ and monitoring required during a release (55.4)

Gaseous waste effluent: grab sampling and analysis of gaseous waste during release recommended (55.4)

Process gases: grab sampling at appropriate points in the system recommended (55.4)

b. Liquid radwaste processing system (55.6)

Liquid waste effluent: analysis required prior to release (6430.1A, 55.4)

Reactor, radwaste, and auxiliary area sumps: grab sample recommended (55.6)

Process equipment influent and effluent streams: grab sample required (6430.1A, 55.6)

Collection, monitoring, and sampling tanks: grab sample on recirculation piping required (55.6)

c. Solid radwaste processing system (e.g., resins) (55.1)

Liquid slurry (55.1): sampling required, means and frequency not specified because of variations in processing and radionuclide content

d. Volume reduction system(s) (if any) (all from 40.35)

Input stream: grab sample recommended

Gaseous effluent: grab or continuous sample recommended

Final waste form or process residues: grab sample recommended

Waste distillate: grab sample required

Liquid effluent: grab or continuous sample recommended

e. Measurement capability shall be provided to determine the volume and radioactivity of wastes fed to collection tanks (6430.1A).

f. An installed capability should be provided for obtaining containment sump, emergency core-cooling-system pump-room sumps, and other similar auxiliary building sump liquid samples (RG 1.97).

5. Effluent radiation monitors in systems shall automatically terminate release upon a high radiation signal $(55.4,55.6)$.

6. It should be assumed that tritium glovebox cooling loops will likely become contaminated (MLM-3719). The cooling water should thus be monitored periodically (MLM-3719).

7. The annular space in doubly contained tanks containing tritium shall normally be evacuated, monitored, and provided with a leakage alarm (MLM-3719). Leakage monitoring shall be provided to detect leakage into the space between the primary pipe and the secondary confinement (6430.1A); in the case of transfer lines between gloveboxes, the interannular 
space should be monitored for pressure or vacuum inside one glovebox (MLM-3719). Where a vacuum dewar is used as secondary containment for cryogenic processes, the annular space should be evacuated, monitored, and provided with a leakage alarm (MLM-3719). Sensing probes for oxygen and water vapor detection should be placed in the exhaust line of a tritium glovebox to monitor the integrated result of leaks anywhere in the glovebox; care should be taken that these are placed in the exhaust stream, not in a stagnant area of the glovebox (MLM-3719).

8. For real-time measurement of the tritium concentration in a glovebox, an ionization chamber is recommended (MLM-3719). It should be used to switch to a high purge rate in the event that the box reaches a preset level of contamination (MLM-3719).

9. ANSI/ANS 57.2 gives "facility performance requirements" for releases of radioactive materials that are based on 10 CFR 20 release limits; 10 CFR 50, Appendix I "ALARA" guidelines; and 10 CFR 100 dose limits. These limits and guidelines have already been listed in these design criteria, and the requirements involving $10 \mathrm{CFR} 100$ appear to be somewhat arbitrary (e.g., "Provide for isolation and filtration....to limit the potential release of iodine and other radioisotopes to 10 percent of 10 CFR Part 100 limits for [a frequency of $10^{-1}$ to greater than $10^{-2}$ per year]"). Therefore these requirements will not be reiterated here and are not recommended to be included as part of ANS design.

\subsection{ACCIDENT MONITORING AND SAMPLING AND NUCLEAR ACCIDENT DOSIMETRY}

"Accident monitoring" as used here includes monitoring during a DBA and during the postaccident period (at least a month).

Note that ANSI/ANS-4.5 gives three types of variables to be monitored to provide information to the control room operator. These are Type A variables, which provide information to support preplanned manual actions to achieve and maintain shutdown for DBAs; Type B, which provide information to permit assessments associated with the process of performing or maintaining critical safety functions (such as radioactive effluent control); and Type $C$, which provide information to monitor parameters relating to potential breaches of safety barriers, especially the extent to which the parameters may have exceeded design-basis values. The statements below whose references are ANSUANS-4.5 apply to all three types unless otherwise specified.

Regulatory Guide 1.97 mostly follows the guidance of ANSI/ANS-4.5, but differs in the following respects. The definition of Type A variables is given as "those variables to be monitored that provide the primary information required to permit the control room operators to take the specified manually controlled actions for which no automatic control is provided and that are required for safety systems to accomplish their safety function for design-basis accident events." For the purposes of the present document, this definition does not appear to differ significantly from that of ANSI/ANS-4.5. Also, Regulatory Guide 1.97 defines two additional variable types, D and E. Type D variables are those that provide information to indicate the operation of individual safety systems and other systems important to safety (and include no radiological variables, apparently), and Type $E$ are those that must be monitored as required for use in determining the magnitude of the release of radioactive materials and for continuously assessing such releases. As Regulatory Guide 1.97 notes, the five types are not mutually exclusive categories. Regulatory Guide 1.97 attempts to "provide the minimum number of variables that needs to be monitored by control room personnel during and following an accident." 
Regulatory Guide 1.97 is difficult to interpret, compared to ANSI/ANS-4.5; consequently, the references to Regulatory Guide 1.97 may not be as complete as they perhaps should be.

1. To the extent practical, the selected variables for accident monitoring systems shall be those that most directly monitor the function to be performed (RG1.97, 4.5). To the extent practical, the same variables shall be used for accident monitoring as are used for normal facility monitoring (since the operator is most familiar with these) (RG1.97, 4.5). The monitoring variables and system shall be chosen and configured such that measurements shall be adequate to detect the possibility of a gross breach of one or more fission-product barriers (4.5). However, Type $C$ variables chosen shall be only that minimum set needed to monitor adequately fission-product barriers, which shall include fuel cladding, the reactor coolant system pressure boundary, and the primary containment (4.5). A method shall be readily available for estimating the quantity of airborne radioactive material released and may include the use of data from the accident monitoring and sampling system in the environs of the facility (N320).

2. Continuous measurement of airborne noble gas concentrations in the containment shall be performed; monitoring for airborne radiohalogens and particulates need not be continuous, but capability for taking samples and monitoring them for this radioactivity shall be provided (N320). The Type B variables monitored to indicate radioactive effluent control shall include noble gas monitoring at planned facility release points (4.5).

3. Regulatory Guide 1.97 states that "the design envelope for shielding, handling, and analytical purposes should assume 30 minutes of integrated sampling time at sampler design flow, an average concentration of $10^{2} \mu \mathrm{Ci} / \mathrm{cc}$ of radioiodines in gaseous or vapor form, an average concentration of $10^{2} \mu \mathrm{Ci} / \mathrm{cc}$ of particulate radioiodines and particulates other than radioiodines, and an average gamma photon energy of $0.5 \mathrm{MeV}$ per disintegration."

4. Accident monitoring systems should be capable of measurement over a wide spectrum of energies and range of exposure rates (N320). For direct measurement of channeled releases, such as those in a stack, the range capability should be consistent with potential accident release levels including an appropriate margin (N320). High-range monitoring systems are necessary for assessment of effluent radioactive material (N320). For monitoring conditions in the environs of the reactor facility, an air-monitoring and -sampling system shall be provided (N320). Some particulars are given below.

a. The lower detection limit for monitors measuring concentrations of noble gases in containment and in the stack shall be $\leq 10^{-2} \mu \mathrm{Ci} / \mathrm{cm}^{3}$, and the upper detection limit shall be $\geq 10^{4} \mu \mathrm{Ci} / \mathrm{cm}^{3}$ (N320). The lower detection limit for monitors measuring concentrations of radiohalogens in containment shall be $\leq 10^{-3} \mu \mathrm{Ci} / \mathrm{cm}^{3}$, and the upper detection limit shall be $\geq 10^{3} \mu \mathrm{Ci} / \mathrm{cm}^{3}$ (N320). The lower detection limit for monitors measuring concentrations of particulates in containment shall be $\leq 10^{-3} \mu \mathrm{Ci} / \mathrm{cm}^{3}$ and the upper detection limit shall be $\geq 10^{3} \mu \mathrm{Ci} / \mathrm{cm}^{3}(\mathrm{~N} 320)$.

b. The minimum detection limit for monitors measuring the exposure rate within the reactor building shall be $\leq 1 \mathrm{R} / \mathrm{h}$, and the minimum upper detection limit shall be $\geq 10^{6} \mathrm{R} / \mathrm{h}$, both for photons (N320). Where required in other buildings, exposure rate monitors shall have a measurement range of $10^{-1}-10^{4} \mathrm{R} / \mathrm{h}$; integrated exposure monitors shall have a measurement range of $10^{-1}-10^{5} \mathrm{R} / \mathrm{h}(\mathrm{N} 320)$. 
c. Environmental air samplers shall have a (field) range for particulate activity of $10^{-7}-10^{-1} \mu \mathrm{Ci} / \mathrm{cm}^{3}$ gross beta for $100 \mathrm{keV}$ and above and a range for radiohalogen activity of $10^{-8}-10^{-2} \mu \mathrm{Ci} / \mathrm{cm}^{3}$ (N320). Exposure rate monitors shall have a measurement range of $10^{-3}$ to $10^{4} \mathrm{R} / \mathrm{h}(\mathrm{N} 320)$.

d. Although Type $\mathrm{C}$ variables are not mechanistically related to a postulated accident scenario (4.5), the related radiological system parameters should be appropriately chosen so as to cover the items listed in Table 14.1 (or the equivalent for ANS) (4.5, RG 1.97).

e. Type E variables should be appropriately chosen so as to cover the items listed in Table 14.2 (or the equivalent for ANS) (all references in it are to RG 1.97).

5. An accident monitor shall continue to read out and remain full upscale when the dose rate exceeds the maximum limit of its range and shall return to the ambient level within $1 \mathrm{~min}$ (N320). The ranges of accident monitoring should overlap the ranges of appropriate nonaccident monitoring systems by a decade or more (N320; Regulatory Guide 1.97 specifies only an overlap). In the absence of analysis of minimum and maximum requirements for a particular site, it shall be assumed that monitoring components outside containment must function even after a photon exposure of up to $5 \times 10^{5} \mathrm{R}$ for energies between 0.6 and 1.3 $\mathrm{MeV}$ (N320) and that monitoring components inside the containment must function even after a photon exposure of up to $10^{8} \mathrm{R}$ for this energy range (N320).

6. Installed instrumentation system(s) intended to provide accident monitoring shall be provided with remote readout at a location which will be habitable under accident conditions (5480.30, N320). Physical protection of monitoring systems may be necessary (N320).

7. Accident sampling components shall generally be as given in Sect. 14.8 below. In addition, if samples are to be collected at a location remote from the containment, the maintenance of containment integrity and the minimization of sample losses in transit shall be given consideration (N320). If samples are removed from containment, provisions shall be made to do so while minimizing the dose to personnel and the risk of contamination of other areas (N320). In any case, handling and transport capability for samples shall be provided as needed if analysis is not done in place (RG1.97). Sampling provisions for Type C variables shall permit one sample to be taken every $6 \mathrm{~h}$ or less (4.5). Environmental samplers should be located so as not to be unduly influenced by unusual micrometeorological or other conditions (such as the proximity of large buildings) that could result in unrepresentative samples (N320).

8. Portable air samplers for postaccident use inside the facility shall generally be designed for use with a portable survey meter (N320). Portable instrumentation for postaccident use in assessing the type and quantity of radioactive material in areas away from the reactor facility should be provided (N320) at a location in or near the ANS where access is possible during and following an accident. Nonportable instrumentation installed in specially equipped vehicles may be provided also (N320).

9. Instrumentation required to isolate the (primary) containment purge system on a high-radiation signal shall be redundant (56.6). The radiation monitor that generates the isolation signal should have a fast processing time considering the monitor location relative to the isolation valves, the air velocity in the duct, and the valve closure time (56.6). 
10. Regarding tritium releases, room monitors shall be relied on to indicate tritium levels in a room following a release; portable tritium monitors shall also be used when personnel enter a room following a release (MLM-3719).

11. Regarding a fuel-handling accident, ANSI/ANS 57.3 states that provision shall be made for systems to detect and limit the release of radioactivity that may result in exposure of the public and operators; ANSI/ANS-57.2 has a generic requirement for radiation monitors also. (Note that the requirement to limit the release can imply an actuation function for the detector.)

Also, regarding fuel-handling accidents, ANSI/ANS 57.2 gives "facility performance requirements" for releases of radioactive materials that are based on 10 CFR 20 release limits; 10 CFR 50, Appendix I ALARA guidelines; and 10 CFR 100 dose limits. These limits and guidelines have already been listed in these design criteria, and the requirements involving 10 CFR 100 appear to be somewhat arbitrary (e.g., "PC $\mathrm{IV}$ and V faults [corresponding to a frequency of $10^{-2}$ to greater than $10^{-6}$ per year] shall not cause a release of radioactive material that exceeds 25 percent of the Guidelines of 10 CFR 100" and "Provide for isolation and filtration....to limit the potential release of iodine and other radioisotopes to 25 percent of 10 CFR Part 100 limits for [a frequency of $10^{-2}$ to greater than $10^{-6}$ per year]"). Therefore these requirements will not be reiterated here and are not recommended to be included as part of ANS design.

12. Emergency power shall be provided for all monitoring systems required to operate during and following an accident (N320). Instrumentation shall be capable of returning to normal operation after undergoing switching transients (N320).

13. A system of fixed nuclear accident dosimeter units shall be suitably placed in appropriate areas (10CFR835, 5480.11, HPM), considering the nature of the operations performed there, the structural design (including intervening shielding), the accessibility to personnel, and the ease of retrieval after a criticality or other event (5480.11).

\subsection{NUCLEAR CRITICALITY DETECTION}

1. A criticality monitoring and alarm system shall be installed in all locations wherein the quantities of fissionable material may exceed $700 \mathrm{~g}$ of $\mathrm{U}-2.35$ (5480.5; ANSI/ANS-8.3 says "shall be evaluated") and shall be considered for any operation using an inventory of $520 \mathrm{~g}$ of $\mathrm{U}-233,450 \mathrm{~g}$ of Pu-239, or $450 \mathrm{~g}$ of any combination of U-235, U-233, and Pu-239 (8.3) or significant quantities of other fissionable isotopes as per ANSI/ANS-8.15 (8.3). A separate or additional system is not required if the operating instrumentation of facilities such as nuclear reactors meets the (standard) requirements (8.3). A criticality monitoring and alarm system is not required for areas where the maximum foreseeable absorbed dose in free air will not exceed $12 \mathrm{rad}$ (or a maximum yield of $2 \times 10^{19}$ fissions for events outside reactor cores) (8.3). ANSI/ANS-57.3 states that new fuel storage area radiation monitors should "be designed and should function in a manner consistent with ANSI/ANS-8.3-1979," i.e., in a manner consistent with criticality monitors; ANSI/ANS-57.2 states that a criticality monitor may be used to meet the requirement for an area monitor alarming in both the control room and the spent fuel pool area. 
2. A criticality monitoring and alarm system should use detectors capable of detecting a criticality condition that produces an absorbed dose in free air of $20 \mathrm{rad}$ of combined neutron and gamma radiation at an unshielded distance of $2 \mathrm{~m}$ from the fissionable material within $60 \mathrm{~s}$ $(5480.5,8.3)$. The alarm signal shall activate promptly when the dose rate at the detectors equals or exceeds $20 \mathrm{rad} / \mathrm{min}$ at $2 \mathrm{~m}$ from the material, or equivalent; also, the system shall not fail to initiate an alarm when subjected to a radiation field of at least $10 \mathrm{rad} / \mathrm{s}$ and shall produce the signal within $0.5 \mathrm{~s}$ of activation (8.3). It may be assumed for design purposes that the minimum duration of the radiation transient is $1 \mathrm{~ms}(8.3)$.

3. Provisions such as the use of two detectors whose response must be correlated in order to activate the alarm should be made to reduce the possibility of a false criticality alarm ( 5480.5 , 8.3). The alarm trip point should be set high enough to minimize the probability of an alarm from sources other than criticality, at least $10 \mathrm{mrem} / \mathrm{h}$ above normal or operational background at the monitoring point; the trip point may be set in the $\mathrm{rad} / \mathrm{h}$ range as long as the criterion above (Item 2) is met (8.3). Malfunction warnings should not register as the criticality (evacuation) alarm, but should have their own alarm $(5480.5,8.3)$. A means of manual initiation of the evacuation alarm may be provided; manual resets should be provided outside the area to be evacuated (8.3).

4. A means shall be provided to test the response and performance of the criticality system without causing an evacuation (8.3).

5. The criticality system is not required to monitor special nuclear material that is packaged for transport, if there is no other special nuclear material in the area not so packaged, or that is being moved underwater, if the water depth is enough to provide adequate shielding in the event of a criticality (5480.5).

6. Other criticality controls shall be as per ANSI/ANS-8.1-1983 (5480.5).

\subsection{REQUIREMENTS FOR SAMPLING LINES AND COMPONENTS AND FOR SAMPLE HANDLING}

1. All sample line and seal material of construction shall be compatible with the materials handled by the system (40.35). Consideration should also be given to the selection of line material that will minimize the potential loss of radioactivity due to adsorption or plateout onto the line wall (IGE2, RG1.97, RG8.25). In general, sample lines and seals shall be of stainless steel or shall be of or be lined with other appropriate corrosion-resistant material $(40.35,55.1$, 55.6). If samplers are used for collecting airborne particulates, lines should be made of a material not subject to significant charge effects (such as grounded metal) (IGE2, RG8.25); for connecting the sampling line to the sample collector, however, up to several feet of flexible tubing may be used (RG8.25).

2. For liquid and slurry radwaste service, lines shall generally be sized to maintain turbulent flow $(40.35,55.1,55.6)$ with a minimum Reynolds number of 4000 (55.6) and a minimum tubing inner diameter (ID) of $3 / 8$ in. $(0.95 \mathrm{~cm}) \mathrm{ID}(55.1,55.6)$. (ANSI/ANS40.35 states that whenever slurries are sampled, minimum line diameter should be 1 in. $\mathrm{ID}$ up to and through the shielded portion of the sampling station and decreased to a minimum of $3 / 8$ in. after the 
first isolation valve external to the shielded portion). Sample line diameter should be minimized (IGE2).

3. In general, all sample line bends shall have a minimum radius of 5 line diameters (IGE2, $40.35,55.1,55.6)$. Lines shall be routed to be as short and direct as possible consistent with reducing dose to personnel (IGE2, RG8.8, RG8.25, 55.6). Horizontal line runs should be minimized (IGE2).

4. Heat tracing shall be provided for fluid sample lines if the fluid contained therein is likely to solidify at ambient temperatures (40.35). For tritiated water vapor, the temperature of the sample shall be maintained above the dew point (IGE2). The differences between deposition rates of the various iodine species shall be considered (IGE2).

5. Connections of sample lines to process piping shall be via a probe or other method capable of obtaining a representative sample of the stream (RG1.97, 40.35, 55.6). The sampling location shall be chosen so as to provide a representative sample; this will most often be in a well-mixed turbulent zone (RG1.97). Connections to a horizontal pipe shall be made at the side or top $(40.35,55.6)$. Grab sampling connections shall maximize container-port compatibility (RG1.97). Grab sampling connections in high-activity portions of pressurized systems shall be all welded, double valved, and capped to minimize the potential for leakage (55.4).

6. Operation of the sampling lines in a continuously recirculating mode to provide for representative samples should be considered in the design; for this reason, spargers and recirculating lines should be considered for tanks (40.35).

7. The following caveat from MLM-3719 (p. E-17) regarding representative sampling of gases containing tritium shall be taken into account: "Fresh contamination by hydrocarbons will yield higher mass $\mathrm{C}_{n} \mathrm{H}_{2 n+x}$ species until radiolytic decomposition reduces them to methane species. Air leaks first lead to the formation of water vapor as a result of the beta-induced reaction of oxygen with the hydrogen species. Following the conversion of oxygen to water, ammonia begins to form as a result of the beta-induced reaction of nitrogen with the hydrogen species. The condensable impurities, water and ammonia, are not representatively transferred through the capillary lines and thus are typically undermeasured if present in the gas."

8. In general, sample lines should be routed to sample stations to prevent spills and to allow for sufficient purging (40.35). Lines for all frequently taken samples should be routed to a common sample station located for convenience and low dose rate, consistent with obtaining representative samples $(40.35,55.6)$, and shielded as necessary $(40.35)$.

9. Connections shall be provided for flushing or purging before each tritiated material sampling if capillary tubing is used, in order to ensure a representative sample (MLM-3719). Connections shall be provided for flushing or purging after any sampling $(40.35,55.1,55.6)$. For any type of sample, liquid sample return should be to the collector tank of the subsystem being sampled $(40.35,55.1,55.6)$; to another compatible waste system (55.1); to a subsystem of poorer quality water (55.6); or, for slurries, to the source (40.35). Gaseous samples should be returned via a closed pipe system to a monitored vent for release (55.4). 
10. Sample holders, supports, and seals should prevent deformation of the filter, provide a good seal, facilitate changeout of the filter, be easy to decontaminate, and contribute negligibly to pressure drop (IGE2). Seals should be inspected monthly (IGE2).

11. Air movers that compensate for pressure drop should be considered (IGE2). Where applicable, the flow rate should be adjustable at or near the sampling head (IGE2). A reliable air flow measuring device should be installed downstream of the sample collector (IGE2).

12. For air samples taken on filters or equivalent, the penetration of particles with an aerodynamic equivalent diameter of $10 \mu \mathrm{m}$ should be at least $50 \%$ (RG8.25).

13. Means should be provided so that cross-contamination of samples can be avoided and the samples can readily identified, e.g., by being placed in labeled containers (IGE2).

Arrangements should be made for sample storage prior to counting and between counts if multiple counts are required (IGE2).

14. A tracking system for air samples should be established (IGE2). 
Table 14.1. Accident related requirements for monitoring and sampling: Type $\mathrm{C}$ variables

\begin{tabular}{|c|c|c|}
\hline Area & Variable & Required monitoring range \\
\hline Fuel cladding & $\begin{array}{l}\text { In-core breach potentially } \\
\text { resulting in loss of } \geq 1 \% \text { of gap } \\
\text { and plenum activity: gross } \\
\text { gamma, reactor coolant }(4.5)\end{array}$ & $\begin{array}{l}0.5 \times \text { allowable Tech Spec } \\
\text { coolant activity to } 100 \times \text { Tech } \\
\text { Spec activity ( } 4.5, \mathrm{RG} 1.97) \\
0.01-10 \mathrm{mCi} / \mathrm{ml} \text { or TID-14844 } \\
\text { source term (RG } 1.97)\end{array}$ \\
\hline \multirow[t]{2}{*}{$\begin{array}{l}\text { Reactor coolant } \\
\text { pressure boundary }\end{array}$} & $\begin{array}{l}\text { Containment area radiation } \\
\text { (RG 1.97) }\end{array}$ & $\begin{array}{l}10^{0}-10^{4} \mathrm{R} / \mathrm{h}(\mathrm{RG} 1.97) \\
\text { (minimum of } 2 \text { well-separated } \\
\text { monitors) }\end{array}$ \\
\hline & $\begin{array}{l}\text { Effluent radioactivitiy: noble } \\
\text { gases from condenser air } \\
\text { removal system exhaust } \\
\text { (RG 1.97) }\end{array}$ & $10^{-6}-10^{-2} \mu \mathrm{Ci} / \mathrm{cc}$ (RG 1.97) \\
\hline \multirow[t]{3}{*}{$\begin{array}{l}\text { Reactor } \\
\text { containment } \\
\text { pressure boundary }\end{array}$} & $\begin{array}{l}\text { Breach potentially resulting in } \\
\text { radioactivity releases producing } \\
\text { doses in excess of limits given } \\
\text { in } 10 \text { CFR } 100 \text { at exclusion area } \\
\text { boundary: gross gamma in } \\
\text { facility environs or secondary } \\
\text { containment (4.5) }\end{array}$ & $\begin{array}{l}\text { Range for either facility environs } \\
\text { or secondary containment: } \\
10^{-3}-10^{2} \mathrm{R} / \mathrm{h} \text { (4.5) }\end{array}$ \\
\hline & $\begin{array}{l}\text { Containment effluent } \\
\text { radioactivity: noble gases from } \\
\text { identified release points } \\
\text { (RG } 1.97 \text { ) }\end{array}$ & $10^{-6}-10^{-2} \mu \mathrm{Ci} / \mathrm{cc}$ (RG 1.97) \\
\hline & $\begin{array}{l}\text { Noble gases from buildings } \\
\text { connected by penetrations to the } \\
\text { primary containment }\end{array}$ & $10^{-6}-10^{-3} \mu \mathrm{Ci} / \mathrm{cc}$ (RG 1.97) \\
\hline
\end{tabular}


Table 14.2. Accident-related requirements for monitoring and sampling:

Type E variables (Regulatory Guide 1.97)

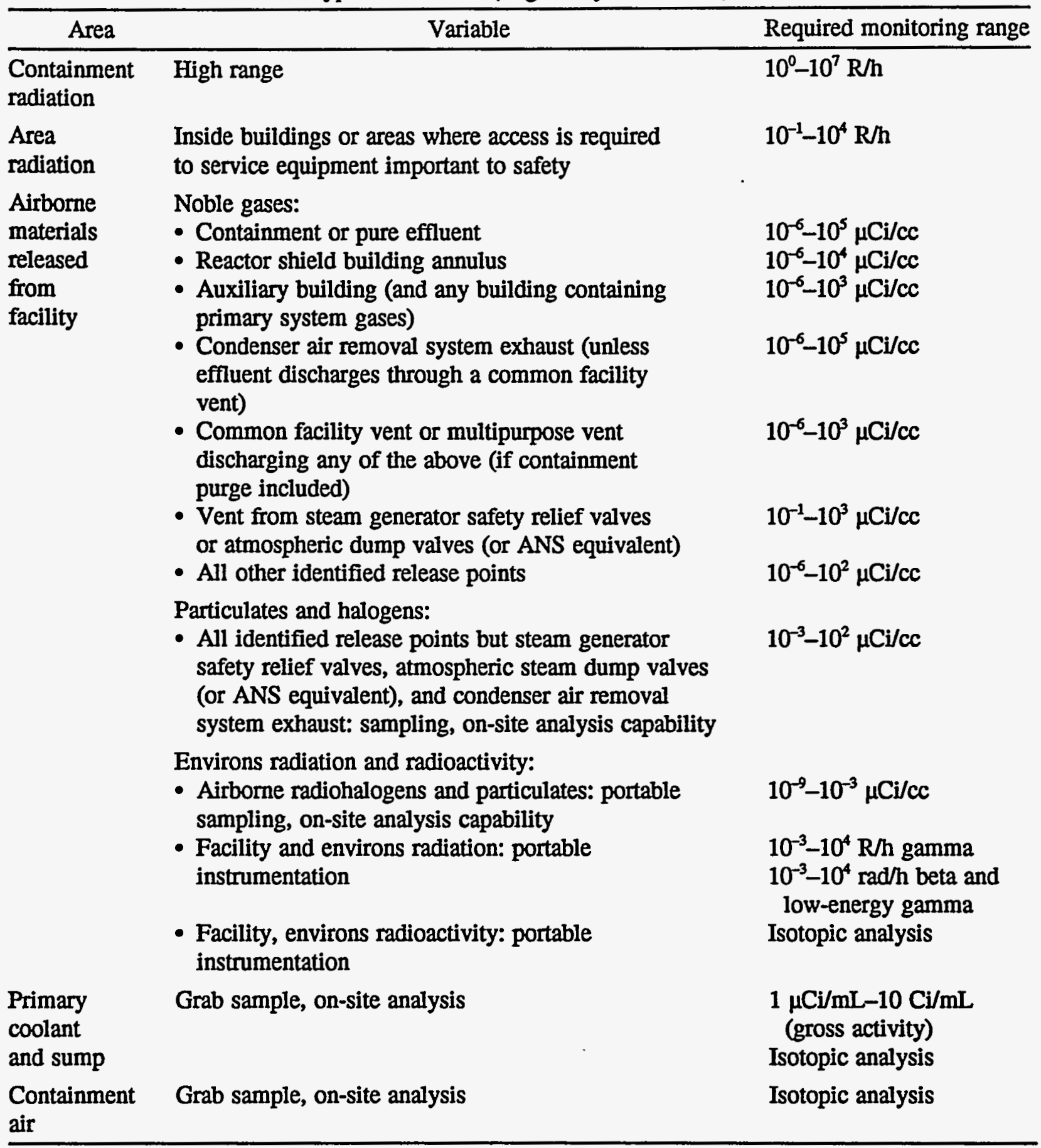




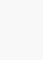




\section{RADIATION PROTECTION FACILITIES AND OPERATIONS}

\subsection{RADIATION PROTECTION AND RELATED FACILITIES}

1. A low-background counting room shall be provided (RG8.8). Consideration should be given to reduction of the fluctuations in the background as well as of its magnitude.

2. Instrumentation to be provided in the radiation protection (RP) counting room(s) shall include at least one multichannel gamma pulse-height analyzer; low-background alpha-beta proportional counter or scintillation counters; end-window Geiger-Muller (G-M) counters; and at least one liquid scintillation counter for tritium analyses (RG8.8).

3. Space shall be provided for additional equipment and a laboratory(-ies) if bioassays, whole-body counting, or environmental sample analyses are performed on site (RG8.8).

4. Sufficient office space shall be provided to accommodate temporary and permanent RP staff, records, and technical literature (HPM, RG8.8). The main RP office should be at or very near the main access control point into the containment.

5. Adequate space for storage of RP clothing and equipment shall be provided (HPM). This requirement includes local stations established at appropriate locations near operational areas for the storage of portable rad survey equipment, signs, ropes, and respiratory protection equipment (HPM).

6. Adequate space and equipment for posting of radiological signs (HPM), erecting temporary rope and other barriers, and the attachment of tags shall be provided at or near operational areas.

7. Convenient restroom facilities with space for storing clean bottles, a table or shelf for filling out labels, etc., should be provided in areas where urinalysis samples may be taken.

\subsection{PORTABLE AND PERSONNEL MONITORING INSTRUMENTATION}

1. For normal area and object portable monitoring activities, the following instrumentation shall be provided as appropriate: low-range ion chambers or G-M rate meters (0-5 R/h), high-range ion chambers (to $10^{4} \mathrm{R} / \mathrm{h}$ or more), beta monitoring devices (ion chambers or scintillation chambers), alpha scintillation or proportional count rate meters, neutron dose equivalent rate meters, and air samplers for short-term use with particulate filters (RG8.8). "Smart" instruments that can be read out into a computer shall be considered.

2. For normal personal monitoring, the following instrumentation shall be provided as appropriate: G-M friskers, direct-reading low-range (0-200 mR) and intermediate-range (0-1000 $\mathrm{mR}$ ) pocket dosimeters, alarming and other electronic dosimeters, thermoluminescent dosimeters, hand-and-foot monitors, portal and half-body monitors, and personal air samplers (RG8.8). A portal or half-body monitor should be provided at each outside entrance. "Smart" instruments that can be read out into a computer shall be considered. 
3. Portable instruments shall be supplied to make radiological measurements at locations not covered by installed instrumentation (N320), especially during accidents. High-range portable survey instruments and personnel dosimeters shall be supplied to permit rapid assessment of high exposure rates and time-integrated dose (N320).

4. Equipment shall be provided to facilitate communication between all areas for RP purposes (RG8.8). Such equipment may include telephones, walkie-talkies, computers, help buttons, and the like.

\subsection{PERSONNEL AND EQUIPMENT ACCESS CONTROL POINTS}

1. Control points shall be established at appropriate locations for access into and exit from buildings and areas containing Radiological Areas and RBAs, such as the containment building, the detritiation building, and radwaste processing areas. The number of such points shall be minimized.

2. Control points shall be established at appropriate locations for the movement of radioactive materials throughout the facility, with particular attention paid to entry and exit controls at docks.

3. Control points shall be established at appropriate locations for access into and exit from Radiological Areas and Radiological Buffer Areas.

4. The requirement that personnel go through control points should not preclude necessary exits through emergency doors. However, alarms on such doors should be considered, both as a rapid means of indicating when a person may be involverl in a true emergency and require help and as a means of indicating when doors are being used for convenience and thus when control is being subverted.

\subsection{RADIATION PROTECTION PERSONNEL ACCESS}

For the purpose of planning for the number of RP personnel and the timing and frequency of their entries into Radiological Areas, the following assumptions should be made.

1. Routine radiation dose rate surveys shall be performed with the frequencies given below (RCM). Measurements shall be taken for the general area, at a distance of $30 \mathrm{~cm}$ from a source or surface of interest, and on contact with potential sources of radiation where there is a potential for hands-on work (RCM).

a. Daily: in offices located in RBAs

b. Weekly: in routinely occupied RBAs and Radiation Areas; during continuing operations in High Radiation Areas; at HEPA-filtered ventilation units; at temporary boundaries of Radiation Areas

c. Monthly: in Radioactive Material Areas; at potentially contaminated ducts, piping, and hoses in use outside radiological facilities 
d. Upon entry: initially and when levels are expected to change for work in High Radiation Areas; in Radioactive Material Areas, if entries are less frequent than monthly

e. Whenever operations are being performed that might result in personnel being exposed to small intense beams of radiation

f. Before, during, and at the completion of work with the potential for causing changes in levels of radiation and radioactivity

2. Routine contamination surveys shall be performed at the frequencies given below (RCM). Surveys should include measurements for both fixed and removable contamination (RCM). Items with inaccessible surfaces that are or have been in known or suspected contamination areas or Airborne Radioactivity Areas should be treated as potentially contaminated and appropriately controlled until proven otherwise (RCM). The requirements for surveying representative samples of bulk material (such as plate steel and sweeping compounds) are given in 5400.5 (RCM).

a. Daily: at contamination area control points, change areas, and step-off pads when in use (or every shift if in high use); in offices located in RBAs; in lunchrooms or eating areas near RBAs; in areas with the potential for having "hot" particles when particle-generating work is not in progress

b. Weekly: in routinely occupied RBAs; in Radioactive Materials Areas; at the boundaries of contamination areas; in areas with the potential for having "hot" particles when particle-generating work is not in progress

c. Upon entry: in Radioactive Materials Areas and at the boundaries of contamination areas, if entries are less frequent than weekly; initially for entry into a known or suspected contamination area

d. Prior to the transfer of equipment and material from one RBA to another; prior to the transfer of equipment and material from contamination areas within RBAs unless they are bagged or wrapped

e Periodically during and at the completion of work in an actually or potentially contaminated area

f. After a leak or spill of contaminated materials

\subsection{MISCELLANEOUS}

1. Automated thermoluminescent dosimetry (TLD) systems and computerized instrument output and dose records systems shall be provided where feasible (RG8.8). 


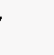




\section{ALARA AND OPTIMIZATION}

\subsection{ALARA}

The statements below give miscellaneous requirements regarding the ALARA concept. Note that these are not just vague statements that ALARA should be considered, but are specific regarding the way it should be applied or the area in which it should be applied.

1. In general, ALARA determinations shall be made on the basis of dose (usually per job or per year), not an instantaneous dose rate. This principle particularly applies to shielding cases.

2. In general, ALARA determinations shall take into account the dose from all work that a worker might be involved in in the course of a year, rather than just the dose from an individual task.

3. In general, both individual and collective dose shall be minimized to the extent practical. However, minimization of individual dose shall be emphasized over minimization of collective dose.

4. PNL-6577 should be used as guidance for determining ALARA radiological design criteria (5480.11, HPM).

5. All ventilation systems associated with confinements shall be designed to limit airborne contamination levels in accordance with ALARA principles (6430.1A).

6. All operations that involve known or potential sources of radioactive contamination shall be planned and performed to result in ALARA quantities of radioactive waste (RCM; 5820.2A). Waste shall be stored in such a way as to maintain radiation exposures as low as reasonably achievable (5420.2A).

7. Pressurized radioactive gas tanks shall be designed so as to minimize dose when recombiner cartridges are changed (55.4).

8. Filter housing and internals shall be, consistent with design and process requirements, designed to reduce operator exposure during the removal of filter media $(55.6,56.6)$.

9. Shielding in general shall be designed such that personnel exposures are ALARA (required by many references).

10. The size, number, and duration of RBAs and contamination areas shall be reduced to ALARA levels (RCM, HPM).

11. The time spent in performing work in Radiological Areas shall be minimized to the extent possible (generally required, but particularly mentioned in 57.2). Maintenance and other tasks in high radiation areas shall be carefully scheduled so as to allow for maximum decay time (RG8.8, 55.4, 55.6). 
12. Repetitive RP surveys that do not provide data of significant usefulness shall be eliminated (RG8.8). On the same principle, the frequency of inspections and other repetitive activities shall be reduced to the number necessary for safe and efficient operation, commensurate with dose reduction.

13. Measures shall be taken or equipment provided where feasible to record observations, data, operations, running dose and time notations, etc., in order to maximize the accuracy, completeness, and timeliness of the information collection (inferred from RG 8.8). Such measures and equipment may include the use of videocameras, tape recorders, computer entry points, and the like.

\subsection{OPTIMIZATION}

1. Optimization analyses (usually as cost-benefit analyses) shall be performed as appropriate in the design of new facilities (10CFR835, 5480.11, RCM, RG8.8). Optimization analyses shall be performed according to an ORNL-approved method (HPM).

2. Radioactively contaminated facilities for which the DOE is responsible shall be managed in a safe, cost-effective manner to ensure that release of and exposure to radioactivity and other hazardous materials comply with Federal standards (5820.2A).

3. Included in the radwaste system shall be all items of reasonably demonstrated technology that, when added to the system sequentially and in order of diminishing cost-benefit ratio, will effect reductions in dose to the population expected to be within 50 miles of the reactor (10CFR50, Appendix I).

4. Planning for decommissioning during the design of a research reactors shall include consideration of minimizing overall cost while minimizing dose (15.10).

5. As approved by the ORNL ALARA Steering Committee, the values to be used for the man-rem are $\$ 2000$ for member of the public and for occupational workers who are not approaching an administrative or regulatory limit and $\$ 10,000$ for occupational workers who are approaching an administrative or regulatory limit. [Note that 10CFR50, Appendix I, states that for radwaste systems, "As an interim measure and until establishment and adoption of "better" values (or other appropriate criteria) the value of $\$ 1000$ per man-rem (or such a lesser value as may be demonstrated to be suitable in a particular case) shall be used." This regulation does not appear to have as objective and contemporary a basis as the ORNL values, which are based on recommendations by. Dr. J. W. Baum of the Brookhaven ALARA Center.] 


\section{HUMAN FACTORS AND INDUSTRIAL HYGIENE AND SAFETY}

Human factors and industrial hygiene and safety shall be considered in the design of new facilities $(5480.23,5480.30)$.

1. Instrumentation, communication provisions, operational aids, and labeling should be chosen to support timely and reliable human performance. Layout, physical access, the need for protective clothing and breathing apparatus, noise levels, temperature, humidity, and like factors should also be considered (5480.23).

In particular, piping, valves, and other process equipment shall be arranged and marked so that the operator can easily identify the flow paths $(40.35,55.1)$; a clearly legible current process flow diagram shall be available in the immediate vicinity of the control panel $(55.4,55.6)$.

2. Physical safety features shall be provided for personnel operating the fuel-handling equipment (e.g., nonskid walking surfaces and guard rails) (57.1).

3. The use of mockups for high-exposure or complex tasks should be considered (RCM).

4. A loudspeaker system shall be provided in the reactor containment (57.1), the spent fuel-handling area (57.1), and the detritiation building for rapid communication from the control room to these areas.

5. The following specifications from ANSI N42.17B-1989, "Performance Specifications for Health Physics Instrumentation-Occupational Airborne Radioactivity Monitoring Instrumentation" should be applied (IGE2). The audible alarm intensity shall be a minimum of $75 \mathrm{~dB}$ at $15 \mathrm{~cm}$. In work areas that have a high ambient noise level ( $295 \mathrm{~dB})$, a visual alarm should activate with the audible alarm. The visual alarm should be distinctive so that it cannot be mistaken for other alarms.

6. Human factors considerations shall be particularly taken into account in accident monitoring and sampling (RG1.97). 


\section{MISCELLANEOUS REQUIREMENTS}

1. Design guidance shall be incorporated in written procedures, criteria, guides, or checklists and shall apply to designers, vendors, and constructors (RCM). Design reviews shall be performed (RCM, RG8.8) at appropriate intervals (RCM). Actions taken to maintain exposures ALARA, including the facility design and control actions required by 10 CFR 835.1001 and 1002 , shall be documented (10CFR835).

2. In the selection of a site for a new reactor, the specific site evaluation criteria given in DOE 5400.5, DOE 5480.6 and DOE 5480.28 and in the RCM (Article 128) shall apply (5480.30); 10 CFR 100 and 6430.1A also apply where appropriate (5480.6). In the construction of a new reactor, 10 CFR 50, Appendix A, shall apply as applicable $(5480.6,5480.30)$. 


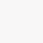




\section{REFERENCES}

Some of the references below are not used in the current text, but are included for completeness because they are of potential application. Some annotations appear for the purpose of informing the reader regarding the scope or potential usefulness of the references. Note the reference conventions described in Sect. 1.3.

\subsection{CODE OF FEDERAL REGULATIONS}

1. 10 CFR Pt. 20, "Standards for Protection Against Radiation," 1990 revision

This NRC-issued rule contains specific requirements for occupational radiation protection, but must be used with caution because a DOE requirement may be more stringent or may be preferable or more applicable for other reasons.

2. 10 CFR Pt. 50, "Domestic Licensing of Production and Utilization Facilities."

Appendix I contains requirements for ALARA in design of facilities. If used at all, this aging document must be used with caution because the numbers are given in what is essentially a de facto or "below regulatory concern" manner. It is not an acceptable approach at present to use numbers apparently not backed up by a risk-based or other such standard analysis.

3. 10 CFR Pt. 100, "Reactor Site Criteria."

This regulation contains specific bases for safety analyses, but must be used with caution because a DOE requirement may be more stringent or may be preferable or more applicable for other reasons.

4. 10 CFR Pt. 835, "Occupational Radiation Protection."

This DOE-issued rule is now in effect, applies to DOE facilities, and takes precedence over the RCM and DOE Orders.

5. 40 CFR Pt. 61, Subpart H, "National Emission Standard for Radionuclide Emissions from Department of Energy Facilities."

This regulation is referenced in DOE Order 5400.5, but would be applicable even if 5400.5 did not reference it.

\subsection{U.S. DEPARTMENT OF ENERGY ORDERS, POLICY STATEMENTS, AND GUIDANCE}

1. DOE Order 5400.5, Radiation Protection of the Public and the Environment, Feb. 8, 1990.

This order covers dose, dose rates, contamination considerations, best available technology, etc., for the cases of exposure of the public and releases to the environment. 
2. DOE Order 5480.5, Safety of Nuclear Facilities, Sept. 23, 1986.

This order gives some sketchy safety requirements for nonreactor nuclear facilities.

3. DOE Order 5480.6, Safety of Department-Owned Nuclear Reactors, Sept. 23, 1986.

This order gives general safety requirements for reactor facilities.

4. DOE Order 5480.11, Radiation Protection for Occupational Workers, Dec. 21, 1988 and as amended June 17, 1992.

This order covers dose, dose rates, contamination considerations, access control, etc., for the occupational case. It is mostly superseded by $10 \mathrm{CFR} 835$.

5. DOE Order 5480.23, Nuclear Safety Analysis Reports, Apr. 10, 1992.

6. DOE Order 5480.30, Nuclear Reactor Safety Design Criteria, Jan. 19, 1993.

This order gives some specific design requirements and definitions for reactors.

7. DOE Order 5500.3, Reactor and Nonreactor Nuclear Facility Emergency Planning,

Preparedness, and Response Program for Department of Energy Operations, Aug. 13, 1981 and as amended July 2, 1990.

This order gives some emergency planning requirements that bear on accident dose assumptions.

8. DOE Order 5820.2A, Radioactive Waste Management, Sept. 26, 1988.

This order gives some specific design requirements for handling radwaste, including decommissioning activities.

9. DOE Order 6430.1A, General Design Criteria, June 4, 1989.

This order gives detailed design criteria for nonreactor nuclear facilities, such as the ANS detritiation plant. Although it does not specifically apply to the reactor complex, appropriate guidance from 6430.1A should be applied to it, in accordance with the ANS Plant Design Requirements, Sect. 4.3.2, and DOE 5480.6 and 5480.30, in all of which it is recognized that DOE 5480.6 and related NRC guidance documents do not contain the wealth of design detail of DOE 6430.1A (e.g., regarding the design of confinements). Note that for ANS, DOE 5480.30 should be referenced instead where applicable.

10. G-10 CFR 835/E2, Workplace Air Monitoring, Implementation Guide (for 10 CFR 835), Rev. 1, November 1994.

11. G-10 CFR 835/G1, Posting and Labeling for Radiological Control, Implementation Guide (for 10 CFR 835), Rev. 1, November 1994.

12. U.S. Department of Energy, Environmental Regulatory Guide for Radiological Effluent Monitoring and Environmental Surveillance, DOE/EH-0173T, 1991.

13. U.S. Department of Energy, Radiological Control Manual, DOE/EH-0256T, Rev. 1, April 1994. 
This is the current revision of the DOE Radiological Control Manual. DOE Notice N5480.6 directed the implementation and use of Revision 0 of the RCM, also numbered N5480.6, of June 1992. The RCM is a comprehensive set of specifications regarding operations, but some of it concerns design too. Note that where there is a conflict between the RCM and any of several orders listed on p. R-2 of the RCM, including 5480.11, the RCM takes precedence. 10 CFR 835, however, takes precedence over the RCM.

14. U.S. Department of Energy, A Guide for Effluent Radiological Measurements at DOE Installations, DOE/EP-0096, 1983.

15. R. L. Kathren and J. M. Selby, A Guide to Reducing Radiation Exposures to As Low As Reasonably Achievable (ALARA), DOE/EV/1830-T5, April 1980.

16. Oak Ridge Operations Office, U.S. Department of Energy, Contamination Control Policy, October 1989.

17. J. C. Elder et al., A Guide to Radiological Accident Considerations for Siting and Design of DOE Nonreactor Nuclear Facilities, LA-10294-MS, Los Alamos National Laboratory, Los Alamos, N.M., 1986.

18. L. H. Munson et al., Health Physics Manual of Good Practices for Reducing Radiation Exposure to Levels That Are As Low As Reasonably Achievable (ALARA), PNL-6577, Pacific Northwest Laboratories, Richland, Wash., June 1988.

19. H. F. Anderson et al., Health Physics Manual of Good Practices for Tritium Facilities, MLM-3719, EG\&G Mound Applied Technologies, Miamisburg, Ohio, draft of December 1991. In spite of its name, this report contains much design information and was authored by engineers and scientists experienced in tritium work as much as it was by health physicists. Although it is still in draft form, it has been through many reviews and is therefore likely to be the final form of the document.

\subsection{NUCLEAR REGULATORY COMMISSION (NRC) GUIDANCE}

1. Regulatory Guide 1.13, "Fuel Storage Facility Design Basis," Rev. 1, December 1975.

2. Regulatory Guide 1.52, "Design, Testing, and Maintenance Criteria for Atmosphere Cleanup System Air Filtration and Adsorption Units for Light-Water-Cooled Nuclear Power Plants," Rev. 2, March 1978.

3. Regulatory Guide 1.69, “Concrete Radiation Shields for Nuclear Power Plants," Rev. 0, December 1973.

4. Regulatory Guide 1.105, "Instrument Setpoints," Rev. 2, February 1986.

5. Regulatory Guide 1.110, “Cost-Benefit Analysis for Radwaste Systems for Light-Water-Cooled Nuclear Reactors," Rev. 0, March 1976. 
6. Regulatory Guide 1.140, "Design, Testing, and Maintenance Criteria for Normal Exhaust System Air Filtration and Adsorption Units of Light-Water-Cooled Nuclear Power Plants," Rev. 1, October 1979.

7. Regulatory Guide 3.9, "Concrete Radiation Shields," June 1973.

8. Regulatory Guide 8.8, "Information Relevant to Ensuring That Occupational Radiation Exposures at Nuclear Power Stations Will Be As Low As Is Reasonably Achievable," Rev. 3, June 1978, and Second Proposed Rev. 4, May 1982.

9. Regulatory Guide 8.10, "Operating Philosophy for Maintaining Occupational Radiation Exposures As Low As Is Reasonably Achievable," Rev. 1-R, May 1977.

10. Regulatory Guide 8.25, “Air Sampling in the Workplace,” Rev. 1, June 1992.

11. Regulatory Guide 8.38, "Control of Access to High and Very High Radiation Areas in Nuclear Power Plants,” Rev. 0, June 1993.

12. Manual of Respiratory Protection Against Airborne Radioactive Materials, NUREG-0041, 1976.

13. T. M. Hall et al., Determining Effectiveness of ALARA Design and Operational Features, NUREG/CR-0446, April 1979.

14. Handbook of Human Reliability Analysis with Emphasis on Nuclear Power Plant Applications, NUREG/CR-1278, May 1983.

15. Technology, Safety, and Costs of Decommissioning Reference Nuclear Research and Test Reactors, NUREG/CR-1756, Pacific Northwest Laboratory for the U.S. Nuclear Regulatory Commission, March 1982.

16. Technology, Safety, and Costs of Decommissioning Fuel Cycle and Non-Fuel Cycle Facilities Following a Postulated Accident, NUREG/CR-3203, Pacific Northwest Laboratory for the U.S. Nuclear Regulatory Commission, 1984.

17. T. S. LaGuardia and J. F. Risley, Identification and Evaluation of Facilitation Techniques for Decommissioning Light Water Power Reactors, NUREG/CR-3587, 1986.

18. J. R. White et al., Evaluation of Robotic Inspection Systems at Nuclear Power Plants, NUREG/CR-3717, 1984.

19. J. W. Baum and G. R. Mathews, Compendium of Cost-Effectiveness Evaluations of Modifications for Dose Reduction at Nuclear Power Plants, NUREG/CR-4373, December 1985.

\subsection{FEDERAL POLICY STATEMENT}

1. Environmental Protection Agency, "Radiation Protection Guidance to the Federal Agencies for Occupational Exposure," Federal Register, Vol. 52, No. 17, 1987. 


\subsection{STANDARDS}

1. ANSI N8.3-1979, "Criticality Accident Alarm," American National Standards Institute.

2. ANSI N13.1-1969, "Guide for Sampling Airborne Radioactive Materials," American National Standards Institute, reaffirmed 1993.

3. ANSI N13.10-1974, "Specification and Performance of On-Site Instrumentation for Continuously Monitoring Radioactivity in Effluents," American National Standards Institute.

4. ANSI N42.17B-1989, "Performance Specifications for Health Physics Instrumentation-Occupational Airborne Radioactivity Monitoring Instrumentation," American National Standards Institute.

5. ANSI N42.18-1980, "Specification and Performance of On-Site Instrumentation for Continuously Monitoring Radioactivity in Effluents" (Redesignation of ANSI N13.10-1974; reaffirmed 3/19/1991).

6. ANSI N101.1-1972, "Efficiency Testing of Air-Cleaning Systems Containing Devices for Removal of Particles," American National Standards Institute.

7. ANSI N320-1985, "Performance Specifications for Reactor Emergency Radiological Monitoring Instrumentation," American National Standards Institute.

8. ANSI N323-1983, "Radiation Protection Instrumentation Test and Calibrations," American National Standards Institute.

9. ANSI N512-1974, "Protective Coatings for the Nuclear Industry," American National Standards Institute.

10. ANSI Z88.2-1980, "Practices for Respiratory Protection," American National Standards Institute.

11. ANSI/ANS-4.5-1980, "Criteria for Accident Monitoring Functions for Light-Water-Cooled Reactors," American National Standards Institute.

12. ANSI/ANS-6.4-1977 (N403), "Guidelines on the Nuclear Analysis and Design of Concrete Radiation Shielding for Nuclear Power Plants," American National Standards Institute.

13. ANSI/ANS-6.4.2-1977 (N403), "Specification for Radiation Shielding Materials," American National Standards Institute.

14. ANSI/ANS-8.3-1986, "Criticality Accident Alarm System," American National Standards Institute.

15. ANSI/ANS-15.10-1981, "Decommissioning of Research Reactors," American National Standards Institute. 
16. ANSI/ANS-15.11-1987, "Radiation Protection at Research Reactor Facilities," American National Standards Institute.

17. ANSU/ANS-40.35-1991, "Volume Reduction of Low-Level Radioactive Waste or Mixed Wastes," American National Standards Institute.

18. ANSI/ANS-55.1-1979, "Solid Radioactive Waste Processing Systems for Light-Water-Cooled Reactor Plants," American National Standards Institute.

Perhaps replaced by 1993 version.

19. ANSI/ANS-55.4-1979, "Gaseous Radioactive Waste Processing Systems for Light-Water-Cooled Reactor Plants," American National Standards Institute.

20. ANSI/ANS-55.6-1979, "Liquid Radioactive Waste Processing Systems for Light-Water-Cooled Reactor Plants," American National Standards Institute.

21. ANSI/ANS-56.6-1986, "Pressurized Water Reactor Containment Ventilation Systems," American National Standards Institute.

22. ANSI/ANS-57.1-1980, "Design Requirements for Light Water Reactor Fuel Handling Systems," American National Standards Institute.

23. ANSI/ANS-57.2-1983, "Design Requirements for Light Water Reactor Spent Fuel Storage Facilities at Nuclear Power Plants," American National Standards Institute.

24. ANSI/ANS-57.3-1983, "Design Requirements for New Fuel Storage Facilities at Light Water Reactor Plants," American National Standards Institute.

25. ANSI/ANS-HPSCC-6.8.1-1981, "Location and Design Criteria for Area Radiation Monitoring Systems for Light Water Nuclear Reactors," American National Standards Institute.

26. ANSI/ASME N509-1976, "Nuclear Power Plant Air Cleaning Units and Components," American National Standards Institute.

27. ANSI/ISA-S67.10-1986, "Sample-Line Piping and Tubing Standard for Use in Nuclear Power Plants," American National Standards Institute.

28. ASTM E10.03.06, "Final Decommissioning Plan Guideline Standard on Nuclear Facilities," American Society for Testing and Materials, June 1983.

29. IEEE 279-1971, “Criteria for Protection Systems for Nuclear Power Generating Stations," Institute of Electrical and Electronic Engineers.

30. IEEE 323-1979, "IEEE Standard for Qualifying Class 1E Equipment for Nuclear Power Generating Stations," Institute of Electrical and Electronic Engineers.

31. Military Standard, Human Engineering Design Criteria for Military Systems, Equipment, and Facilities, U.S. Department of Defense, MIL-STD-1472D, Mar. 14, 1989. 
32. Fire Protection Handbook, FPH-1791, National Fire Protection Association, 1991.

\subsection{OTHER AUTHORITATIVE GUIDANCE}

1. Industrial Ventilation, A Manual of Recommended Practice, Committee on Industrial Ventilation, American Conference of Governmental Industrial Hygienists, 1980.

2. Nuclear Air Cleaning Handbook, ERDA 76-21, available from the National Technical Information Service, Springfield, Virginia, October 1979.

3. R. W. Pack et al., Human Engineering Design Guidelines for Maintainability, EPRI NP-4350, Electric Research Institute, Palo Alto, Calif., December 1985.

4. H. P. Van Cott and R. G. Kincade, eds., Human Engineering Guide to Equipment Design, rev., U.S. Government Printing Office, Washington, D.C., 1972.

5. Human Engineering Design Data Digest, Redstone Arsenal, Alabama, December 1984, obtainable by writing to the Chief, Human Engineering Detachment, Attn: SLCHE-MI, U.S. Army Missile Command, Redstone Arsenal, AL 35898-7290.

6. M. B. Bruce and M. V. Davis, Radiation Effects on Organic Materials in Nuclear Plants, EPRI NP-2129, Electrical Power Research Institute, Palo Alto, Calif., November 1981.

7. F. Bouquet and J. Winslow, Radiation Data for Design and Qualification of Nuclear Plant Equipment, EPRI NP-4172M, Electrical Power Research Institute, Palo Alto, Calif., August 1985.

8. J. E. Gover and J R. Srour, Basic Radiation Effects in Nuclear Power Electronics Technology, SAND85-0776, Sandia National Laboratory, Albuquerque, N.M., 1985.

9. H. A. Lee, Guide to Fire Protection in Caves, Canyons, and Hot Cells, USAEC Report ARH-3020, Atlantic Richfield Hanford Company, Richland, Wash., July 1974.

10. Recommendations of the ICRP, ICRP Publication No. 26, International Commission on Radiation Protection, Pergamon Press, Oxford, U.K., 1977.

11. Limits for Intakes of Radionuclides by Workers, ICRP Publication No. 30, International Commission on Radiation Protection, Pergamon Press, Oxford, U.K., 1978.

12. Cost-Benefit Analysis in the Optimization of Radiation Protection, ICRP Publication No. 37, International Commission on Radiation Protection, Pergamon Press, Oxford, U.K., 1983.

13. Optimization and Decision-Making in Radiological Protection, ICRP Publication No. 55, International Commission on Radiation Protection, Pergamon Press, Oxford, U.K., 1989.

14. Radiation Alarms and Access Control Systems, NCRP Report No. 88, National Council on Radiation Protection, Pergamon Press, Oxford, U.K., 1986. 
15. Recommendations on Limits for Exposures to Ionizing Radiation, NCRP Report No. 91, National Council on Radiation Protection, Pergamon Press, Oxford, U.K., 1987.

16. Design for Safety of Nuclear Power Plants: A Code of Practice, IAEA Safety Series Guide No. 50-C-D, International Atomic Energy Agency, Vienna, 1978.

17. Design Aspects of Radiation Protection for Nuclear Power Plants, IAEA Safety Series Guide No. 50-SG-D9, International Atomic Energy Agency, Vienna, 1985.

18. Operational Radiation Protection: A Guide to Optimization, IAEA Safety Series Guide No. 101, International Atomic Energy Agency, Vienna, 1990.

19. Application of Remotely Operated Handling Equipment in the Decommissioning of Nuclear Facilities, IAEA Technical Reports Series No. 348, International Atomic Energy Agency, Vienna, 1993.

20. Planning and Management for the Decommissioning of Research Reactors and Other Small Facilities, IAEA Technical Reports Series No. 351, International Atomic Energy Agency, Vienna, 1993.

21. Offgas and Air Cleaning Systems for Accident Conditions in Nuclear Power Plants, IAEA Technical Reports Series No. 358, International Atomic Energy Agency, Vienna, 1993.

22. D. R. Doman, Design Guides for Radioactive Material Handling Facilities and Equipment, American Nuclear Society, Lagrange Park, Ill., 1988.

23. D. C. Stewart, Handling Radioactivity, John Wiley and Sons, New York, 1983.

24. J. N. Anno, Notes on Radiation Effects in Materials, Hemisphere Publishing Corporation, Washington, D.C., 1984.

25. J. W. Baum, "ALARA at Nuclear Power Plants," in Implementation of Current NCRP and ICRP Guidance and Revised 10 CFR Part 20, proceedings of the 24th Midyear Topical Meeting of the Health Physics Society, Raleigh, N.C., Jan. 21-24, 1991.

26. W. C. Reinig, "Tritium Protection at the Savannah River Plant," Savannah River Plant, unpublished report.

27. Tritium Safe Handling Course (TSHC) Notes, CFFTP Report I-9053, Canadian Fusion Fuels Technology Project, Toronto and Chalk River, Ontario, Canada, 1990.

19.7 MARTIN MARUETTA ENERGY SYSTEMS (MMES) AND OAK RIDGE NATIONAL LABORATORY (ORNL) REQUIREMENTS AND PROCEDURES

1. MMES Radiological Control Manual (MMES RCM), Martin Marietta Energy Systems, Inc., December 1992. 
This has essentially the same content as the DOE Radiological Control Manual, except that a value for the MMES Administrative Control Level has been added.

2. ORNL Health Physics Procedure Manual (HPM), Rev. 22, ORNL/M-804, Martin Marietta Energy Systems, Inc., Oak Ridge Natl. Lab., January 1995.

The latest revision incorporates the requirements of 10 CFR 835, the DOE Radiological Control Manual (where applicable), and DOE Orders. Note that the HPM has the status of an ORNL Standard Operating Procedure.

3. R. S. Booth, Advanced Neutron Source Plant Design Requirements, ORNL/TM-11625/R5, Martin Marietta Energy Systems, Inc., Oak Ridge Natl. Lab., December 1994. 



\section{GLOSSARY}

absorbed dose- see dose

Airborne Radioactivity Area-an area where levels of airborne contamination are greater than or equal to $10 \%$ of the DAC for any isotope (RCM). (Note that this is called Airborne Contamination Area in DOE 5480.11, which the RCM supersedes. Note that 10 CFR 20 defines an airborne radioactivity area as one in which concentrations exceed the DAC or in which an individual could, in the hours he spends there in a week, receive an intake of at least $0.6 \%$ of the ALI, or $12 \mathrm{DAC}$-hours.)

ALARA - as low as (is) reasonably achievable, a philosophy or concept regarding radiation protection that states that individual and collective radiation exposures for both occupational workers and the public are to be kept as low as can reasonably be managed, given the current state of technology, costs, and operating requirements

ALI - annual limit of (or on) intake, the quantity of a single radionuclide that, if inhaled or ingested in 1 year, would irradiate a person (represented by the ICRP's "reference man") to a total effective dose (equivalent) of 5 rem [or a dose (equivalent) of 50 rem to any organ] over the succeeding 50 years. See dose.

anticipated operational occurrence (AOO) - an event that is an unplanned departure from normal operations but that is expected to occur one or more times during the life of the facility. Such events are also called "anticipated operational events."

background-(1) "ordinary" background is the dose rate resulting from natural sources ("natural background") such as the earth, cosmic radiation, and the like, and from manmade sources such as fallout, smoke detectors, and the like, but not from anything occupational (2) "general" background in an area is the dose rate including all contributions except that of a specific source(s) of interest, if any

Bremsstrahlung - $\mathrm{a}$ form of $\mathrm{X}$ rays produced when charged particles are slowed down in matter. Practically speaking, this is significant only for higher-energy betas slowing down in high- $Z$ (high atomic number) material such as lead.

\section{Collective dose- see dose}

\section{committed effective dose equivalent (CEDE)—see dose}

Confinement, confinement area, confinement system - a vessel, tank, room, enclosure, or the like that encloses a volume or area containing radioactive materials and serves to prevent or reduce passage of radioactive or other hazardous materials to the area(s) outside. It includes one or more physical barriers and any associated subsystems (such as ventilation systems). The primary confinement (sometimes called a "primary confinement system") is typically a container or enclosure that most immediately holds the radioactive material, such as a tank or glovebox, with its associated ventilation system if any. A secondary confinement may be the outer wall of a double-walled tank; the room containing a glovebox, with the room ventilation system; or the like. A tertiary confinement may be the vault around a double-walled tank, the building containing a room with a glovebox, or the like. Note that DOE 5480.30, Attachment 2, defines confinement as "the barrier and its associated systems (including ventilation) between areas containing hazardous materials and the environment or other 
areas in the nuclear facility [which, in 5480.30, explicitly includes reactor facilities] that are normally expected to have levels of hazardous materials lower than allowable concentration limits"; however, "allowable limits" is not defined in DOE 5480.30. See also containment.

containment or containment system-as defined by DOE 5480.30, Attachment 2, "a structurally closed barrier and its associated systems (including ventilation) between areas containing hazardous materials and the environment or other areas in the nuclear facility (which, in 5480.30, explicitly includes reactor facilities) that are normally expected to have levels of hazardous materials lower than allowable concentration limits. A containment barrier is designed to remain closed and intact during all design-basis accidents." "Allowable limits" is not defined in DOE 5480.30. See also confinement.

contact-handled $(\mathrm{CH})$ waste—see radwaste

contact-handled transuranic waste (CH TRU)-see radwaste

contamination-radioactivity deposited or existing in an undesirable or unanticipated location.

Contamination may be termed removable (readily removable by wiping, rubbing, or mild scrubbing); fixed (not easily removable without scraping or removing the surface of the contaminated object); or airborne.

contamination area - a generic contamination area, either a Contamination Area or a High Contamination Area

Contamination Area-an area where levels of surface contamination are greater than or equal to 1 times but less than 100 times the limits specified in Appendix D of 10 CFR 835 or, for tritium, Table 2-2 of the RCM. (Note that this area was defined as 10 times the limits in DOE Order 5480.11, which 10 CFR 835 and the RCM supersede.) The term should always be capitalized when used this way.

controlled area-an area to which access is controlled in order to protect people from exposure to radiation and radioactive materials. At ORNL, all areas inside the fence(s) have traditionally been considered to be part of a single controlled area. (This is essentially what the NRC calls the unrestricted area (10CFR20).) However, the RCM appears to require that controlled areas be as small and discrete as possible, for example by being restricted mostly to a facility or part of a facility.

cost-benefit analysis - an evaluation of the costs and the benefits of a design, operation, or modification of either and a form of optimization analysis. The costs are usually monetary but may also include such effects as restriction of flexibility of operation. The benefits are usually expressed in terms of monetary, time, or dose savings. Some factor of equivalence, such as dollars per man-rem saved, is assumed in order to determine whether the design, operation, or modification is worthwhile.

crud -in a reactor, strictly speaking, material that has been eroded or corroded off the inside of a pipe or other wetted surface; carried by the coolant to the core; activated in the core; and carried out of the core by the coolant to be deposited in cracks, crevices, pipe elbows, etc. The term has often been extended to mean radioactivity leaked from the fuel and carried off by the coolant to be deposited in a similar way. In this guide, it is also used for any radioactive material carried by liquids and deposited on wetted surfaces such as the interiors of pipes, pumps, heat exchangers, etc.

cumulative dose (equivalent)—see dose 
DAC - the derived air concentration, a unit of air concentration as defined by the International Commission on Radiological Protection. The DAC for a given isotope corresponds to a concentration that, if breathed by a worker during $2000 \mathrm{~h}$ of work time over a year, would result in a committed effective dose equivalent of $5 \mathrm{rem}$. The values to be used in the design of the ANS are given in 10 CFR 835, Appendixes A and C. The category to be used [e.g., D(aily, W(eekly), or Y(early)] depends on the chemical and biological form of the isotope; when this is not known, the lowest value given should be used. For a mix, the value to be used is the sum of the fractional DAC values, i.e., the overall DAC $=\sum C_{i} \mathrm{DAC}_{i}$, where $C_{i}$ is the concentration of isotope $i$ and $\mathrm{DAC}_{i}$ is the value of the DAC for isotope $i$.

Note that for tritiated water, 10 CFR 835 states that the DAC values given, which are for inhalation, include "an additional 50\% absorption through the skin" as described in ICRP 30; thus, for skin absorption only or for inhalation only, the value would have to be adjusted.

DAC-hour - the product of the concentration of radioactivity in the air, expressed as a fraction or multiple of the DAC, and the duration of the exposure to the radioactivity in hours. (10 CFR 20 notes that one may take 2000 DAC-hours to represent one ALI and to be equivalent to a CEDE of 5 rem.)

DCG - the derived concentration guide, a unit of air or water concentration as defined by DOE Order 5400.5. The DCG for a given isotope corresponds to a concentration such that, under a year of continuous exposure by one mode (inhalation, ingestion of water, or submersion in air), an effective dose equivalent of 100 mrem would be received. The values to be used in the design of the ANS are given in DOE Order 5400.5, Figs. III-1 through III-3. The category to be used [e.g., D(aily, W(eekly), or $Y($ early)] depends on the chemical and biological form of the isotope; when this is not known, the lowest value given should be used. For a mix, the value to be used is the sum of the fractional DCG values, i.e., $\mathrm{DCG}=\sum C_{i} \mathrm{DCG}_{i}$, where $C_{i}$ is the concentration of isotope $i$ and $\mathrm{DCG}_{i}$ is the value of the DCG for isotope $i$.

Note that for tritiated water, DOE Order 5400.5 states that the DCG values given, which are for inhalation, include "an additional 50\% absorption through the skin" as described in Reference ICRP 30 ; thus, for skin absorption only or for inhalation only, the value would have to be adjusted.

decommissioning - the series of actions taken to reduce the potential health and safety impacts of DOE contaminated facilities, including activities to stabilize, reduce, or remove radioactive materials or to demolish the facilities (5820.2A)

decontamination - the removal of radioactive contamination from facilities, equipment, or soils by washing, heating, chemical or electrochemical action, mechanical action, or other techniques

derived air concentration-see $D A C$

derived concentration guide-see $D C G$

design life-the period of time over which a piece of equipment, structure, etc., is designed to function assuming normal maintenance and testing. It includes normal operating life and, where applicable, anticipated abnormal occurrence and accident life as well.

dose- a measure of the energy deposited by radiation in the body. It can be related to the biological effect to the recipient. There are various types of dose, of which the following are of interest here. Here the 
word "dose" will be generally used for all meanings, with the qualifying adjectives added only when necessary for clarification. The terminology below generally follows $10 \mathrm{CFR} 835$. Note that only the occupational dose is relevant for the purposes of this document.

1. The absorbed dose is the energy deposited per unit mass of target material. It is measured in rad (or in SI units, gray). Equipment qualification doses and very high doses to personnel are normally given in rad.

2. When the absorbed dose in tissue (i.e., to a human body) is adjusted for the types and energies of radiation producing the dose, it is then called the dose equivalent (DE). The adjustment factors are called the quality factors for those types and energies of radiation. All dose equivalents are measured in rem (or in SI units, sievert). Collective dose equivalents (to a group) are measured in man-rem (or man-sievert).

3. When the dose equivalent to an organ is adjusted by a weighting factor, it is called the effective dose equivalent (EDE) to that organ; the sum of the organic effective dose equivalents to all organs is "the" organic effective dose equivalent, so to speak. Although the doses to which this term applies are usually internal doses, such body parts as the gonads and the breast are included as organs and have weighting factors even when the dose to them is external. Note that doses to the extremities, the lens of the eye, and the skin are omitted from this summation, although the effective dose equivalent to each of them must be calculated and recorded. External doses to the whole body are in effect weighted by 1 , so that for the whole body the external dose equivalent is the same as the external effective dose equivalent.

The purpose of the weighting is, given an internal dose to an organ, to find the corresponding level of whole-body dose that is biologically equivalent, in terms of risk, to the dose to the single organ; this makes internal dose to an individual organ commensurate with internal or external whole-body dose.

4. The committed dose equivalent applies to internal dose only and is the dose received over the 50 years following an intake due to radioactivity deposited in the whole body or a single organ as a result of the intake. The dose equivalent received in any one year is calculated and attributed to that year. The committed effective dose equivalent (CEDE) is the weighted version of this dose and is normally what is meant when the generic term internal dose is used.

5. External (effective) dose equivalent and internal effective dose equivalent can be added to produce the total effective dose equivalent, or the TEDE. This is what is normally meant when the term dose is used generically. (This definition is consistent with 10 CFR 835. DOE Order 5400.5 calls the total effective dose equivalent (TEDE) simply "the" effective dose equivalent, specifically including external dose, but DOE Order 5480.11 refers to an annual (total) effective dose equivalent only.)

6. The collective dose is the sum of total effective dose equivalents to all individuals in a specified group or population.

7. The cumulative dose is the sum of the total effective dose equivalents for an individual for all years of his life to date. [DOE Order 5480.11 defines this as "for (all years) of employment at a DOE or DOE contractor facility since the effective date of this Order," but that is for DOE reporting purposes, not for practical risk control for which an individual's lifetime risk should be tracked.]

In some references dose is sometimes used interchangeably with exposure, but in this document only the word dose is used when referring to a measurable deposition of energy by radiation in a person or piece of equipment. See also exposure, man-rem, rad, rem, and roentgen. 
dose equivalent-see dose

effective dose equivalent-see dose

exclusion area-in 10 CFR 100 , that area surrounding the reactor in which the reactor licensee has the authority to determine all activities including exclusion or removal of personnel and property from the area. The area may be traversed by a highway or waterway so long as this is not so close to the facility as to interfere with normal operations of the facility and provided that control of traffic on the highway or waterway can be maintained in case of emergency. Activities unrelated to the operation of the reactor may be permitted in an exclusion area under appropriate limitations.

exposure-strictly speaking, a measure of the energy deposited by gamma rays or $\mathrm{X}$ rays per unit volume of air. It is expressed in units of roentgen, or $\mathrm{R}$. See rad, rem, roentgen, and dose. In this guide exposure is used only in its general sense (e.g., "exposure of electrical equipment to high radiation fields is inadvisable").

external hazard $-a$ form of radiation or a radiation source that delivers a potentially significant dose from outside the body. In this document external hazards are gamma, X-ray, neutron, and sometimes beta radiation, or substances, objects, or equipment that contains material that emits these forms of radiation.

general access area - an area where the dose rate above ordinary background is very low or even zero, so that it may be continuously occupied by workers and requires no radiological controls as to its access

grab sampling - a sampling process in which a flask, evacuated container, etc., is used to draw a liquid or gaseous sample from a flow stream. The sample may be different in concentration or pressure than it was in the flow stream, but because the factor of dilution or depressurization is known, the correct concentration of radioactivity in the flow stream can be determined.

hazardous waste-strictly speaking and in accordance with DOE Order $5820.2 \mathrm{~A}$, any waste that is designated hazardous by EPA regulations ( 40 CFR 261); thus radioactive wastes appear not to be hazardous wastes, by definition. However, caution must be used when reading DOE orders, since some of them implicitly include radioactive wastes as hazardous wastes and others refer to the two classes as though hazardous wastes included only nonradioactive wastes. (These contradictory usages can appear in the same document. see, e.g., pp. II-2 and III-1 of DOE 5820.2A.)

High Contamination Area-an area where levels of surface contamination are greater than 100 times the limits specified in Appendix D of 10 CFR 835 or, for tritium, in Table 2-2 of the RCM.

High Radiation Area - any area accessible to personnel in which a major portion of the body could receive a dose greater than 100 mrem but not more than $500 \mathrm{rad}$ in $1 \mathrm{~h}$ at $30 \mathrm{~cm}$ from a radiation source or from any surface through which radiation penetrates (10 CFR 835, RCM). (This should be compared to the definition of very high radiation area, where the distance is taken at $100 \mathrm{~cm}$. DOE is in the process of correcting this disparity.) The term should always be capitalized when used this way.

Hot Spot (hot spot) - informally (lower case), a small localized area in which the dose rate is significantly higher than that of the surrounding area. As long as it is limited in its spatial effects (i.e., the dose rate falls off rapidly with distance), its dose rate may be permitted to exceed the limit for its radiation zone 
under certain conditions. According to the RCM, a Hot Spot (initial capitals) has a contact dose rate that is more than $100 \mathrm{mrem} / \mathrm{h}$ and is at least 5 times the general area dose rate. In this document, a (generic) hot spot is also considered to be any spot that has a dose rate higher than that of the general area, down to about twice the general or typical area dose rate.

internal hazard-a form of radiation or a radiation source that delivers a potentially significant dose from inside the body. In this guide internal hazards are alpha, beta, and sometimes gamma radiation, or material that emits these forms of radiation from inside the body.

isolation-the principle of physical separation of radioactive streams from components or from nonradioactive or other radioactive streams within a system or between connecting systems

low-level waste (LLW)_waste that contains radioactivity and is not classified as high-level waste, transuranic waste, spent nuclear fuel, or byproduct material, as defined by DOE 5820.2A. However, test specimens of fissionable material, irradiated for research and development only, may be classified as low-level waste, provided that the concentration of transuranics is less than $100 \mathrm{nCi} / \mathrm{g}$.

low-population zone-as defined by $10 \mathrm{CFR} 100$, the area immediately surrounding the exclusion area that contains residents in such number and density that there is a reasonable probability that appropriate protective measures could be taken in their behalf in the event of a serious accident

man-rem-a unit of collective dose representing the sum in rem of all the doses received by the members of a group of people

mixed waste-according to DOE Order $5820.2 \mathrm{~A}$, waste containing toth radioactive and hazardous components as defined by the Atomic Energy Act and the Resource Conservation and Recovery Act, respectively (see also hazardous waste)

monitor-in this document, one of the following:

1. A device that measures the radiation dose rate or count rate in an area, often from a highly radioactive or potentially radioactive piece of equipment or structure, is called an area radiation monitor, or ARM.

2. A device that measures the radiation dose rate or count rate from a fluid passing through it or through a pipe or line very near it or from radioactivity deposited on a filter or sieve by the fluid is called a process radiation monitor.

3. A device that measures the radiation dose rate or count rate from (ventilation) air passing through it, whether directly or as deposited on a filter, is called a continuous air monitor, or CAM (at ORNL this may be called a constant ambient air monitor, or CAAM).

Monitors usually have alarms that activate when a setpoint is exceeded, and they may also have some control function, such as closing a valve or locking a door.

nonoccupational visitor - a person visiting ORNL on a transient basis for a tour or meeting. Such a person is not expected or allowed to enter a Radiological Area and is treated, for radiological purposes, as a member of the public. 
occupational visitor - a person visiting ORNL on a transient basis to conduct business, such as repairing or servicing equipment, who is not expected or allowed to enter a Radiological Area without an escort. Such a person is treated, for radiological purposes, as a member of the public.

occupational worker - a person working at ORNL whose employer is the Department of Energy, Martin Marietta Energy Systems, MK-Ferguson, or an ORNL contractor or subcontractor. It may also be a person visiting ORNL to conduct business, including research, who may possibly need to enter a Radiological Area without an escort and who therefore must receive a certain required amount of training and orientation.

penetration-a hole or other opening in a shield wall made to allow the passage of pipes, conduit, HVAC ducts, people, equipment, or air

quality factor-see dose

rad-a unit of radiation dose, usually accompanied by the name of the material for which it is measured. Rads carbon is usually used for radiation qualification of equipment and rads tissue for the dose to human beings.

radiation area - a generic term denoting a Radiation Area, a High Radiation Area or a Very High Radiation Area.

Radiation Area - any area accessible to personnel in which a major portion of the body could receive a dose greater than $5 \mathrm{mrem}$ but not more than $100 \mathrm{mrem}$ in $1 \mathrm{~h}$ at $30 \mathrm{~cm}$ from a radiation source or from any surface through which radiation penetrates (10 CFR 835, RCM, 5480.11). The term should always be capitalized when used this way.

radiation zone - an area that, for design or control purposes, has been determined to lie within a certain range with regard to a radiological parameter and that has thus been assigned a designation corresponding to that range. In particular, the parameters for ANS are potential dose rate, potential surface contamination level, and potential airborne level. A radiation zone is not to be confused with a radiation area.

radioactive material - material that has been in a Contamination, High Contamination, or Airborne Radioactivity Area and has not yet been surveyed and released (RCM). In addition, for ANS this will also be considered to be material that has been in an area in which it may potentially have become activated; according to the RCM, however, the requirements for survey and release do not apply to areas where only gaseous, short-lived $\left(t_{1 / 2}<1 \mathrm{~h}\right)$ activation products are present or might have been created. This definition includes sealed and unsealed sources (RCM).

radioactive material area - a designated area in which radioactive material may be stored or kept (RCM). It is not considered to be a radiological area.

radiological area - any area within a controlled area where an individual could receive a dose greater than $5 \mathrm{mrem}$ in $1 \mathrm{~h}$ at $30 \mathrm{~cm}$ from a radiation source or from any surface through which radiation penetrates (10 CFR 835, RCM); where airborne radioactive concentrations greater than $1 / 10$ of a DAC are present (or are likely to be) (10 CFR 835, RCM); or where surface contamination levels greater than those specified in Appendix D of 10 CFR 835 (10 CFR 835) or, for tritium, Table 2-2 of 
the RCM are present (RCM). Thus a radiological area has or may have some radiological impact or hazard and can be a Radiation Area, a High Radiation Area, a Very High Radiation Area, Contamination Area, High Contamination Area, or Airborne Radioactivity Area (10 CFR 835). $10 \mathrm{CFR} 835$ and the RCM do not include radiological buffer areas or radioactive material areas in their list of radiological areas.

radiological buffer area (RBA) — any area within a controlled area that serves as a buffer area to a contamination area or radiation area (RCM). It is not considered to be a radiological area.

radwaste-according to DOE 5820.2A, solid, liquid, or gaseous material that contains radionuclides regulated under the Atomic Energy Act of 1954, as amended, and of negligible economic value considering costs of recovery. At ORNL, the general solid radwaste classifications are as follows. See also low-level waste.

1. All beta- and gamma-emitting radioactive wastes, excluding fissile and transuranic wastes, are to be considered to be low-level beta- and gamma-contaminated radwaste. Low-range low-level or contact-handled $(\mathrm{CH})$ radwaste is radioactive waste for which the radiation reading at contact with the outer surface of the individual unshielded package does not exceed $200 \mathrm{mrem} / \mathrm{h}$; high-range low-level or remote-handled $(\mathrm{RH})$ radwaste is radioactive waste for which the radiation reading at contact with the outer surface of the individual unshielded package exceeds $200 \mathrm{mrem} / \mathrm{h}$. Also, all wastes from inside hot cells and gloveboxes used for work involving pure beta emitters are included in this category if they cannot be surveyed prior to being packaged.

2. Without regard to source or form, transuranic (TRU) waste is waste that is contaminated with alpha-emitting transuranium radionuclides with half-lives greater than 20 years and concentrations greater than $100 \mathrm{nCi} / \mathrm{g}$ at the time of assay. Contact-handled transuranic $(\mathrm{CH}$ TRU) waste contains transuranic waste materials with a dose rate at the surface (of the item or package) that is $\leq 200 \mathrm{mrem} / \mathrm{h}$; remote-handled transuranic (RH TRU) wastes are waste materials with a dose rate at the surface of $2200 \mathrm{mrem} / \mathrm{h}$. Also, at ORNL wastes contaminated with Ra-226 and $\mathrm{U}-233$ to levels greater than $100 \mathrm{nCi} / \mathrm{g}$ are to be handled in the same way as transuranic wastes.

3. Wastes contaminated with U-233, U-235, Pu-238, Pu-239, Pu-241, or any of the isotopes of Np, $\mathrm{Am}, \mathrm{Cm}, \mathrm{U}$, and $\mathrm{Cf}$ are considered to be fissile waste. Some isotopes of these elements are not fissile; however, unless the material analysis is known, any of these elements should be considered to contain the fissile isotopes in unknown quantities.

rem-a unit of radiation dose (equivalent) that specifically applies to human tissue. It is adjusted for the effect each type of radiation has on the human body. The abbreviation mrem means millirem, or one thousandth of a rem (sometimes $m r$ is used for convenience, but this is not strictly correct).

remote-handled $(\mathbf{R H})$ waste—see radwaste

remote-handled transuranic waste (RH TRU)—see radwaste

roentgen - $\mathrm{a}$ unit of radiation exposure (see exposure) and is abbreviated $\mathrm{R}$. The abbreviation $m R$ means milliroentgen, or one thousandth of a roentgen (sometimes $m r$ is used for convenience, but this is not strictly correct). 
segregation-the principle of the physical separation of two or more components by difference in source strength or leakage potential. It may be provided by distance or by use of a physical barrier such as a separating wall(s) or berm.

separation-the principle of the physical separation of two or more identical or comparable components in order to reduce the dose rate at one from the other. It may be provided by distance or (more usually) by use of a physical barrier such as a separating wall(s) or berm.

single failure - an occurrence that results in the loss of capability of a component to perform its intended function, according to $10 \mathrm{CFR}$ 50, Appendix A. Multiple failures resulting from a single occurrence are considered to be a single failure.

shadow shield - a shield of limited size that attenuates only the direct radiation component of a particular source but may still allow the worker or piece of radiation-sensitive equipment to "see" scattered radiation or another source

streaming - radiation passing through an opening or void in shielding, usually in the phrase radiation streaming

total effective dose equivalent (TEDE)-see dose

transuranic waste (TRU)—see radwaste

total effective dose equivalent (TEDE)—see dose

uptake-radioactive material taken into the body

Very High Radiation Area-any area accessible to personnel in which a major portion of the body could receive a dose greater than $500 \mathrm{rad}$ in $1 \mathrm{~h}$ at $100 \mathrm{~cm}$ from a radiation source or from any surface through which radiation penetrates ( $10 \mathrm{CFR} 835, \mathrm{RCM})$

void-a region of lower density in a shield or a hole in the shield that does not go all the way through. It reduces the effectiveness of the shield at its location.

waste treatment-any method, technique, or process designed to change the physical or chemical character of waste to render it less hazardous, safer to transport, store, or dispose of, or reduced in volume

zone-see radiation zone 

Internal Distribution

1. R. M. Harrington

2-5. R. L. Johnson

6. G. T. Mei

7. R. L. Mlekodaj

8. D. L. Selby

9. C. S. Sims

10. C. D. West
11-15. J. L. Westbrook

16. ORNL Patent Office

17-18. Central Reserach Library Document Reference Sect.

19. Y-12 Technical Library

20-21. Laboratory Records Dept.

22. Laboratory Records, RC

\section{External Distribution}

23. T. A. Khan, Brookhaven National Laboratory, Department of Advanced Technology, BNL ALARA Center, Bldg., 703M, P.O. Box 5000, Upton, NY 11973.

24. U.S. Department of Energy, ANS Project Office, Oak Ridge Operations Office, FEDC, MS-8218, P.O. Box 2009, Oak Ridge, TN 37831-8218.

25-26. Office of Scientific and Technical Information, P.O. Box 62, Oak Ridge, Tennessee 37831 


\section{.}

